\title{
Non-linear investment and labour adjustment dynamics
}

Citation for published version (APA):

Polder, J. M. (2005). Non-linear investment and labour adjustment dynamics. [Doctoral Thesis, Maastricht University]. Universiteit Maastricht. https://doi.org/10.26481/dis.20050616jp

Document status and date:

Published: 01/01/2005

DOI:

10.26481/dis.20050616jp

Document Version:

Publisher's PDF, also known as Version of record

\section{Please check the document version of this publication:}

- A submitted manuscript is the version of the article upon submission and before peer-review. There can be important differences between the submitted version and the official published version of record.

People interested in the research are advised to contact the author for the final version of the publication, or visit the DOI to the publisher's website.

- The final author version and the galley proof are versions of the publication after peer review.

- The final published version features the final layout of the paper including the volume, issue and page numbers.

Link to publication

\footnotetext{
General rights rights.

- You may freely distribute the URL identifying the publication in the public portal. please follow below link for the End User Agreement:

www.umlib.nl/taverne-license

Take down policy

If you believe that this document breaches copyright please contact us at:

repository@maastrichtuniversity.nl

providing details and we will investigate your claim.
}

Copyright and moral rights for the publications made accessible in the public portal are retained by the authors and/or other copyright owners and it is a condition of accessing publications that users recognise and abide by the legal requirements associated with these

- Users may download and print one copy of any publication from the public portal for the purpose of private study or research.

- You may not further distribute the material or use it for any profit-making activity or commercial gain

If the publication is distributed under the terms of Article $25 \mathrm{fa}$ of the Dutch Copyright Act, indicated by the "Taverne" license above, 
Non-linear InVEstment and Labour AdJUSTMENT Dynamics 
(C2005 J.M. Polder, Rotterdam

All rights reserved. No part of this publication may be reproduced without the written permission of the anthor.

ISBN 90-9019562-9

Printed by Print Partners Ipskamp, Enschede (NL) 


\section{NON-LINEAR INVESTMENT \\ AND LABOUR ADJUSTMENT DynamiCs}

\section{PROEFSCHRIFT}

ter verkrijging van de graad van doctor

aan de Universiteit Maastricht

op gezag van de Rector Magnificus Prof. mr. G.P.M.F. Mols

volgens het besluit van het College van Decanen

in het openbaar te verdedigen op

donderdag 16 jumi 2005 om 16.00 uur door

Johnny Michael Polder 
Promotores:

Prof. dr. G.A. Pfann

Prof dr. B.M. Balk (Erasmus Universiteit Rotterdam)

Copromotor:

Dr. W.A. Letterie

Beoordelingscommissie:

Prof. dr. M.A. Corree (voorzitter)

Prof. dr. P.A. Mohnen

Dr. ه.A. Nilsen (Norges Handelshoskole) 
"[...] any wisdom to which 1 might ever aspire could consist only in realizing more fully the infinity of my ignorance."

KARL POPPER - Unended Quest 



\section{Contents}

Acknowledgements ix

1. Introduction 1

2 A survey of non-linear dynamic factor demand models and empirical evidence 11

2.1 Introduction . . . . . . . . . . . . . . 11

2.2 Linear models of adjustment . . . . . . . . . . . 13

2.2 .1 The $\mathrm{Q}$ model . . . . . . . . . . . . . . . . 16

2.2 .2 The Euler equation . . . . . . . . . . . . . 17

2.3 Alternative adjustment costs structures . . . . . . . 18

2.4 Non-linear extension of the Q model . . . . . . . 20

2.5 The Euler equation and non-convexities......... 24

2.6 Alternative approaches . . . . . . . . . . 26 26

2.6 .1 The gap approach . . . . . . . . . . . 26. 26

2.6 .2 Simulation based inference . . . . . . . . . . 28

2.7 The present study . . . . . . . . . . . . . . . . . . 29

3 Stylised facts for factor adjustment in Dutch manufacturing 33

3.1 Introduction . . . . . . . . . . . . . . 33

3.2 Data . . . . . . . . . . . . . . . 33

3.3 Summary statistics of key variables $\ldots \ldots \ldots \ldots$

3.4 Lumpy and intermittent adjustment . . . . . . . . . 39

3.5 Adjustment regimes . . . . . . . . . . . . . 47 
3.6 Aggregate adjustment and lumpiness $\ldots \ldots \ldots \ldots . \ldots 1$

3.7 Conclusion. . . . . . . . . . . . . . . . 53

3.8 Appendix: The capital stock measure . . . . . . . . 54

4 Factor adjustment spikes and interrelation 57

4.1 Introduction . . . . . . . . . . . . . 57

4.2 Data and descriptive statistics . . . . . . . . . . 58

4.3 Lumpiness and interrelation . . . . . . . . . . 61

4.4 Concluding remarks. . . . . . . . . . . . . 63

5 Non-linear investment dynamics and labour demand $\quad 67$

5.1 Introduction . . . . . . . . . . . . . . 67

5.2 Theoretical model . . . . . . . . . . . . . 70

5.3 Data . . . . . . . . . . . . . . . . . . 74

5.4 Empirical model and estimation issues . . . . . . . . 76

5.4.1 Estimation of the investment threshold . . . . . . 77

5.4 .2 Estimation of the system . . . . . . . . . . . 79

5.5 Estimation results . . . . . . . . . . . . . . 81

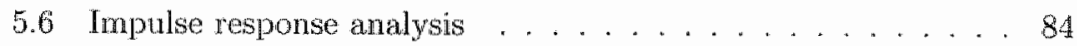

5.6.1 The Generalised Impulse Response Function . . . . . 86

5.6 .2 Results . . . . . . . . . . . . . . . . . . . 88

5.7 Conclusion . . . . . . . . . . . . . . . . 92

6 Dynamics of labour and capital adjustment - a comparison of Germany and the Netherlands 95

6.1 Introduction . . . . . . . . . . . . . 95

6.2 Institutional background . . . . . . . . . . . . . . . . 98

6.3 Econometric model and identification . . . . . . . . . 102

6.4 Data and summary statistics . . . . . . . . . 106

6.5 Results. . . . . . . . . . . . . . . 114

6.5 .1 Investment equation . . . . . . . . . . . 11.5

6.5.2 Labour adjustment equation . . . . . . . . . 117 
6.5.3 An alternative specification for interrelation . . . . . 121

6.5 .4 Sample selection bias . . . . . . . . . . . . 124

6.6 Conclusion . . . . . . . . . . . . . . . . . . 129

7 Estimating the speed of labour adjustment: a problem of selection $\quad 133$

7.1 Introduction . . . . . . . . . . . . . . . 133

7.2 The selection problem in the PAM ....... 136

7.3 Controlling for selection bias . . . . . . . . . . . 139

7.3.1 Moment conditions . . . . . . . . . . . . . 140

7.3 .2 Asymptotic Least Squares . . . . . . . . . . . . 142

7.3.3 Estimation of the linear projections . . . . . . 142

7.4 Data . . . . . . . . . . . . . . . . . . . 144

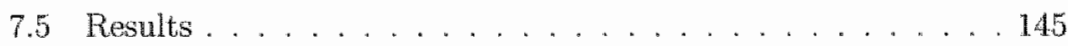

7.5 .1 Reduced form estimates . . . . . . . . . 145

7.5 .2 Partial adjustment model . . . . . . . . 147

7.6 Conclusions . . . . . . . . . . . . . . . 1.51

8 Conclusion $\quad 155$

$\begin{array}{ll}\text { References } & 165\end{array}$

$\begin{array}{ll}\text { Nederlandstalige samenvatting } & 177\end{array}$

$\begin{array}{ll}\text { Curriculum vitae } & 185\end{array}$ 



\section{List of Tables}

3.1 SB193 two-digit industry classification . . . . . . . 35

3.2 Summary statistics . . . . . . . . . . . . 37

3.3 Statistic by two-digit industry . . . . . . . . 40

3.4 Inaction by firm size . . . . . . . . . . . . 44

3.5 Ranked adjustment rates . . . . . . . . . . . 4 46

3.6 Adjustment regimes . . . . . . . . . . . . . . . . . 48

3.7 Regimes of lumpy adjustment . . . . . . . . . . . 49

4.1 The relation between spikes and adjustment rates . . . . . 59

4.2 Effect of investment spikes on employment . . . . . . . . 62

4.3 Effect of employment spikes on investment . . . . . . 63

5.1 Summary statistics . . . . . . . . . . . 75

5.2 Results threshold estimation of the investment model . . . 83

5.3 System estimation results . . . . . . . . . . 83

5.4 Average Generalised Impulse Responses. . . . . . . . . . . 91

6.1 Macroeconomic indicators . . . . . . . . . . . . . 99

6.2 Summary statistics . . . . . . . . . . . . . . 108

6.3 Censoring of investment and labour adjustment rates . . . . 112

6.4 Adjustment regimes . . . . . . . . . . . . . 113

6.5 Estimation results Euler equation (capital) . . . . . . 116

6.6 Estimation results Euler equation (labour) . . . . . . . . 119

6.7 Estimation results with interrelation in rates (capital) . . . 122

6.8 Estimation results with interrelation in rates (labour) . . . 123 
6.9 Probit results two-period selection model (investment) . . 126

6.10 Probit results two-period selection model (labour adjustment) 127

7.1 Summary statistics . . . . . . . . . . . . . . 144

7.2 Zero net hiring per year . . . . . . . . . 145

7.3 Probit estimation results . . . . . . . . . . . . 146

7.4 Bias-corrected OLS estimation of reduced forms . . . . . . 146

7.5 Estimation results of the Partial Adjustment Model . . . . . 149 


\section{List of Figures}

3.1 Average and median investment rate over time . . . . . 38

3.2 Average and median hiring rate over time . . . . . . . 39

3.3 Investment rate distribution $\ldots \ldots \ldots \ldots . \ldots . \ldots 42$

3.4 Net hiring rate distribution $\ldots \ldots \ldots \ldots . \ldots 43$

3.5 Net firing rate distribution . . . . . . . . . 43

3.6 Investment, investment rate, and spikes . . . . . . . 52

3.7 Hiring, hiring rate, and positive spikes $\ldots \ldots \ldots \ldots 52$

3.8 Hiring, hiring rate, and negative spikes $\ldots \ldots \ldots \ldots 2$

5.1 Average responses of $I / K$ to technology shock $(t+1$, size $2 \sigma) \quad 89$

5.2 Average responses of $H / L$ to technology shock $(t+1$, size $2 \sigma) \quad 89$

6.1 Investment rate distribution (Germany) . . . . . . 110

6.2 Investment rate distribution (Netherlands) . . . . . . 110

6.3 Labour adjustment rate distribution (Germany) . . . . . . 111

6.4 Labour adjustment rate distribution (Netherlands) . . . . . 111 



\section{Acknowledgements}

Although the title page of this thesis displays only a single name, many people have contributed to it, in either a direct or indirect way. At this point I would like to express my gratitude to them.

First of all, I am greatly indebted to my promotor Gerard Pfann. His knowledge and ideas on the topic of this dissertation, and economics in general, have been a great source of inspiration. After one of our frequent discussions, I always had new motivation to dig deeper into the subject. I very much appreciate his efforts to create an environment in which I could do my work in an optimal way.

I am also very grateful to Wilko Letterie, who acted as my supervisor during my time in Maastricht. He helped me a great deal with the many questions $\mathbb{I}$ had about the literature, provided excellent comments on my writings, and always had time when $\mathbb{I}$ had trouble with a mathematical result. Fortunately, there was more to talk about than researcli. On our frequent walks or during a game of snooker, the topic of discussion was usually soccer or the indisputable beauty of Rotterdam. Gerard and Wilko have also coauthored the papers that are the basis of Chapters 4 and 5 , and I thank them for letting me use this material here.

I would like to thank my promotor Bert Balk for the opportunity to work with the data of the CEnter for Research of Economic Microdata (CEREM) at Statistics Netherlands (CBS), as well as for his help in using the data, and his valuable comments on the draft version of the thesis.

A special word of thanks goes to Sher Verick. As the co-author of the 
paper on which Chapter 6 of this thesis is based, I would like to thank to thank him for letting me use our joint work here. Our collaboration has been very pleasant and fruitul, and I think the whole thesis has benefited from it. His excellent feedback on my research is also very much acknowledged.

I experienced working at the University of Maastricht as very pleasant. I thank Jasper Kok for being a great room- and lunch-mate. I would also like to thank my former colleagues at BIRC: Ben Kriechel, Thomas Dohmen, Mindel van de Laar and Boris Blumberg. Karin van den Boom, Haydée Hallmanns, and Ingrid van Weers provided excellent secretarial assistance.

I would like to thank IZA for giving me the opportunity for a research visit to Bomn, and Hielke Buddelmeyer for providing me with a place to stay during that visit. The cooperation of many people at CEREM and CBS Heerlen and Voorburg is gratefully acknowledged. Finally, $\mathrm{I}$ enjoyed and benefited from. the Ph.D. course program of the NAKE.

Although most of them will have no clue of what this thesis about, I owe much gratitude to my family and friends. In an indirect way, they helped and supported me to finish this research. I would like to thank. Angela and Ard Stolle, Paul Goldman, Kevin Pak, my fellow badminton-players at B.C. Asterix, my band-mates, and all other family and friends, for making me forget about research every now and then.

I. owe most gratitude to my parents. Your love, care and support is invaluable to me. 



\section{Chapter 1}

\section{Introduction}

The adjustment of the employment level or capital stock is costly for a firm. Besides the investment outlay associated with the purchase of capital goods, and wage payments to newly hired workers, the firm also incurs indirect costs related to the act of adjusting. Installing new capital may involve temporarily closing down all or part of the operations of a firm, workers may have to be retrained to operate the new machinery, and time and effort need to be put into organising and planning the restructuring of the production process. Likewise, adjusting the level of employment involves costs associated with, for instance, the search for and recruiting of new employees, training, and reorganisation. In addition, firms incur costs when making negative adjustments. Capital goods may not sell at their actual value in the second-hand market because of asymmetric information. For employment, there are explicit costs of firing workers in most countries, in addition to possible implicit costs associated with the working ambience and the morale of workers at a downsizing or reorganising firm.

These adjustment costs are an important reason why firms respond slowly to changes in economic circumstances. They form the basis of most empirical research on dynamic factor demand over the last decades. Unlike investment outlays or wage payments, adjustment costs are often not observed. Empirical models therefore require the assumption of a functional form relating the 
costs of the adjustment to its size. By far the most popular assumption is that the costs of adjustment are quadratic in (some measure of) the adjustment size. This specification was fust suggested by Holt, Modigliani, Muth, and Simon (1960). The main reason for its popularity is that in structural models of adjustment, where first-order conditions for optimal adjustment are estimated, the quadratic specification conveniently yields a linear relation between adjustment and its determinants. In addition, quadratic adjustment costs imply that marginal costs increase with the size of adjustment, so that $a$ sequence of small adjustments is less costly than one large adjustment. Thus, firms have the incentive to spread adjustment, which provides a rationale for the use of distributed lag models.

There are however some peculiar features to the quadratic "approximation' of adjustment costs. Perhaps most prominently is that it ignores the possibility of economies of scale. Rothschild (1971) finds the reasons for assuming stifictly convex adjustment costs "hardly compelling", and notes that "[i]t is possible that there are some fixed costs to adjustment that are incurred whenever the capital stock is changed, regardless of how much it is changed." Nickell (1978a) makes a similar point with respect to labour adjustment in noting that "there seems little reason to suppose costs per worker associated with either hiring or firing increase with the rate at which emplloyees flow in or out. [... I]t may even be more reasonable to suppose that the average cost. $[. . \mid$ diminishes [...] with the speed of adjustment." Thus, it appears that there is no reason to assume a prion that adjustment costs are quadratic, or more generally, strictly convex. With economies of scale - for example due to a fxed (or, more generally, non-convex) component in adjustment costs firms have the incentive to concentrate adjustment, instead of spreading it over several periods like with strictly convex costs. If the gains to adjustment are not high enough to overcome the fixed costs, a firm does not adjust. On the other hand, if adjustment is profitable, it is cost efficient to concentrate adjustment because average costs are decreasing in the size of adjustment. Thus, the implied dynamics involve periods of inaction alternated with pe- 
riods of heavy adjustment. In other words, with fixed costs, factor demand is 'intermittent' and 'lumpy'. In addition, it is possible that a firm does not adjust in response to a single small shock, but that it will adjust after a sequence of these shocks. Factor demand is therefore adjusted in a non-linear way, as a firm can react differently to equally sized shocks.

Due to the lack of micro-data, for a long time most of the empirical research was based on sectoral or economy-wide data. This partly explains the widely spread use of the quadratic adjustment costs specification, because aggregation tends to smooth out non-linearities at the micro-level. However, with the increasing availability of micro-data it has become clear that richer specifications of the adjustment costs structure are needed to describe the dynamics of factor demand. An increasing literature shows that adjustment dynamics are indeed characterised by intermittency and lumpiness. The evidence ranges from statistical analysis providing stylised facts of micro-level adjustment (e.g. Doms and Dunne (1998)), to the finding that non-linear adjustment models derived from structural optimisation problems give a better description of factor demand dynamics than linear models of adjustment. ${ }^{1}$ It should be noted though that strictly convex costs per se do not need to be abandoned. There may be some aspects of the adjustment processes of capital and labour that urge firms to spread, and a strictly convex adjustment costs component can serve as a suitable device to model these. From the recent literature, however, it is more than clear that strictly convex adjustment costs alone do not yield an appropriate description of factor demand dynamics at the micro-level.

An important topic that has not received much attention in this context is how factors of production are interrelated. While there is a large literature that analyses the dynamic interrelation between input factors using linear systems of equations (starting with the seminal paper by Nadiri and Rosen (1969)), the literature on non-linear factor demand has confined itself to studies on the demand for a single factor. An interesting theoretical

\footnotetext{
${ }^{1}$ This literature is reviewed in Chapter 2.
} 
contribution by Abel and Eberly (1998) shows that neglecting whe mutual dependence of tecisions on factor adjustment can yield spurious conclusions about what drives the underlying dynamics. In their two-factor model one input (Interpreted as capital) is subject to fxed adjustment costs, while the other (interpreted as labour) incurs no adjustment costs (that is, it is "fully fexibley, Capital and labout are interrelated through the production function. Abel and Eberly show that labou is adjusted in a non-linear way even though it is fully flexible. In line with the traditional literature on interrelated factor demand, they remark that this finding "casts doubt on any attempts to metsure the costs of adjusting employment simply by focusing on the behaviour of employment without looking at other factors of production." Although the model that they consider is stylised, this is an intuitive and conomically sensible point. Because firms are likely not to adjust factors of production independently, it is important to consider the consequences of adjusting one factor for the dymanics of the other.

The aim of this thesis is to contribute to the mnderstanding of the dynamics of firm investment and labour adjustment. The focus is twofold. Firstly, the non-linear nature of factor dymamics, resulting from non-convex adjustment costs, is investigated. To achieve this, statistical evidence is presented and theoretical models of adjustment are tested and evaluated with data for the Dutch manufacturing sector. The second main theme is to investigate the intercelation between cepital and labour in the context of non-convexities. As mentioned above, this is potentially important aspect that sofar has received little attention. The analysis of the economic models in this thesis, specifically in Chapters 5 to 7 , relies on recently developed econometric techniques, in particular from the literature on estimation and inference in linear and non-linear dynamic panel data models. In most cases, the application of these techniques has not been considered within the factor demand literature.

The thesis is written in such a way that each chapter can in principle be read independently from the rest. However, Chapter 2 provides the general theoretical framework, and Chapter 3 an extensive statistical analysis 
of the data, to which the subsequent chapters occasionally refer. Chapter 2 presents a survey of theoretical models of dynamic factor demand, and the existing empirical evidence on the existence of non-convexities at the microlevel. First, the traditional $Q$ model and Euler equation are derived, which provides an introduction to the main issues in factor demand modelling, central concepts, and notation. Subsequentlly, non-convex adjustment costs are introduced, and empirical research using non-linear extensions of the $\mathrm{Q}$ approach and the Euler equation are discussed. In addition, some attention is paid to two alternative approaches, namely the so-called 'gap approach' and simulation based inference.

Next, in Chapter 3 an extensive preliminary analysis of the data is carried out in order to find statistical support for the two main themes of this thesis. Throughout the thesis, data for the Dutch manufacturing sector at the Center for Research of Economic Microdata (CEREM) at Statistics Netherlands (CBS) are used. The available data are the Investment Statistics (IS) and Production Statistics (PS) for the years 1978 to 2000 . For various reasons, each individual chapter uses a different subsample of the data. The results of the analysis in Chapter 3 , however, give a representative image of the statistical features of factor demand dynamics in the Dutch manufacturing sector. First, the existence and extent of lumpy and intermittent adjustment is documented using descriptive statistical analysis along the lines of other studies on this phenomenon. In addition, statistical evidence for the interrelation between capital and labour in the context of Jumpiness is provided. Finally, the relation between aggregate dynamics and lumpiness is considered.

Chapter 4 extends the statistical analysis of interrelation in Chapter 3 to include dynamics. It is investigated how an input factor is adjusted if the other input factor exhibits an adjustment spike in the previous, current or next year. Linear reduced form panel data models are estimated, relating the adjustment of a factor to the timing of an adjustment lump, or 'spike", in the other factor. This approach allows to investigate in a simple way the dynamic relation between factor adjustment and the incidence of lumps in 
another input. The chapter has been published in Economics Letters. ${ }^{2}$

The remaining chapters all employ structural models of adjustment that are explicitly derved from the assumption that firms pursue profit maxmisation. This allows the identification of structural parameters that govern the dynamics of adjustment. Chapter 5 investigates the suggestion by Abel and Eberly (1998) that non-linear employment dymamics can arise due to interrelation, even without non-convex labour adjustment costs. It is assumed that investment is subject to non-convexities but that labour adjustment faces only strictly convex costs. A non-linear model is derived for investment, whereas labour adjustment is described by a linear model. The structure of the empirical model is such that lumpy employment dynamics can arise only if there are large changes in labour productivity. Thus, it is inwestigated whether investment lumps lead to jumps in labour productivity, and how labour adjustment responds to these jumps. The system of factor demand equations is estimated simultaneously with the production function as a system of Seemingly Unrelated Regressions (SUR), allowing for contemporaneous correlation of the disturbances across equations as well as furmspecific effects. However, the investment equation contains an endogenous threshold for non-zero investment, which is estimated in preceding step. To my knowledge this is the first study to consider simultaneous estimation of the factor demand equations where the demand for one of the factors is subject to non-conwexities, and both factors are costly to adjust. To investigate the impact of investment on employment dynamics, the effect of different economic shocks to the system is analysed by means of an impulse response analysis. Because of the nom-linaar nature of the investment equation, however, traditional impulse response analysis is unsuitable, and the Generalised Timpulse Response Function (GIRF) approach recently suggested by Koop, Pesaran, and Potter (1996) is used.

In Chapter 6 a comparison of the German and Dutch manufacturing sector is carried out. For this purpose additional firm-level data from the Centre

\footnotetext{
${ }^{2}$ Seo Letterie, Pfarn, and Polder (2004).
} 
for European Economic Research (ZEW), Mannhem, is used. Of central interest in this chapter is the influence of the institutional setting on factor demand dynamics at the micro-level. In particular, it is argued that while conditions for investment are similar in Germany and the Netherlands, the German labour market is more strictly regulated. Dutch firms can rely on more flexible arrangements with respect to part-time and temporary wonk, and there is less influence of labour unions in the Netherlands. As a consequence, German firms are less flexible in adjusting the employment level than Dutch fims. With this motivation, capital and labour adjustment dynamics in the Netherlands and Germany are investigated, paying specilic atitention to whether there is any evidence that the institutional differences are reflected in the firm-level decisions regarding dymamic factor demand. The conditions for optimal adjustment provide the moment restrictions that can be exploited for Generalised Method of Moments (GMM) estimation. The theoretical model in this chapter includes interrelated adjustment costs, which allows for possible cost efficiencies when adjusting capital and labour simultaneously. A firm may want to synchronise the timaing of the adjustment to the different factors, for instance to reduce the time of disruption to the production process. Attempts to identify this type of costs using microdata are rare. In addition, in the presence of non-convexities, the estimating equations are only valid for the subsample of observations where adjustment is non-zero. Thus, only this subsample is used in the estimations. However, selection is potentially enclogenous in this case, which may invalidate the estimation method. Therefore, by means of a Heckman two-step approach, a pragmatic robustness check is carried out for whether the results are subject to non-random selection.

One of the main reasons for studying factor denand dyamics is the interest in how fast firms can adapt to changing economic circumstances. Knowledge abont the adjustment speed is of key importance to policies aimed at directing the demand for factors of production. Whille there is strong evidence for the non-linear dynamics of capital and employment in the micro-economic 
literature, the implications for the aggregate dynamics is the subject of an interesting debate. Macro-economic research often relies on linear time-series models to estimate the speed of adjustment of economic wariables to policy changes and other economic shocks. The idea is that linear partial adjustment models provide a useful approximation to the actual dynamics, as nonlinearities at the micro-level 'smooth out' with aggregation. It can, however, be shown that the estimates obtaimed for the adjustment speed from aggregate data using a linear partial-adjustment model are subject to a severe bias (Caballero and Engel 2004). Within the framework of the partial adjustment model it is shown in Chapter 7 that there is a problem of selection similar to that in Chapter 6. As discussed there, the estimating equation only applies to the subsample of observations where adjustment is non-zero, and estimation based on this subsample is subject to non-random selection. While this is the topic of ongoing research (Arellano and Honore 2001), techniques to control for this bias in dynamic panel data models with endogenous regressors and this particular type of censoring are not available. However, under some (restrictive) assumptions, the partial adjustment model can be written as an AR(1) panel data model, thus eliminating the problem of endogenous regressors. For this model it is possible to control for selection using an Asymptatic Least Squares procedure proposed by Arellano, Bover, and Labeaga (1999). The estimated adjustment speed from this procedure is compared to that obtained from more aggregated data, and from estimation without correcting for selection.

The man findings of the thesis are summarised in Chapter 8 , along with some directions in which future research could head. 



\section{Chapter 2}

\section{A survey of non-linear dynamic factor demand models and empirical evidence}

\section{$2.1 \quad$ Introduction}

Economies of scale play an important role in the investment in turbogenerators by electric utility firms. This is the conclusion reached by Peck (1974) in a case study of the electric ntility industry, analysing data on 15 individual firms. According to this study, investment in turbogenerators is intemittent and lumpy, and cannot be appropriately described with a distributed lag model. While Rothschild (1971) already shows that such adjustment behaviour is implied by a theoretical model of dynamic factor demand with non-convex adjustment costs, the study by Peck is probably the first empirical study to provide evidence on the relevance of these costs in firm-level investment decisions, and question the appropriateness of a linear model to describe investment dynamics.

Despite this remarkable early contribution, the literature on factor demand continued to be dominated by linear models for almost two more decades. This can be partly explained by the fact that most of the research 
was baised on aggregate (sectoral, or economy-wide) data. Aggregation masks non-linearities at the firm-level and makes adjustment appear to be smooth. Therefore, the need to consider more general models of dynamic adjustment was not recognised. Howewer, thirty years after Rothschild and Peck, the view that the adjustment of physical capital occurs in lumps has prevailed: the increasing availability of micromata has undeniably comfirmed the non-linear dymamics of investment. In addition, the same arguments that explain nonlinearity for investment apply to the adjustment of the employment level, and there is also clear empirical evidence that this production factor is adjusted in a lumpy fashion.

This chapter surveys empirical research that uses micro-data to investigate Iumpy investment and labour adjustment behaviour. The literature using linear adjustment models or aggregate data is not considered in detail. . Nevertheless, the next section starts with a discussion of two popular linear models for factor adjustment, the $Q$ model and the Euler equation. This allows to introduce some central concepts and notation. Next, Section 2.4 shows how the $Q$ model can be extended to account for non-convexities, as proposed by Abel and Eberly (1994). Section 2.5 shows how the Euler equation approach can be modified to account for non-convex adjustment costs. Both Section 2.4 and 2.5 review various prominent empirical studies in the fidc of investment and labour clemand that have used these approsches. In Section 2.6 two alternative approaches to modelling non-linearities are discussed: the 'gap' approach and simulation based inference. The chapter is concluded by Section 2.7, which gives a brief discussion of how the individual chapters of this thesis are related to the existing literature.

\footnotetext{
"For this, see the surveys by Nickell (1986) and Hamermesh (1993) for labour demand models, and Chitinko (1993) and Caballero (1999) on inwestment.
} 


\subsection{Linear models of adjustment}

The unit of analysis is the frm, or a subdivision of it deciding independently on investment and labour adjustment. For convenience all units will be referred to as "firms". The goal of the firm is to maximise the future stream of net profits by optimally choosing the level of imvestment $\left(I_{t}\right)$ and labour adjustment $\left(H_{t}\right) .^{2}$ Net profits in year $t$ are given by (assuming that all other input factors have been maximised out)

$$
\pi_{t}(\cdot)=R\left(A_{t}, K_{t}, L_{t}\right)-p_{t} I_{t}-w_{t} L_{t}-C\left(I_{t}, H_{t}, K_{t-1}, L_{i t-1}\right)
$$

where $\pi_{t}$ are net profits in year $t, R(\cdot)$ is the production function; ${ }^{3} C(\cdot)$ is the costs of adjustment $K_{i}$ and $L_{t}$ denote respectively the firm's capital stock and employment level; $p_{t}$ is the price of capital goods; $w_{t}$ is the total labour costs per worker; and $A_{t}$ is a stochastic shock to the production function. Note that there is no distinction between different types of capital or workers. Prices per unit of capital or labour costs per worker should therefore be interpreted as an average or index over all types of the concerning imput.

The natural motion of capital is given by

$$
K_{t}=(\mathbb{1}-\delta) K_{t-1}+I_{t}
$$

with $\delta$ a constant depreciation rate. The fact that $I_{t}$ enters the capital stock reflects the assumption that capital becomes immediately productive. This assumption is necessarily ad hoc, but not unimportant for the ultimate dynamics of capitall in the model. In contrast, some studies assume that there is a one-period lag before newly installed capital becomes productive, by letting $I_{1}-1$ instead of $I_{t}$ enter capital stock. This assumption relates to the tirne to build aspect of installing new capital, see Kydland and Prescott (1982). As

\footnotetext{
${ }^{2}$ As usual, this theoretical model is simplified in many ways. For example, borrowng constraints, taxes, incentive problems, risk aversion we implicity assurned away here.

${ }^{3}$ As noted by Bond and Van Reenen (2002), $R(+)$ is most realistically interpreted as a function for walue added rather thari gross outpuit.

"The adjustment cost function is sonetimes specified whith currem capital stock thol enployment instead of lagged stock variables (see below).
} 
mentioned above, the firm's capital stock considered here is an aggregate of various types. Any timing assumption may apply more to one type of capital than to another. In addition, the length of an actual period in the model is also an issue: some types of capital may not be productive after a quarter of a year, but may become operational within a year. For reasons of exposition alone, equation (2.2) is maintained in this discussion.

In a similar wein, it can be argued that employment is subject to natural motion due to quits and other reasons for separation by workers. That is,

$$
L_{t}=(1-\tau) L_{t-1}+H_{t}
$$

where $\tau$ is a constant separation rate. However, as data on gross worker flows are often not available, it is usually assumed that the firm decides on net labour adjustment, that is $H_{t}=L_{t}-L_{t-1}$. Because in the data, used in this thesis also only net employment changes are observed, the derivations below are also based on this definition of $H_{t}{ }^{5}$

Adjustment costs, as represented by $C(\cdot)$, embody the costs of adjusting factor inputs in addition to 'direct' costs, that is the investment outlay in the case of capital, and additional wage and other labour costs in the case of employment. For capital, one can think of costs associated with installation activities, search costs, the need to retrain workers, and the need to temporarily close or cut down production activities. For employment, adjustment costs arise from search and recruitment activities, from training or on-the-job learning, explicit firing costs due to dismissal protection, and so on. Adjustment costs bring a dynamic quality to the firm's factor demand decisions. In the absence of adjustment costs, firms would adjust factor demand immediately to a new equilibrium in response to an economic shock. This, however, is at odds with the empirical finding that adjustment tends to be sluggish. The assumption that adjustment is costly captures the fact that

\footnotetext{
${ }^{5}$ Unlass net and gross hiring are the same (i.e. the separation rate is zero), however, this creates an asymmetry in the treatment of capital and employment.

Gee Hamermesh and Pfann (1996) for an extensive survey of the adjustment costs literature.
} 
adapting to changing economic conditions is in general not instantaneous.

The firm's optimisation probiem can be stated as

$$
V\left(A_{t-1,1}, K_{t-1}, L_{t-1}\right)=\max _{\{l\}_{t}^{\infty}\left\{H_{t}\right\}_{t}^{\infty}} \sum_{s=t}^{\infty} \beta^{s-t} E\left[\pi_{t}(u) \mid \Omega_{t-1}\right]
$$

where $V$ is the value of the firm given the state variables $A_{t-1,}, K_{t-1}$ and $L_{t-1}$, the information available at the time of decision making is denoted by $\Omega_{t-1}$, and $\beta$ is a constant discount factor. The problem can be reformulated more concisely using Bellman's equation, or recursive functional,

$$
V\left(A_{t-1}, K_{t-1}, L_{t-1}\right)=\max _{I_{i}, H_{t}} E\left[\pi_{t}(\cdot)+\beta V\left(A_{t}, K_{t}, L_{t}\right) \mid \Omega_{t-1}\right]
$$

This formulation reduces the control variables to $I_{t}$ and $H_{t}$ by collapsing all decisions made after period $t$ into one single forward-looking expectation, namely the second tem on the right-hand side of (2.5).

When all relevant functions are differentiable, the first-order conditions for problem (2.5) are given by

$$
\begin{aligned}
\frac{\partial C}{\partial I_{t}}+\frac{\partial C}{\partial K_{t}}+p_{t} & =\frac{\partial R}{\partial K_{t}}+\beta \frac{\partial E\left[V\left(A_{t}, K_{t}, L_{t}\right) \mid \Omega_{t-1}\right]}{\partial K_{t}} \\
\frac{\partial C}{\partial H_{t}}+\frac{\partial C}{\partial L_{t}}+w_{t} & =\frac{\partial R}{\partial L_{t}}+\beta \frac{\partial E\left[V\left(A_{t}, K_{t}, L_{t}\right) \mid \Omega_{t-1}\right]}{\partial L_{t}}
\end{aligned}
$$

These equations show that at the optimum the marginal costs of an additional unit of input are equated to the marginal benefits.

For its analytical convenience, a quadratic specification has been by far the most popular functiongl form for adjustment costs. In particular, a frequently encountered specification is due to Summers (1981)

$$
C_{\text {cap }}\left(I_{t n} K_{t-1}\right)=\frac{\gamma_{k}}{2}\left(\frac{I_{t}}{K_{t-1}}\right)^{2} K_{t-1}
$$

where $\gamma_{k}$ reflects the adjustment speed of capital. A similar adjustment costs function can be specified for labour, 


$$
C_{\mathrm{lab}}\left(H_{t}, L_{t-1}\right)=\frac{\gamma}{2}\left(\frac{H_{t}}{L_{t-1}}\right)^{2} L_{t-1}
$$

If there are no interrelated adjustment costs, total adjustment costs are given by $C=C_{\text {cap }}+C_{\text {latk }}$. The additive separability of $C$ in principle allows for the separate analysis of capital and employment. Note that with this specification of adjustment costs the second term on the left-hand side in both first-order conditions (i.e. $\partial C / \partial K_{t}$ and $\partial C / \partial L_{t}$ ) is zero. Alternatively, the investment rate can be defined as $I_{t} / K_{i}$ so that this term is not eliminated, as in Section 2.5.

\subsubsection{The $\mathrm{Q}$ model}

The main problem with the estimation of the first-order conditions (2.6) and (2.7) is posed by the unobservable expectation terms. Howewer, as noted by Hayashi (1982), with adjustment costs given by (2.8) and denoting the right-hand side of (2.6) by $q$, the investment equation can be written

$$
\begin{aligned}
\partial C / \partial I_{t}=\gamma_{t}\left(t_{t} / K_{t-1}\right) & =q_{t}-p_{l} \\
\Leftrightarrow\left(r_{t} / K_{t-1}\right) & =\left(1 / \gamma_{k}\right)\left(q_{t}-p_{t}\right) \\
& =\left(1 / \gamma_{k}\right) p_{t}\left(q_{t} / p_{t}-1\right)
\end{aligned}
$$

where $q / p_{t}$ is known as 'marginal $q$, the ratio of the narginal value of an additional unit of capital to purchase costs. Hayashi (1982) also presents conditions under which marginal a can be replaced by awerage (or Tobin's) q, which is the ratio of the value of the firm to the replacement value of its capital stock. "Thus, under the Hayashi conditions, $q_{t} / p_{t}=Q_{t} \equiv V_{t} / K_{t-1}$, where $Q_{t}$ is average $q$. If prices are roughly constant over time, $Q_{t}$ is a sufficient statistic for investment. This gives rise to the popular $\mathrm{Q}$ model for investment. The value of the firm is usually obtained from stock market data, which

\footnotetext{
The Hayshic conditions imply that there is perfect competition, the production function has constant returns to scale, and that adjustment costs are convex.
} 
involves the additional assumption of an efficient stock market. In the absence of stock market data, which is often the case in data sets with smaller firms, average $q$ is often replaced by a proxy based on the sales-capital ratio, see e.g. Gilchrist and Himmelberg (1995) and Nilsen and Schiantarelli (2003). Alternatively, Abel and Blanchard (1986) suggest to estimate marginal $q$ itself.

\subsubsection{The Euler equation}

Another approach to solve the problem of the unobserved expectations is to estimate the Euler equation. For convenience, $K_{t-1}$ is usually replaced with $K_{t}$ in the adjustment cost function (2.8) with this approach. Similarly, $L_{t}$ replaces $L_{t-1}$ in $(2.9){ }^{8}$ Thus, adjustment costs are redefined as

$$
\begin{aligned}
& C_{\text {cap }}\left(I_{t}, K_{t}\right)=\frac{\gamma_{k}}{2}\left(\frac{I_{t}}{K_{t}}\right)^{2} K_{t} \\
& C_{\text {lab }}\left(H_{t}, L_{t}\right)=\frac{\gamma_{t}}{2}\left(\frac{H_{t}}{L_{t}}\right)^{2} L_{t} .
\end{aligned}
$$

Like before, total adjustment costs are given by $C=C_{\text {cap }}+C_{\text {lab. }}$. Using the envelope theorem, it can be shown that $E\left[\partial V\left(A_{t}, K_{t}, L_{i}\right) / \partial K_{t}\right]=(1-$ б) $E\left[\partial C_{t+1} / \partial I_{t+1}+p_{t+1}\right]$, and likewise for labour. Using this in (2.6) and $(2.7)$, it follows that ${ }^{10}$

$$
\begin{aligned}
& \frac{\partial C_{t}}{\partial I_{t}}+\frac{\partial C_{t}}{\partial K_{t}}+p_{t}-\frac{\partial R_{t}}{\partial K_{t}}=\beta(1-\delta) E\left[\frac{\partial C_{t+1}}{\partial I_{t+1}}+p_{t+1}\right] \\
& \frac{\partial C_{t}}{\partial H_{t}}+\frac{\partial C_{t}}{\partial L_{t}}+w_{t}-\frac{\partial R_{t}}{\partial L_{t}}=\beta E\left[\frac{\partial C_{t+1}}{\partial H_{t+1}}+w_{t+1}\right] .
\end{aligned}
$$

These Euler equations are intertemporal optimality conditions such that (net) marginal costs in period tequal (expected) discounted marginal costs

\footnotetext{
${ }^{8}$ This specification of adjustnnent costs has the advantage that it allows to formulate the ultimate estimating equation as an ordinary dynamic regression.

${ }^{9}$ For parsimony in the notation, the conditioning on $\Omega_{t-1}$ is suppressed here.

${ }^{10}$ The functions are indexed to refer to the pertinent period.
} 
in period $t+1$. For example, with $C_{\text {cas }}$ as in (2.11), and a Cobb-Douglas prom duction function $R(\cdot) \equiv Y_{t}=A_{t} K_{t}^{\alpha_{k}} L_{t}^{\alpha_{i}}$, the Euter equation for investment becomes

$$
E\left[\frac{I_{t+1}}{K_{t+1}}\right]=\frac{1}{\psi}\left[\gamma_{k} \frac{I_{t}}{K_{t}}-\frac{\gamma_{k}}{2}\left(\frac{I_{t}}{K_{t}}\right)^{2}-\alpha_{k} \frac{Y_{t}}{K_{t}}+p_{t}-\beta(1-\delta) E\left[p_{t+1}\right]\right]
$$

where $\psi=\beta \gamma k(1-\delta)$. The parameters can be estimated by replacing the expectations for next period with their realisation. Under rational expectations, this creates a forecast error $\varepsilon_{t+1}$ that is orthogonal to all available information at the time of decision making, i.e. $E\left[\varepsilon_{t+1} \mid \Omega_{t-1}\right]=0$. Thus, any variable in the information set $\Omega_{t-1}$ is orthogonal to the disturbance, and these restrictions can be exploited for parameter identification in a Generalized Method of Moments (GMM) setting, as first suggested by Hansen (1982) and Hansen and Singleton (1982).

\subsection{Alternative adjustment costs structures}

The $\mathrm{Q}$ model and the Euler equation are based on the assumption of quadratic adjustment costs. As pointed out in Chapter 1 , this specification is restrictive in a number of ways. Most importantly, the fact that marginal costs depend on the size of adjustment implies that non-zero adjustment is al ways optimal." "That is, the adjustment size can always be chosen such that marginal costs equal marginal benefits. The possibility of inaction is therefore infinitesimal. In addition, because marginal costs are increasing in the size of adjustment, it is less costly to spread adjustment over time than to concentrate adjustment in a short period. Thus, this specification predicts that firms adjust smoothly towards a new equilibrium. Finally, because of the symmetry of the quadratic function, negative and positive adjustments are assumed to be equally costly.

\footnotetext{
${ }^{11}$ Strictly speraing, it is not impossible that inaction occurs, but its probability is infinitesimal.
} 
All these implications are strongly at odds with recent empirical evidence on frm-level factor adjustment, which shows that adjustment is lumpy and intermittent. This motivated the stidy of altemative specifications of adjustment costs. Hamermesh (1989) considers purely fixed adjustment costs that do not vary with the adjustment size. This introduces economies of scalle into the adjustment decision, and generates a possibility of inaction when the gains to adjustment are not high enough to overcome the costs. His study of the adjustment pattern of labour of seven manufacturing plants confirms the occurrence of inaction and "lumps" implied by the theoretical model.

Nickell (1978b) and Dixit and Pindyck (1994) consider linear adjustment costs, which imply that marginal adjustment costs are constant. This form of adjustment costs is related to the issue of the (partial) irreversibility of an adjustment. It may not be costless to sell investment goods in second-hand markets, for example due to transaction costs or the well known "lemons" problem (Akerlof 1970). In countries with dismissal protection, the firm incurs exwplicit costs when firing workers, for example as a consequence of mandatory severance payments. When making the adjustment decision, firms take into account the fact that the adjustment cannot be costlessly reversed should economic circumstances turn out to be unfavorable. For example, Bentolila and Bertola (1990) find that linear adjustment costs lead to labour hoarding in times of economic downturn, but to pridence with respect to hiring new workers during economio upturns. Like fixed costs, this type of costs also creates inaction, which technically speaking arises from the fact that the adjustment costs function is not differentiable at zero. However, unlike fixed costs, linear costs cannot generate adjustment lumps.

Finally, to account for the fact that adjustment costs may differ between positive and negative adjustments, asymmetric adjustment costs specifications have been considered by e.g. Pfann and Verspagen (1989) and Pfann and Palm (1993). In the specification used in these studies the strict convexity of the adjustment costs function is maintained, so that the optimisation problem is still fully differentiable. However, the quadratic specification is 
replaced by a more general functional form that allows the costs of negative and positive adjustments of the same magnitude to vary. While using sectorLewel data, both studies find strong evidence for differences in costs between hiring and firing.

\subsection{Non-linear extension of the Q model}

Abel and Eberly (1994) consider the following augmented adjustment costs function including a fixed, linear and convex component, ${ }^{12}$

$$
C_{\text {cap }}=\frac{\gamma}{2}\left(\frac{I_{t}}{K_{t-1}}\right)^{2} K_{t-1}+\varphi I_{t}+F K_{t-1} 1\left[I_{t} \neq 0\right]
$$

where $p$ is the linear adjustment costs parameter, and $F K_{t-1}$ are fixed costs. The indicator variable $1[$.$] reflects that fixed costs are only mcurred when$ investment is non-zero. The latter term is proportional to the lagged capital stock to reflect that fixed costs may vary with firm size. To allow for asymmetry the parameters can be allowed to depend on the direction of adjustment. Because of the lack of data on negative investment (henceforth "disinvestment") in this thesis, dynamics resulting from asymmetric adjustment costs or partial reversibility cannot be identified. Therefore, and for reasons of exposition, asymmetry will not be considered here, and $\varphi$ is set equal to zero. ${ }^{13}$

To derive an expression for optimal investment with the adjustment costs given by (2.15), we proceed in two steps. First, note that conditional on adjustment, the optimal investment rate is given by $I_{t} / K_{i-1}=(1 / \gamma)\left(q_{t}-p_{i}\right)$, as in the quadratic case, see (2.10). This follows from the fact that in this case $1\left[I_{t} \neq 0\right]=1$, and the term $F K_{t-1}$ does not depend on $I_{t}$. Thus, fixed costs affect the extensive but not the intensive margin of the investment decision (that is, fixed costs affect the decision whether or not to adjust, but, if a

\footnotetext{
${ }^{12}$ The details for investment are given here, but the discussion for labour is analogous. The subscript on the parameters is dropped.

${ }^{13 r}$ These extensions, howewer, are faily straightforward, see e.g. Abel and Eberly (2002) and Bond dind Van Reenen (2002).
} 
firm adjusts, not by how much). Secondly, firms will only invest if the gains of investment exceed its costs. From Section 2.2 the marginal value of an additional unit of capital is $q_{t}$, so that this criterion can be expressed as

$$
q_{t} I_{t}>p_{\imath} I_{t}+\frac{\gamma}{2}\left(\frac{r_{t}}{K_{t-1}}\right)^{2} K_{t-1}+F K_{t-1} .
$$

Using $I_{t} / K_{t-1}=(1 / \gamma)\left(q_{t}-p_{t}\right)$, it follows after some algebra, that investment is positive if ${ }^{14}$

$$
q_{t}-p_{t}>\sqrt{2 F \gamma}
$$

If $q_{t}$ does not meet this criterion, the firm does not invest. In sum, the investment rate dynamics can be described by the regime-switching type model

$$
I_{t} / K_{t-1}= \begin{cases}(1 / \gamma)\left(q_{t}-p_{t}\right) & \text { if } q_{t}-p_{t}>\sqrt{2 F \gamma} \\ 0 & \text { otherwise }\end{cases}
$$

In addition, Abel and Eberly (1994) show that in this non-linear context; marginal $q$ can be replaced by average quder the conditions discussed by Hayashi (1982) for the linear case.

Various studies have estimated and tested this model empirically using firm-level data. Barnett and Sakellaris (1998) wse the framework for statistical inference in threshold models with panel data provided by Hansen (1996) and subsequent articles. This framework allows to test for the existence of thresholds in the investment behaviour of firms. ${ }^{\text {15 }}$ Although they focus on gross positive investment, they argue that additional thresholds arise due to capital heterogeneity. Because the adjustment costs structures may vary among different types of capital, using investment datia aggregated over types will result in a non-linear relation between investment and $q$; even within the positive regime. In addition, because investment in some types of capital may incur no or low adjustment costs, a regime of true insensitivity may be too restrictive for aggregate capital. Barnett and Sakellaris find evidence

\footnotetext{
Similary, investment is megative if $q_{t}-p_{t}<-\sqrt{2 \pi} \%$.

15 See Chapter 5 for a description and application of the same rnethodology.
} 
for three regimes of positive investment, but no evidence for a regime of inaction. The non-linear relation between investment and $q$ is found to be S-shaped, that is convex for low values of $q$ and concave for high values. This is in line with the findings of Abel and Eberly (2002) who claim that this can be explained by the heterogenous capital argument as well. In a model with heterogeneous capital with different levels of fxed costs, increases of $q$ at lower values affect the extensive as well as the intensive margin of investment. At higher values, changes in $q$ will affect only the intensive margin, causing aggregate investment to be less responsive to fundamentals than at lower values. ${ }^{16}$

Letterie and Pfann (2003) adopt the Abel and Eberly formulation to identify low versus high regimes in equiptnent investment. Their theoretical model distinguishes two types of investment, interpreted as maintenance and expansion expenditures. Maintenance expenditures are subject to convex adjustment costs whereas expansion investment incurs convex and fixed costs. Thus, one type of investment follows a linear model as equation (2.10), while the other is characterised by the threshold model given by (2.18). Total investment is therefore either equal to maintenance investment (the "low" regime), or to the sum of maintenance and expansionary investment (the 'high' regime). However, there is no distinction in the data - a subset of the data used in this thesis - between maintenance and expansionary investment; so that a measure for $q$ can only be constructed for total imvestment. To solve this, a suggestion by Eberly (1997) is followed, who assumes that the $q$ 's for different types of investment equal the $q$ of total investment plus a nomally distributed error term. This allows to characterise the probability that a frm is in either the low or the high regime, and estimate the model as a regine-switching equation with Maximum Likelihood techniques. Letterie and Pfann find evidence that the two-regime model performs better than a model with no regimes. The response to fundamentals is significantly stronger in the higl regime. Moreover, the probability that an observation

\footnotetext{
16. The term 'fundamentals' refers to all variables affecting investment, summarised by $q$.
} 
belongs to the high regime increases with $q$ and deareases with firm size. Finally, it is argued that using this probability to identify "investment spikes" is a potential improvement over more ad hoc definitions. ${ }^{1 / 7}$ If the probability is 'high', the observations can be classified as a spike. The advantage over other definitions is that this classification is based on a structural model and depends on firm-specific characteristics. Of course, the choice of the cut-of point, which Letterie and Prann set equal to 0.5 , is still anbitrary.

Besides providing evidence of non-linearities at the fim-level, these studies also address the implications for studying aggregate inwestment. Unlike in models with strictly convex adjustment costs, in the non-linear $\mathrm{Q}$ model the response of aggregate investment to economic shocks depends on the crosssectional distribution of fundamentals. For example, if the distribution of $q$ is such that many firms are just below the threshold, a common positive shock will trigger a large response in aggregate investment. On the other hand, if most of the firms have levels of $q$ far away from the threshold, the response will be very low. The studies mentioned above all indicate that non-linear Q models perform better in predicting aggregate investment than do linear ones. This is relevant for policy making, as it implies that in order to forecast macro-economic effects of policy changes, an analysis of response at the micro-level is required.

Empirical research on labour adjustment using the $Q$ model is scarce. Nilsen, Salvanes, and Schiantarelli (2003) apply a three regime model (negative adjustment, :naction, positive adjustment) to Norwegian plant level data, allowing for adjustment, costs asymmetries in hiring and firing. In addition, fixed costs are split into a size dependent and size independent component. The adjustment parameters are estimated separately for the negative and positive adjustment regime, using a Heckman two-step procedure to control for selection bias. The results indicate the importance of a size independent fixed component, which explains the fact that smaller plants exhibit more inaction than larger plants. In addition, this component is found to be larger

\footnotetext{
${ }^{17}$ See, among others, Cooper, Haltiwanger, and Power (1999) and Cooper and Haltiwanger (2002). See Chapter 3 and 4 for more discussion ari adjustment spikes.
} 
for firing, while there is no evidence for asymmetry in the other components.

In Chapter 5 a non-linear $Q$ model is specified to describe investment dynamics. It is investigated whether the non-linearity of investment alone can generate non-linearity in labour adjustment, for which a linear $\mathrm{Q}$ model is specified.

\subsection{The Euler equation and non-convexities}

Unlike the $Q$ model, the Euler equation approach does not allow for a simple characterisation of adjustment dynamics in the case of non-convex adjustment costs. The derivation of the Euler equations (2.13) and (2.14) requires that the net profit function $\pi$, and hence the adjustment costs function $C$, are differentiable. Because of a discontinuity at zero this requirement does not hold in the case where fixed adjustment costs are considered. In addition, a linear component leads to a 'kink' at zero so that also in this case adjustment costs are not differentiable. In these cases, adjustment is not always profitable so that inaction can be optimal. This leads to a mass-point at zero that is inconsistent with the Euler equation. However, as can be seen in the derivation of the non-linear Q model, conditional on non-zero adjustment, optimal adjustment is given by the same expression as in the absence of fixed costs. Technically, the firm achieves an interior solution in this case, as opposed to the corner solution at zero.

As noted by Whited (1998) the same point holds for the Euler equation. That is, conditional on non-zero adjustment, optimal adjustment is governed by the Euler equation. The structural parameters can thus be estimated using the subsample where firms adjust in two consecutive periods. Whited (1998) finds that the overidentifying restrictions used in the GMM estimation are only marginally rejected when estimating the Euler equation for investment for a subsample of firms that record only positive investment. In contrast, they are rejected strongly when using the complement of this subsample, and also when using the full sample. Whited interprets this finding as evidence 
that fixed costs are important for the firn's investment decision.

An additional complication in this context, not considered by Whited, is that of enclogenous sample selection. As can be seen by referring back to the non-linear $\mathrm{Q}$ model (2.18), the fixed as well as the convex adjustment costs parameter enter the criterion for non-zero adjustnent. Therefore, firms that have low adjustment costs have a higher probability of being selected into the positive adjustment regime than a firm with high adjustment costs. Thus, conditioning estimation on the abservations in the positive adjustment regime will possibly lead to a downward biased estimate of convex adjustment costs. A solution to this problem is to control for selection bias in the estimation.

This possibility is considered by Alonso-Borrego (1998), who considers a system of Euler equations for production and non-production workers. Adjustment costs are asymmetric, and include a cross-term to capture possible interrelation between the adjustment of both types. The existence of fixed costs are recognised by the fact that the Euler equations are estimated conditional on non-zero adjustment in two consecutive periods, that is $H_{t} \neq 0$ and $H_{t-1} \neq 0$. Thus, the selection variable is defined as $\mathcal{I}_{t}=1\left[H_{t} \neq 0, H_{t-1} \neq 0\right]$, and the Euler equations are estimated for the subsample with $I_{t}=\mathbb{1}$. To control for endogenous selection, Heckmen's two-step procedure (Heckman 1979) is applied. In this approach, selection is specified as a probit model with dependent variable $\mathcal{I}_{t}$. The conditional expectation of the error tem given selection can be estimated using the probit estimation results. Adding this correction term - known as Heckman's lambda - as an additional regressor in principle controls for selection bias. The main findings by Alonso-Borrego are that adjustment costs are higher for non-production workers, and that the costs of adjusting the level of non-production are lowered when production workers are fired simultaneously. There is no strong evidence for asymmetry in hiring and firing costs.

The selection correction technique by Alonso-Borrego is somewhat ad hoc, in the sense that the approach in Heckman (1979) is originally formulated for selection over one period rather than two. In addition, the original approach 
relies on a static model without endogenous regressors. The issue of controlling for endogenous selection in dynamic panel data models - as the Euler equation - is itself the topic of ongoing research. Estimation techniques for this kind of models with additional endogenous regressors have not yet been fully developed. Given this lack of ecomometric techniques, an ad hoc approach does therefore not seem unreasonable although the results should be interpreted with care. In Chapter 6 the same approach as in Alonso-Borrego (1998) is used as a robustness check of the results to selection bias. In Chapter 7 the theoretical model is simplified so that the first-order conditions yield a partial adjustment model without additional regressors, and an Asymptotic Jeast Squares procedure is employed to estimate the adjustment speed parameter of labour without sejection bias. ${ }^{18}$

\subsection{Alternative approaches}

It can be argued that the derivation as well as the implementation of the $Q$ model requires strong assumptions, especially in the case of non-convexities (Caballero and Leahy 1996). With the Euler equation it is only possible to characterise the intensive margin of adjustment, and estimation is hampered by seitection issues. Two alternative approaches that depart from estimating closed form solutions to the dynamic optimisation problem (2.4) are briefly discussed in this section. The aim of this discussion is to provide some intuition with respect to these approaches and to reinforce the evidence on non-convex adjustment costs.

\subsubsection{The gap approach}

In a less structural setting Caballero and Engel (1993) argue that labour adjustment can be characterised as a function of the gap (z) between the

\footnotetext{
${ }^{18}$ Rot2 (2001) also estimates adjustment parameters from the Euler equation with lumpy and kinked adjustment costs. Her approach is based on the literature on mixed discretecontinuous choice problems, see e.g. Aguirregabiria (1997).
} 
actual level of employment and the 'desired' (or 'target') level ( $L$ '), that is $z=L-L^{*}$. This approach is informally known as the "gap approach" ${ }^{79}$ Given the size of the gap the (average or expected) fraction of adjustment for each firm (that is, the ratio of actual to desired adjustment) is defined as $A(z)$ ). This so-called 'adjustment hazard' can be the result of a small number of firms adjusting a large fraction (consistent with non-convexities) or a large number. adjusting a small fraction (consistent with quadratic adjustment costs). The aggregate change in labour can then be expressed as

$$
H_{t}^{a}=\int_{-\infty}^{\infty} z \Lambda(z) f_{t}(z) d z
$$

where $H_{t}^{a}$ is aggregate net hiring, and $f_{t}$ is the crossusectional density of $z$ at time t.

Using sector-level employment data Caballero and Engel (1993) find that the adjustment hazard is increasing in the size of the gap. ${ }^{20}$ This is consistent with a larger number of firms adjusting for high values of $z$, which is the case with non-convex adjustment costs. It contradicts a quadratic specification of adjustment costs, which gives rise to a constant hazard, so that the fraction of the gap that is closed is constant. Using a methodology along the same lines, Caballero, Engel, and Haltiwanger (1995) reach similar conclusions for investment using plant-level data. As mentioned in the discussion of the non-linear Q model, aggregate adjustment depends on the cross-sectional distribution of the variable that drives adjustment, which is $f_{t}(z)$ in this case. This is relevant for policy making as the forecasting of the response of aggregate variables requires a firm-level analysis. Caballero and Engel (1999) provide a structural interpretation of their methodology.

A difficulty with this approach is the fact that the target level $L^{\prime \prime}$ and, hence, the gap $z$ are not abserved. Caballero and Engel (1993) define the target as the employment level that would arise if there were no adjustment costs. Then the target level can be derived from a static optimisation problem,

\footnotetext{
${ }^{19}$ Alternatively, the methodology conld be referred to as a 'generalised $(S, s)$ ' appronch.

${ }^{20}$ Because Caballero and Engel (1993) use aggregate data, additional assumptions are needed to obtain a cross-sectional distribution for $z$.
} 
and can be interpreted as a long-run equilbrim. Altematively, Caballero, Engel, and Haltwanger (1997) use an awiliary model to estimate the gap, assuming that is proportional to the deviation in working hours from its fum-specific time average. The idea is that if labour is quasi-fxed, but working hours are Rexible, frms will initially vary only the latter in response to (modarate) shocks. Thus, there is a relation between the use of hours and the gap. Cooper and Wille (2001) give a critical review of the gap approach, arguing that the results can be the consequence of mismeasurement of the gap.

\subsubsection{Simulation based inference}

Cooper and Haltwanger (2002) take a simulation based approach to estimate the structural parameters of the firm ${ }^{\prime}$ s optimisation problem (2.4). They adopt the method of indirect inference (Courieroux and Monfort 1996) that involves finding the set of parameter values that matches best a set of suitably chosen moments of the data ${ }^{21}$ For different sets of parameter walues a simulated data set is obtained for which the moments are calculated. A searh routine determines the set of parameter values that minimises the difference between the moments from the actual data and the moments from the simulated data, acconding to some distance measure. An attractive feature of this approach is that it only requires the specification of the optimisation problem, and not the derivation of a closed-form solution, to estimate structural parameters. In principle, this allows the imvestigation of farly complex production and adjustment costs functions. However, the choice of the moments to be matched seems rather ad hoc, and it is not clear how the results vary with different choices. In addition, computational problems are likely to become an issue in complicated cases.

Cooper and Haltiwanger find that a model with a rich specification of adjustiment costs, including both convex and non-convex components, provides the best fit to their plant level data. An interesting finding is also that a

\footnotetext{
${ }^{21}$ See Adda and Cooper (2003) for a good exposition of this method and applications.
} 
model with quadratic costs fits the aggregate data reasonably well, although it performs poorly at turning points in the aggregate time series. Cooper, Haltiwanger, and Willis (2004) employ the same methodology to estimate the adjustment parameters of labour. They find that non-convex costs are relevant in explaining plant-level employment dynamics. However, a model with quadratic costs and disruption costs that are proportional to ontput fits the data best.

\subsection{The present study}

It is useful to summarise how the following chapters are related to the literature discussed in this chapter. Chapters 3 and 4 perform a statistical analysis presenting stylised facts that document features of the data that are consistent with dynamics of factor demand predicted by the non-linear structural models discussed. In Chapter 5 a non-linear Q model for investment, as proposed by Abel and Eberly (1994), is estimated together with a linear Q model for labour adjustment - and the production function - as a system of Seemingly Unrelated Regressions (SUR), allowing for contemporaneous correlation of the disturbances as well as firm-specific effects. The aim is to investigate whether non-linearity from the investment equation translates to employment dynamics. This is probably the first study to consider simultaneous estimation of the factor demand equations where the demand for one of the factors is subject to non-convexities, and both factors are costly to adjust.

In Chapter 6 the Euler equations for investment and labour adjustment are used to compare factor dynamics in Germany and the Netherlands. In line with Whited (1998) and Alonso-Borrego (1998), estimation is restricted to the observations where adjustment is non-zero, and the sensitivity of the results to endogenous selection is checked. This chapter makes a number of contributions. Firstly, the existence of non-convexities is not widely recognised in an Euler equation framework. Secondly, interrelated adjustment costs 
wre estimated using micro-level data. Finally, considering both German and Dutch firms allows for a unique international comparison of micro-level factor dynamics, which gives the opportunity to imvestigate the impact of the institutional seting in the respective countries.

Finally, in Chapter 7 , the finding of micro-level non-linear labour adjustment is related to the consequences for aggregate adjustment. To estimate the speed of adjustment of an economic variable, macro-economic research usually relies on a linear partial adjustment model estimated with aggregate data. This, however, can be shown to give biased estimates (Caballero and Engel 2004). In this context, it is shown that with fixed adjustment costs, the partial adjustment model - like the Euler equations - is only valid for the subsample of non-zero observations. Estimation based on these observations, and controlling for endogenous selection, however, in principle gives an unbiased estimate of the adjustment speed parameter. 



\section{Chapter 3}

\section{Stylised facts for factor adjustment in Dutch}

\section{manufacturing}

\subsection{Introduction}

The focus of this dissertation is the dynamics and interrelation of investment and labour adjusment. This chapter presents some stylised facts with respect to these topics for the data used throughout the study. A brief description of the data is given in Section 3.2 , and Section 3.3 presents the summary statistics for the key variables. The statistical approach of various earlier studies is followed to document evidence on lumpy and intermittent factor dynamics. This analysis is presented in Section 3.4. Next, Section 3.5 takes a first look at how capital and labour are interrelated. Finally, Section 3.6 relates the micro-level lumpiness to aggregate dynamics. Section 3.7 concludes.

\subsection{Data}

The data used throughout the study are the Investment Statistics (IS) and Production Statistics (PS) collected by the CEnter for Research of Economic 
Microdata (CEREM) at Statistics Netherlands (CBS). Both data sources contain annual data at production unit level for the Dutch manufacturing sector. ${ }^{1}$ For convenience we will refer to all units as firms. The IS is a census of firms with more than 20 employees. The PS is also a census of firms with more than 20 employees, while firms with less than 20 employees are sampled." Cooperation in the respective surveys is required by law. In comparison to many related international studies this data set contains a high number of smaller firms, which allows to obtain a more complete picture of the adjustment behaviour of firms. For the analyses in this study only observations are used that were obtained directly from the survey, and were not imputed in any way. The sample spans the period from 1978 to 2000 . Table 3.1 gives the two-digit industry classification of the firms according to the Standaard Bedrijfsindeling (SBI) 1993, which is similar to the international standards as specified by the ISIC Rev. 3.1 by the United Nations.

The data do not include a measure for capital stock. Following among others Letterie and Pfann (2003), after estimation of a starting value, the first five years of observations for each firm are used to construct a capital stock measure from the investment figures according to the perpetural inventory method. The appendix to this chapter explains this method in detail. Investment refers to the value of durable tangible assets that are acquired or produced in a certain book year, as well as maintenance expenditures. Not included are investments in foreign establishments, disinvestments, and takeovers if the acquired firm proceeds its original activities. Only gross positive investments are observed, whereas for employment net changes are observed. It is not possible to distinguish between different types of workers, like parttime versus full-time or low-skilled versus high-skilled, nor between different types of capital goods. Neither does the data contain information on working hours.

\footnotetext{
"A production unit is defined as a company or part of a company in which a predomindant production activity takes place, and for which a complete statistical description is possible. In some instances companies are bundled to neet the latter criterion.

"To preserve continuity in the census, firms that drop incidentally below the criterion of 20 employees are maintained in both the IS and PS.
} 


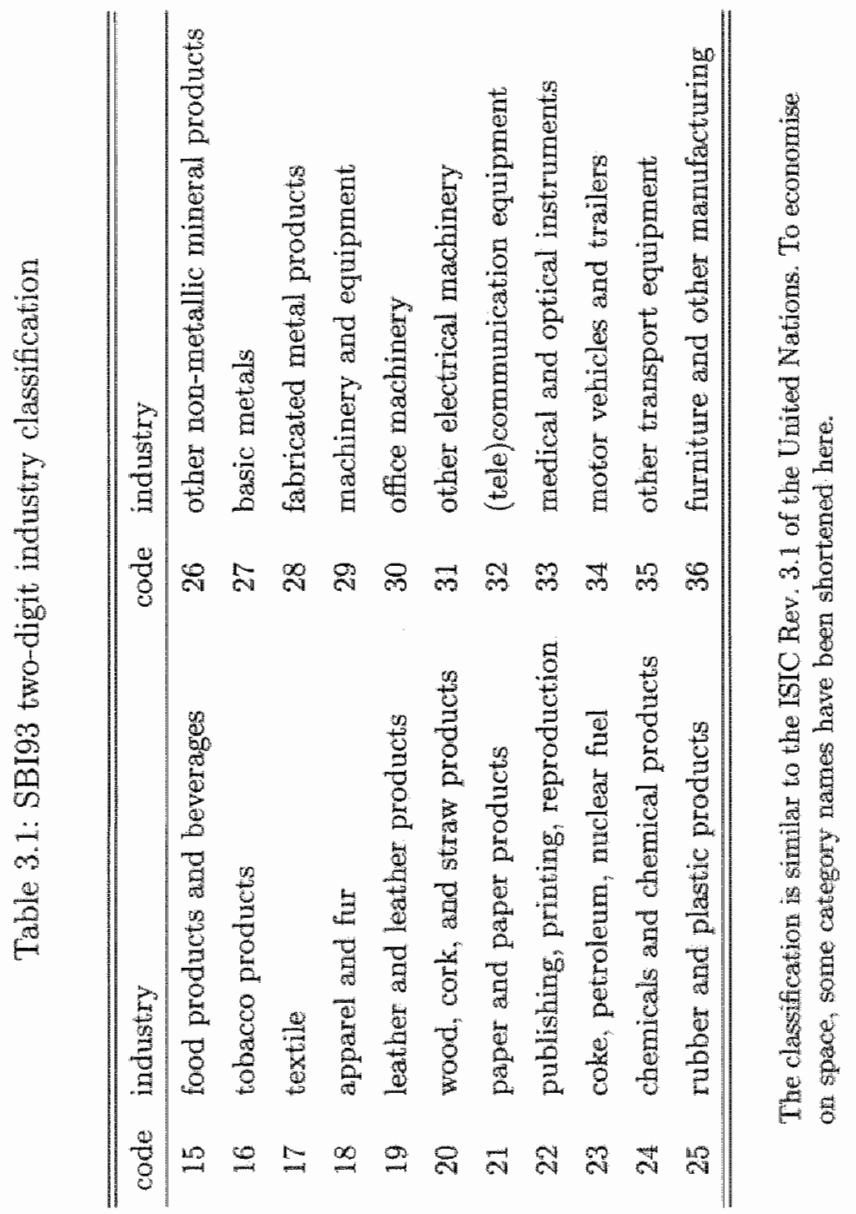




\subsection{Summary statistics of key variables}

Table 3.2 gives the summary statistics for the key variables in the analysis. These statistics refer to the period 1984 to 2000 as the first five years of observations for each firm are always used to construct the capital stock. ${ }^{3}$ In addition, one year is lost because of the construction of the investment rate $\left(I_{t} / K_{t-1}\right)$ and the labour adjustment rate $\left(H_{t} / L_{t-1}\right.$, where as before $\left.H_{t}=\Delta L_{t}\right)$. The average firm in the data invests on average about 3.8 million Dutch guilders (NLG) per year. However, from the median it can be seen that the average is blown up by a few large observations as in 50 percent of the observations investment is below 0.5 million NLG. In fact, the $90 \%$ percentile is around 3.8, so that $90 \%$ of the total annual investment is smaller than the average. Also employment is highly skewed: the average firm in the sample employs 195 workers, while in half of the cases the number of employees is less than 62. Annual sales are on average about 71 million NLG, while the median is again much lower with about 14 million. The average total labour costs, which includes wages, bonuses, and the employer's contribution to social security and health care, is around 63 thousand NLG per worker.

The investment rate is on average $9.3 \%$, while for 50 percent of the observations it is lower than $5 \%$. Although these figures do not relate directly to inwestment dynamics, they are a preliminary indication for the lumpiness of investment. If firms alternate periods of low investment with infrequent periods of very high investment, this will result in a skewed distribution of the investment rate. However, as the statistics relate to the distribution over all firms, the skewness may also result from some firms having a persistently high investment rate, while others have a persistently low rate. In the next section more detailed statistical evidence is presented to support the former interpretation. The average labour adjustment rate is slightly positive; while the median is equal to zero. Therefore, negative and positive changes seem to

\footnotetext{
"Note, however, that not each frrm is present in 1978 . If a firm enters the panel at a later date, the first five years of observations from that year onwards are used to construct. the capital stock measure.
} 
Table 3.2: Summary statistics

\begin{tabular}{lccc}
\hline \hline variable & mean & std. dev. & median \\
\hline total investment & $3,852.85$ & $34,076.07$ & 485.89 \\
employment & 195.13 & 1333.223 & 62 \\
sales & $71,469.78$ & $411,509.3$ & $13,873.46$ \\
investment rate & 0.093 & 0.177 & 0.050 \\
labour adjustment rate & 0.008 & 0.199 & 0 \\
labour costs per capita & 63.360 & 20.058 & 62.276 \\
\hline no. of obs. & 30,139 & & \\
\hline
\end{tabular}

All monetary values are in real terms (bese year = 1995) and expressed in thousands of Dutch guilders. Observations where the investment or labour adjustment rate are above 5 were dropped.

offset each other on average. This is consistent with the finding of simultaneous job creation and destruction as in Davis, Haltiwanger, and Schuh (1996) for the United States and Broersma and Gautier (1997) for the Netherlands.

Figure 3.1 shows the mean and median investment rate through time. Both statistics show that investment rates are higher in the first half of the sample period: for the 1984 to 1991 the average is albout $10 \%$, where from 1992 to 2000 it is around $8 \%$. A possible explanation is that the number of obserwations declines with time, due to the use of the perpetual inventory method in constructing the capital stock mextsure. This influences the size distribution within the sample, with the share of large firms increasing. Since large firms on average have lower investment rates than smaller firms this causes the overall average investment rate to go down. However, as also depicted in the figure, the average investment rate in the balanced subsample (that is, the firms that are observed throughout the whole sarn ple period) closely resembles the overall pattern. This subsample consists of 
Figure 3.1: Average and median investment rate over time

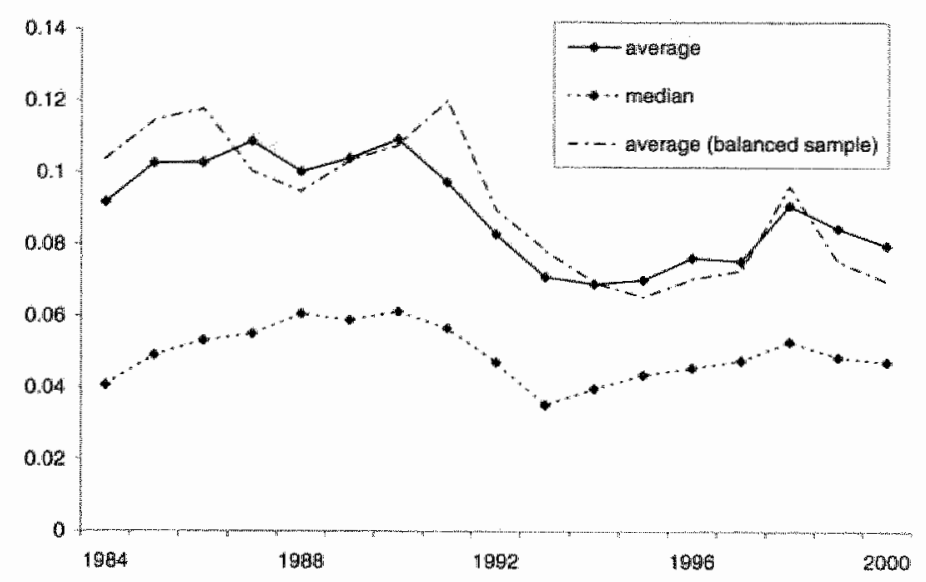

383 mainly larger, and probably more successful firms. Thus, it appears that the investment rates have indeed gone down after 1990, slightly recovering after 1997. Figure 3.2 presents the mean and median over time for net employment changes. The correlation over time between the average investment and labour adjustment rate is almost $70 \%$. The decrease of investment after the early 1990 s is parallelled by on average lower and even negative net employment changes. Although for the balanced sample the average adjustment rate is slightly negative only in 1995 , it is clearly lower in the second half of the sample period as well. The co-movement of investment and labour adjustment is a preliminary indication of the interrelation between the two production factors. This relation is explored further in Section 3.5. In these figures, employment appears more volatile than investment, though it should be kept in mind that negative capital adjustment is not observed.

Another interesting aspect is the extent of sectoral differences. Table 3.3 gives the mean and median of the investment and employment rate by SBI classification. The sectors display a clear heterogeneity with respect to the adjustment rates. The average investment rate ranges, for instance, from 
Figure 3.2: Average and median hiring rate over time

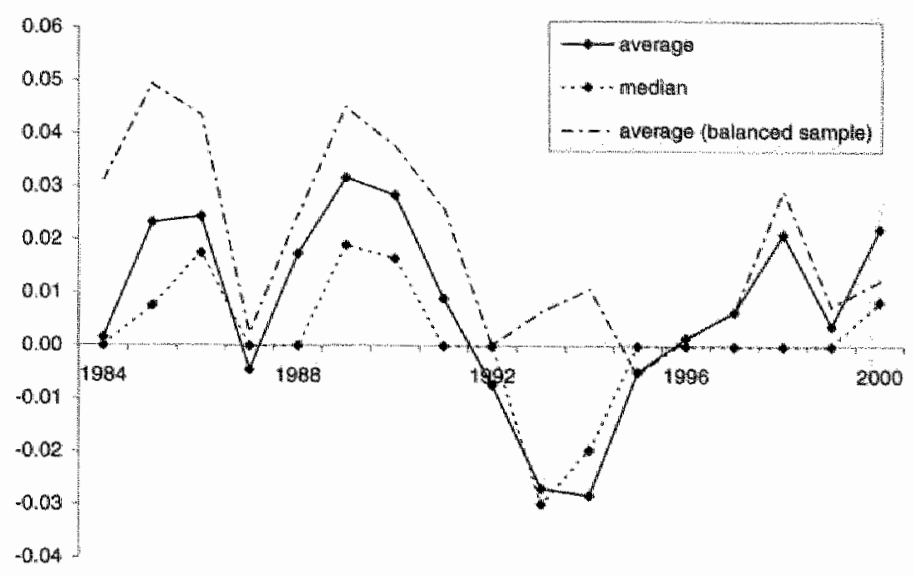

$6 \%$ for apparel (18) to $11 \%$ for other electrical machinery (31) and telecom equipment (32). The average employment rate ranges from $-4 \%$ for tobacco products (16) and apparel to $6 \%$ for office machinery (30). The heterogeneity observed may well be due to the degree of capital intensity of the production process. Overall economic developments that affect sectors in a different way is another aspect. For example, the transfer of low-skilled manufacturing jobs to low-wage countries may explain why adjustment rates are relatively low in the apparel sector.

\subsection{Lumpy and intermittent adjustment}

As discussed in Chapter 2, with the increasing availability of firm-level date it has become clear over the last decade that factor adjustment is not 'smooth' as predicted by the traditional linear-quadratic adjustment costs models. Rather, firms alternate between periods of inaction and heavy adjustment, and tend to concentrate large adjustments into short periods of time. "The observed dynamics of factor adjustment are therefore often characterised as 
Table 3.3. Statistics by two-digit industry

\begin{tabular}{|c|c|c|c|c|c|c|}
\hline \multirow[b]{2}{*}{ SBI93 } & \multicolumn{3}{|c|}{ investment rate } & \multicolumn{3}{|c|}{ labour adjustment rate } \\
\hline & mean & mediun & $=0(\%)$ & mean & median & $=0(\%)$ \\
\hline 15 & 0.10 & 0.05 & 0.06 & 0.01 & 0.00 & 0.14 \\
\hline 16 & 0.07 & 0.04 & 0.01 & -0.04 & -0.02 & 0.03 \\
\hline 17 & 0.09 & 0.05 & 0.06 & -0.01 & 0.00 & 0.16 \\
\hline 18 & 0.06 & 0.03 & 0.20 & -0.04 & 0.00 & 0.11 \\
\hline 19 & 0.07 & 0.04 & 0.09 & -0.03 & -0.01 & 0.13 \\
\hline 20 & 0.08 & 0.04 & 0.07 & 0.00 & 0.00 & 0.16 \\
\hline 21 & 0.1 .0 & 0.07 & 0.03 & 0.01 & 0.00 & 0.09 \\
\hline 22 & 0.09 & 0.05 & 0.05 & 0.02 & 0.00 & 0.14 \\
\hline 23 & 0.07 & 0.03 & 0.00 & 0.00 & -0.01 & 0.13 \\
\hline 24 & 0.10 & 0.06 & 0.01 & 0.00 & 0.00 & 0.13 \\
\hline 25 & 0.10 & 0.06 & 0.04 & 0.01 & 0.00 & 0.22 \\
\hline 26 & 0.07 & 0.04 & 0.06 & 0.00 & 0.00 & 0.18 \\
\hline 27 & 0.10 & 0.05 & 0.02 & 0.01 & 0.00 & 0.08 \\
\hline 28 & 0.10 & 0.05 & 0.05 & 0.02 & 0.00 & 0.14 \\
\hline 29 & 0.10 & 0.05 & 0.07 & 0.01 & 0.00 & 0.13 \\
\hline 30 & 0.09 & 0.08 & 0.02 & 0.06 & 0.02 & 0.08 \\
\hline 31 & 0.11 & 0.06 & 0.03 & 0.01 & 0.00 & 0.14 \\
\hline 32 & 0.11 & 0.06 & 0.05 & 0.04 & 0.00 & 0.12 \\
\hline 33 & 0.08 & 0.05 & 0.02 & 0.00 & 0.00 & 0.14 \\
\hline 34 & 0.08 & 0.04 & 0.04 & 0.03 & 0.02 & 0.12 \\
\hline 35 & 0.10 & 0.04 & 0.06 & -0.01 & 0.00 & 0.12 \\
\hline 36 & 0,09 & 0.04 & 0.04 & 0.02 & 0.00 & 0.16 \\
\hline
\end{tabular}

Industry coding according to the Standaard. Bedriffsindeling (SBI) 1993 of CBS. 
'Jumpy' and 'intermittent'. Statistical evidence on this behaviour is documented in, among others, Davis, Haltiwanger, and Schuh (1996) for labour, and Doms and Dunne (1998), Cooper, Haltiwanger, and Power (1999), and Nilsen and Schiantarelli (2003) for investment. This section presents a descriptive analysis along the same lines.

Figures 3.3 to 3.5 characterise the distribution of the investment and labour adjustment rate. The inaction regime for investment is of a moderate size only with around $5 \%$ of observations. While at first sight this contradicts the relevance of fixed adjustment costs, it is likely to be the result of the fact that investment is aggregated over different types of investment goods. Some investment goods may have no or very low fixed costs, and can therefore be adjusted continuously. Thus, aggregation over heterogeneous capital goods prevents investment from becoming truly zero. In addition, replacement and expansion investment cannot be distinguished. Fims carry out replacement investment on a regular basis. It is therefore likely that these involve lower costs than expansion investment, for instance because of learning effects. Adding up expansion and replacement investment will therefore mask inaction with respect to the former type of investment. This is confirmed by the fact that in more than half of the observations the investment rate is below $5 \%$, which is the figure used for the depreciation rate in this and many other studies. These categories account for only about $22 \%$ of total investment. In contrast, only in about $10 \%$ of observations is the investment rate more than $20 \%$, but strikingly, this small fraction of observations accounts for $23 \%$ of investment. These statistics are consistent with the picture that firms carry out large investments infrequently, and that periods of heavy investment are alternated with periods where only replacement investment are made. The fact that a small number of observations accounts for a large share of total investment is suggestive evidence for the lumpiness of investment, $\mathrm{cl}$. Doms and Dunne (1998) and Nilsen and Schiantarelli (2003).

Labour adjustment is split into positive and (absolute) negative adjust- 
Figure 3.3: Investment rate distribution

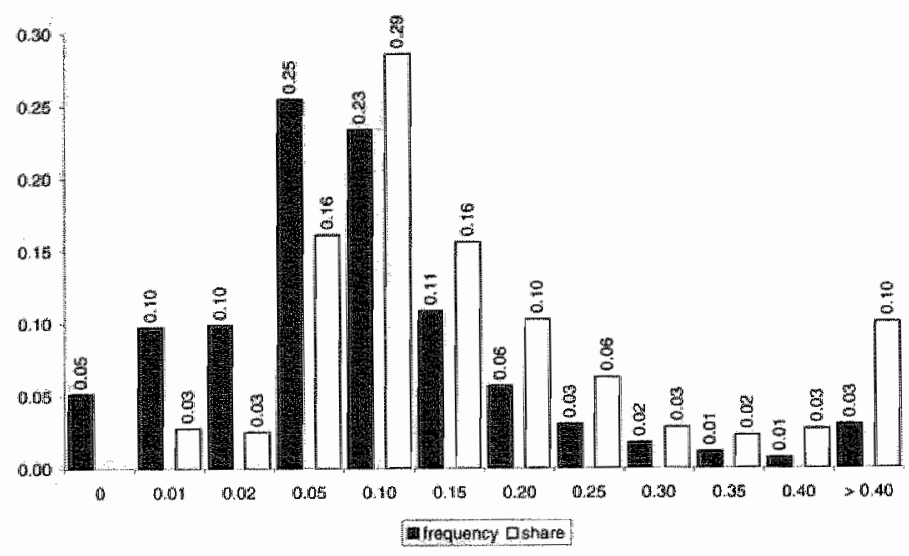

"Share refers to the ratio of total investment in that category to total overall investment. That is, if $r_{i l}^{c}$ is an inwestment categorised in category $c$, the share of category $c$ is $\sum_{i t} I_{i t}^{c} / \sum_{i t} I_{i w}$.

ment which are labeled net hiring and net firing for convenience. The inac" tion regime is much larger thar for investment with about $14 \%$ of the total of observations." However, as only net changes are observed, it camnot be distinguished whether zero adjustment stems from revil inaction or an offet of positive and negative adjustrnents cluring a year. Another issue that plays a role here is that temporary workers are not observed. Jobs created and destroyed within a year, and newly created jobs filled by agency workers are not recorded. Like with investment, small adjustments account for a relatively large share of observations: for both negative and positive labour adjustment: over $90 \%$ of the observations is smaller than $20 \%$. These observations account

\footnotetext{
In the terminology of Davis, Haltiwanger, and Schuh (1996) the columns would be labeled job creation and job destruction.

"The frequencies reported for the zero regime are the frequencies of abservations in the total of respectivaly positive and negative abserwations. Note that these frequencies are not equal because the number of positive observations does not equal the number of negative obserwations.
} 
Figure 3.4: Net hiring rate distribution

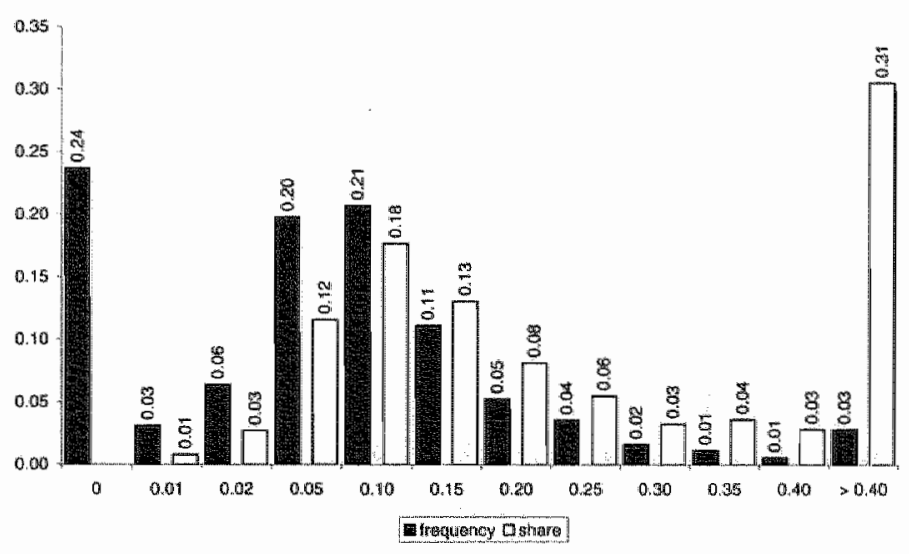

Figure 3.5: Net firing rate distribution

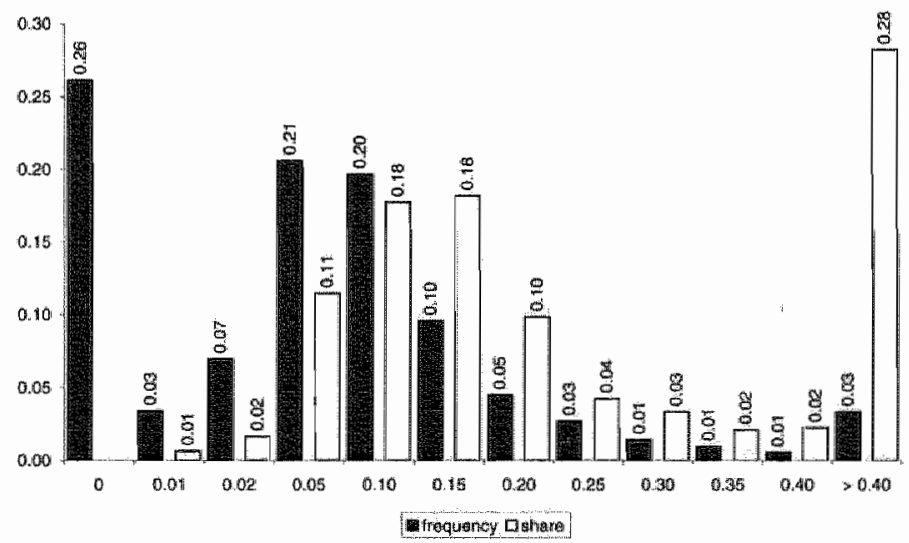

Net hiring (firing) is defined as an obserwation with $H=\Delta L>0(<0)$. Share? refers to the ratio of total (absolute) labour adjustiment in that category to total (absolute) overall adjustment. That iss, if $N H_{i}^{*}$ is a positive net labour adjustment categorised in category $c$, the share of category $c$ is $\sum_{i t} N H_{i t}^{c} / \sum_{i t} N H_{i t}$. Likewise, if $N F_{i t}^{c}$ is a negative net labour adjustment categorised in category c the share of a ret firing category is $\sum_{i t}\left|N F_{i t}\right| / \sum_{i \ell}\left|N F_{i n}\right|$. 
Table 3.4: Inaction by firm size

\begin{tabular}{ccc}
\hline employees & $I / K=0(\%)$ & $H / L=0(\%)$ \\
\hline $10-19$ & 25.58 & 31.07 \\
$20-29$ & 6.58 & 19.66 \\
$50-99$ & 2.86 & 13.47 \\
$100-199$ & 1.91 & 7.42 \\
$200-499$ & 1.15 & 4.70 \\
$\geq 500$ & 0.91 & 1.99 \\
\hline
\end{tabular}

Finm size classification is based on the firm size categorios by CBS. Reported are categories 4 to 9 .

for respectively $60 \%$ of total negative adjustment, and $54 \%$ of positive adjustment. The remaining $1.0 \%$ of the observations account for the renaining $40 \%$ and $46 \%$ of adjustment. Even stronger tham with investment, a small percentage of observations accounts for a large share of adjustment. From these results, it can be concluded that labour adjustment is lumpy. Thus, in other words, a large share of aggregate labour adjustment can be attributed to dramatic changes as mass frings, and large restructurings and expansions (c. Davis, Haltiwanger, and Schuh (1996, section 2.3)).

Table 3.3 also gives the percentage of obserwations with zero adjustment by industry. This table shows that sectors are not only heterogeneous with respect to the size of investments as discussed above, but also with respect to the decision whether or not to adjust. For investment, the apparel industry (18) stands out with as much as $20 \%$ of observations where there is no investoment. In contrast, in the crude oil and chemicals sectors ( 23 and 24) zero investment rarely occurs. Again, the nature of the production process and overall economic developments serve as candiclate explanations for this heterogeneity. 
Large firms are likely to incur (relatively) smalier adjustment costs than small firms. Large firms are often older, and have gained experience on how to carry out adjustments in an efficient way. They are also more likely to have separate departments that deal with organisational and financial issues, thereby reducing possible costly disruptions to the production process. Table 3.4 shows how inaction varies with firm size. It is evident that for both investment and labour adjustment, inaction decreases with firm size. While for the lowest category the investment rate (labour adjustment rate) is zero in about $25 \%(31 \%)$, inaction is rather exceptional in the higher categories with about $1 \%(2 \%)$ for the largest firms. Since it is clear that inaction occurs less in the case of large firms, a purely fixed cost component that does not vary with adjustment and firm size is a possible explanation of this finding, see Nilsen, Salvanes, and Schiantarelli (2003).

Though the evidence presented above is suggestive for lumpy factor adjustment dynamics, the adjustment pattern of individual firms was not considered. To do so, it is necessary to analyse the balanced sample of firms that are observed throughout the whole sample period 1984 to 2000 . As inclusion in the balanced sample is conditional on survival of the firm throughout 17 years, the results are likely to be biased towards larger and more successful firms. On the other hand, it became clear before that the adjustment pattern of small firms appear to be more intermittent and lumpy than for larger firms. Hence, if the analysis of the balanced sample provides evidence for lumpiness this is likely to hold in an even stronger sense for the whole sample. The number of firms in the balanced subsample is 383 .

Following Doms and Dumne (1998), the yearly adjustment rates are ranked for each firm from lowest (rank 1) to highest (rank 17). For each rank the mean adjustment rate over all firms is calculated, and the share of each rank in total adjustment that year. The results are reported in Table 3.5. For labour adjustment the shares of absolute adjustment in that category in total absolute adjustment is reported. The average investment rate in the top rank is $40 \%$, which is more than four times larger than the average overall 
Table 3.5: Ranked adjustment rates

\begin{tabular}{cccccc}
\hline & \multicolumn{2}{c}{$I / K$} & & \multicolumn{2}{c}{$H / L$} \\
rank & average & share & & average & share \\
\cline { 2 - 3 } \cline { 5 - 6 } 2 & 0.01 & 0.02 & & -0.18 & 0.19 \\
3 & 0.02 & 0.03 & & -0.10 & 0.11 \\
4 & 0.03 & 0.03 & & -0.07 & 0.10 \\
5 & 0.03 & 0.03 & & -0.05 & 0.07 \\
6 & 0.04 & 0.04 & & -0.02 & 0.04 \\
7 & 0.05 & 0.04 & & -0.01 & 0.02 \\
8 & 0.05 & 0.04 & & 0.00 & 0.03 \\
9 & 0.06 & 0.05 & & 0.01 & 0.02 \\
10 & 0.07 & 0.05 & & 0.02 & 0.02 \\
11 & 0.08 & 0.06 & & 0.03 & 0.02 \\
12 & 0.09 & 0.07 & & 0.04 & 0.02 \\
13 & 0.10 & 0.07 & & 0.05 & 0.03 \\
14 & 0.12 & 0.09 & & 0.07 & 0.03 \\
15 & 0.15 & 0.10 & & 0.10 & 0.05 \\
16 & 0.21 & 0.12 & & 0.15 & 0.08 \\
17 & 0.40 & 0.13 & & 0.28 & 0.13 \\
\hline \hline
\end{tabular}

'Shane' is the ratio of total (absolute) adjustment in a certain rank to total overalli (absolute) adjustment. That is, if $I_{i t}^{r}$ is an investment with rank $r$, the share of rank $r$ is $\sum_{i t} I_{i t} / \sum_{i t} I_{i l}$. For labour, the share is defined as $\sum_{i t}\left|H_{i t}^{r}\right| / \sum_{i t}\left|H_{i t}\right|$.

imestment rate. In addition, it can be seen that for the lowest 13 ranks investment is moderate with on average less than $10 \%$. In almost half of the ceses the investment rate is smaller than depreciation, and these account for just ower a quarter of total investment. In contrast, the two highest ranks alone account for an equal share. This is clear evidence of lumpiness, as a large share of investment can be attributed to only one or two periods. Many 
firms experience few years with heavy investment, alternated with years of only moderate investment.

The adjustment of labour provides a similar picture. Most of the adjustment is concentrated in the tails. Average adjustment in the lowest rank is $-18 \%$ and in the highest rank it is $28 \%$, almost twice as large as the average in respectively the second lowest and second highest rank. The two lowest and two highest ranks together account for more than half of total absolute labour adjustment. Again this shows that many firms concentrate adjustment into few periods, which is a clear indication of the lumpiness and intermittency of employment changes.

\subsection{Adjustment regimes}

With investment and the net change in employment being both either positive, negative or zero, the simultaneous adjustment of capital and labour can in principle be classified into nine regimes. ${ }^{6}$ As only data on non-negative investment is available, six instead of nine regimes are observed here. To gain some preliminary insights into how factors of production move together, these regimes are summarised in Table 3.6. The table reports frequency estimates of the unconditional and conditional probabilities for each regime. The results in panel (I), where inaction for capital is defined as true zero investment, show that firms almost always adjust one of the production factors: in only $1 \%$ of the cases adjustment equals zero for both capital and labour. The largest regimes are those in which both factors are adjusted. This finding allows for two interpretations. Firstly, the production teclinology may require that both factors are adjusted simultaneously. Secondly, costs to adjustment may be interrelated by which simultaneous adjustment is cost efficient. It is striking that with positive investment both positive and negative labour adjustment takes place, the former regime being slightly larger. Thus, it seems

\footnotetext{
${ }^{6}$ Dixit (1997) presents a theoretical model with kinked linear wajustraent costs that describes the existence and the shape of these adjustment regimes.
} 
Table 3.6: Adjustment regimes

\begin{tabular}{|c|c|c|c|c|c|c|c|}
\hline \multirow{2}{*}{$\begin{array}{l}\text { (A) } \\
I / K\end{array}$} & \multirow{2}{*}{$\begin{array}{l}\text { (B) } \\
H / L\end{array}$} & \multicolumn{3}{|c|}{ (I) } & \multicolumn{3}{|c|}{ (II) } \\
\hline & & PIAB] & $\operatorname{Pr}[B \backslash A]$ & $\operatorname{Pr}[A \mid B]$ & $\operatorname{Pr}[A[B]$ & $\operatorname{Pr}[\mathrm{B} \backslash \mathrm{A}]$ & $\operatorname{Pr}[A \mid B]$ \\
\hline 4 & - & 0.38 & 0.40 & 0.94 & 0.16 & 0.33 & 0.41 \\
\hline 0 & - & 0.08 & 0.50 & 0.06 & 0.24 & 0.47 & 0.59 \\
\hline+ & 0 & 0.13 & 0.14 & 0.92 & 0.06 & 0.13 & 0.44 \\
\hline 0 & 0 & 0.01 & 0.21 & 0.08 & 0.08 & 0.16 & 0.56 \\
\hline+ & + & 0.44 & 0.47 & 0.97 & 0.27 & 0.54 & 0.59 \\
\hline 0 & + & $0.0 \%$ & 0.29 & 0.08 & 0.19 & 0.37 & 0.41 \\
\hline
\end{tabular}

In pariel (I) inaction for capital is defined as true zeroes ( $(0$ ' is $I / K=0$ ). In panel (IT) inaction for capital is defined as investment smaller than depreciation ( $(0)$ is $X / K<5 \%$ ).

that labour is as likely to be substituted by capital than as to complement it. This is confirmed by the conditional probabilities: given that investment: is positive the probability of net hiring and net fring are roughly equal, the former being slightly higher. The probability of zero adjustment, however, is still substantial. This may be due to replacement imvestment which does not require adjustment of the labour force.

To investigate the latter point, inaction for capital is redefined as the investment rate being smaller than depreciation, which is set at $5 \%$. Investments that are above the depreciation rate can be roughy interpreted as expansionary investments. The results are reported in panel (II) of lable 3.6. Naturally, the probability of positive investment together with no net employment adjustment is substantially smaller: it decreases from 0.13 to 0.06. However, the conditional probability remains about the same, which shows that even if firms undertake relatively sizable investments - that exceed the amount needed to cover depreciation - the workforce can be left unchanged. The conditional probability of net hiring given positive invest; 
Table 3.7: Regimes of lumpy adjustment

\begin{tabular}{ccccc}
\hline \hline$(\mathrm{A})$ & $(\mathrm{B})$ & & & \\
investment spike & employment spike & $\operatorname{Pr}[\mathrm{AB}]$ & $\operatorname{Pr}[\mathrm{B}[\mathrm{A}]$ & $\operatorname{Pr}[\mathrm{A} / \mathrm{B}]$ \\
\hline 0 & - & 0.12 & 0.13 & 0.94 \\
0 & 0 & 0.66 & 0.73 & 0.91 \\
0 & + & 0.13 & 0.14 & 0.83 \\
+ & - & 0.01 & 0.08 & 0.06 \\
+ & 0 & 0.06 & 0.64 & 0.09 \\
+ & + & 0.03 & 0.28 & 0.17 \\
\hline \hline
\end{tabular}

'+' denotes a positive spike, '--' a negative spike, and ' 0 ' denotes no spike.

ment is 0.54 , which is much higher than for net firing, which is 0.33 . This difference is much more pronounced than in panel (I). Thus, when firms carry out expansionary investments, labour complementing capital is more likely than substitution.

Looking at the conditional probabilities for investment given the adjustment direction of labour, the differences between the two inaction definitions are striking. With inaction defined as investment equal to zero, in all cases positive investment is most likely with over $90 \%$ of observations. This, of course, stems from the small percentage of true zeroes for investment. With inaction defined as investment smaller than depreciation, however, we see that given net firing, zero investment is more likely than positive investment (0.59 vs. 0.41). Likewise, given that there is net hiring, positive investment is more likely. Thus, when firms are downsizing, positive investment is less likely, and when firms are expanding their labour force, positive investment is more likely. Also, if there is no change in net employment, investment is more likely to be zero than to be positive. In sum, capital and labour generally appear to be complementary, though some degree of heterogeneity is 
observed in this relationship.

In relation to the lumpy sdjustment dynamics described above it is interesting to look at how the spiking behaviour of capital and labour are related. Following Cooper, Haltiwanger, and Power (1999), an investment spike is defined as an investment rate over $20 \%$ of the existing capital stock (i.e. $I_{t} / K_{t-1}>0.2$ ); likewise following Sakellaris (2004), ani observation is classified as a positive (negative) employment spike when the net change is larger (smaller) than $10 \%(-10 \%)$. Again, six regimes can be distinguished according to which spikes a firm has in a certain year. These 'spike regimes' are summarised in Table 3.7. The largest is by far the one in which there is no spike for either factor. The regimes in which both factors have a spike are rare with only $4 \%$ of the observations. It is interesting that in $1 \%$ of the cases an investment spike is accompanied by a mass layoff. The conditional probabilities show that if there is no investment spike, a positive and negative employment spike are equally likely. In contrast, given that an investment spike occurs, a positive employment spike is much more likely than a negative one with $28 \%$ versus $8 \%$. Likewise, given that a positive employment spike occurs, the probability for an investment spike is $17 \%$, whereas with a negative employment spike it is only $6 \%$. These results indicate the interrelation among factor demand decisions in the context of lumpy adjustment dynamiss. In particular, an investment spike increases the probability for a positive employment spike, and decreases the probability of inaction or a negative employment spike. Likewise, a positive employment spike increases the probability for an investment spike, and reduces the chance for inaction. These results suggest that labour and capital are complementary in the production technology. In addition, it is possible that the cost efficiency of simultaneous adjustment plays a role. The relation between the adjustment of one input factor and the timing of spikes in the other is investigated in more detail in the next chapter. 


\subsection{Aggregate adjustment and lumpiness}

To shed some light on the relation between the lumpy micro-level adjustment behaviour and aggregate adjustment, Figures 3.6 to 3.8 depict the time series fluctuation of the aggregate series together with the percentage of spikes over time ${ }^{7}$ Figure 3.6 shows average total investment and the average investment rate over all firms, together with the percentage of firms exhibiting an absolute investment spike. It is clear from this figure that the time series behaviour of aggregate investment is closely related to the number of firms exhibiting an investment spike. The correlation between total investment and the percentage of spikes is over $60 \%$, whereas the correlation between the investment rate and the percentage of spikes is as high as $97 \%$. Thus, fluctuations of aggregate investment over time are closely linked to the fraction of firms experiencing a period of intensive investment, cf. Cooper, Haltiwanger, and Power (1999).

The relation between aggregate labour adjustment and employment spikes is less clear cut, while the spikes can refer to a negative or positive adjustment of labour. In Figures 3.7 and 3.8 the course of the negative and positive spikes are depicted separately. The relation of aggregate labour adjustment with the positive spikes is strongest. While the correlation is only moderate but positive with $33 \%$, the percentage of cases where the direction of change in both the series matches - i.e. the 'hit rate' - is $69 \%$ (J.1 out of 16 ). In contrast, one would expect aggregate labour adjustment to go down with an increase in the fraction of negative spikes, but this occurs only in 7 out of 16 years, and the correlation is negative but small with only about $-5 \%$. However, it is striking that in the second half of the sample period aggregate: labour adjustment appears to move together with the fraction of negative spikes. Thus, although there is a relatively low percentage of negative spikes in more recent years, these appear to be of a large magnitude causing aggre-

\footnotetext{
${ }^{7}$ To avoid the effect of a changing composition of the sample over time, the balanced subsample is used again here. Total investment and labour adjustment are defined as the sums over all firms in the balcnced subsample.
} 
Figure 3.6: Investment, investment rate, and spikes

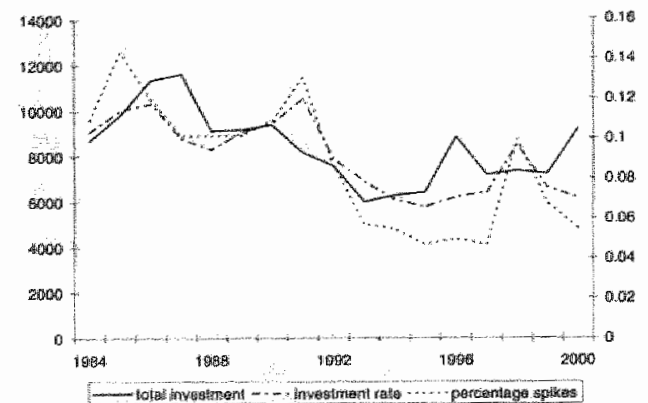

Figure 3.7: Hiring, hiring rate, and positive spikes

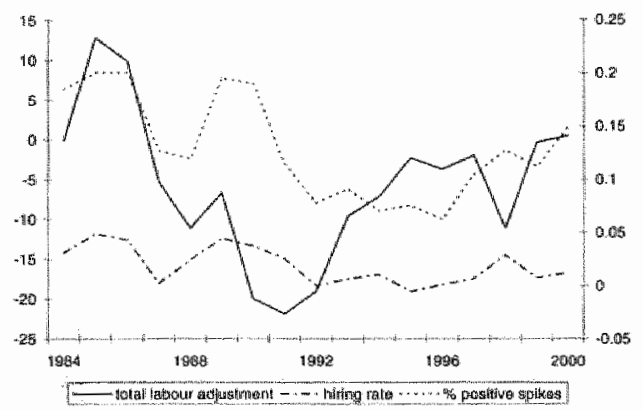

Figure 3.8: Hiring, hirng rate, and negative spikes

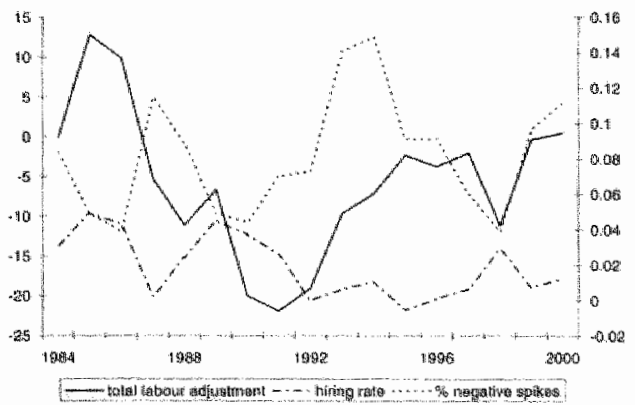


gate adjustment to be negative.

\subsection{Conclusion}

In this chapter some stylised facts of factor adjustment in the Dutch manufacturing sector are presented. The statistical evidence suggests that firms adjust factor levels in a lumpy and intermittent way. In addition, a preliminary look at the interrelation between the factors is carried out by looking at regimes of simultaneous adjustment. This reveals that capital and labour act mostly as complements, but also substitution of one for the other can occur. Moreover, the adjustment of one factor appears to be influenced by the adjustment of the other factor, which is an indication of the interrelation of factor demand decisions. Finally, aggregate adjustment is shown to be related to lumpiness at the micro-level, especially for investment. The results in this chapter provide a motivation for the study of the two main themes, and will be useful in the interpretation of the results in other chapters. 


\subsection{Appendix: The capital stock measure}

It is assumed that capital evolves according to the standard equation of motion

$$
K_{t}=(1-\delta) K_{t-1}+I_{t}
$$

where $\delta$ is a constant depreciation rate, which is set equal to 5 percent. It follows that

$$
K_{t+s}=(1-\delta)^{s} K_{t}+\sum_{j=\mathbb{1}}^{s}(1-\delta)^{s-j} I_{t+j}
$$

In particular, if $K_{0}$ denotes the capital stock in year 0 , capital stock in year 5 is given by

$$
K_{5}=(1-\delta)^{5} K_{0}+\sum_{j=1}^{5}(1-\delta)^{5-j} I_{j}
$$

To obtain a starting walue $K_{0}$ it is assumed that capital grows approximately at the same rate as sales, that is

$$
K_{t}=\left(1+g_{t}\right) K_{t-1}
$$

where $g_{t}$ is the growth rate of sales from year $t-1$ to year $t$. Thus,

$$
K_{5}=\left(1+g_{5}\right)\left(1+g_{4}\right) \ldots\left(1+g_{1}\right) K_{0}
$$

Combining (3.1) with (3.2) and solving for $K_{0}$ gives

$$
K_{0}=\frac{\sum_{j=1}^{5}(1-\delta)^{5-j} I_{j}}{\left(1+g_{5}\right)\left(1+g_{4}\right) \ldots\left(1+g_{1}\right)-(1-\delta)^{5}}
$$

Year 0 is the year before the first observation for a particular firm. Whille this invokes the need for the additional assumption $g_{1}=g_{2}$, one year of observations is gained. Finally, to avoid that the capital stock measure becomes negative, the denominator is set equal to $1-(1-\delta)^{5}$ if it is negative. 



\section{Chapter 4}

\section{Factor adjustment spikes and interrelation}

\subsection{Introduction}

In Chapter 3 statistical evidence is presented documenting the lumpy and intermittent dynamics of capital and labour adjustment in the Dutch manufacturing sector. The findings of that chapter are line with other empirical research on dynamic factor demand, e.g. Doms and Dume (1998) for in vestment, and Hamermesh (1989) for labour adjustment. As discussed in Chapter 2, structural models that stress the importance of non-convex adjustment costs and irreversibilities in this context have been proposed among others by Abel and Eberly (1994). Empirical work along these lines, however, has focused exclusively on models with a single quasi-fixed input factor, see e.g. Barnett and Sakellaris (1998). Recently, Dixit (1997) and Eberly and Van Mieghem (1997) have investigated interrelated factor demand with multiple quasi-fixed input factors where one or more factors are subject to nonconvexities or irreversibility. With adjustment being either positive, zero, or negative for both factors, these studies predict the existence of nine 'adjustment regimes'. Section 3.5 describes these regimes in terms of unconditional and conditional probabilities. In this chapter, the analysis from that section 
is extended. 'A dymamic element is added to the discussion, by looking at. how the adjustment of one factor is related to the timing of spikes in the other. A similar approach is taken in Sakellaris (2004).

\subsection{Data and descriptive statistics}

In this chapter the same data set as in Letterie and Pfann (2003) is used, which is a balanced subsample of the data analysed in Chapter 3 . The use of a balanced subsample has the advantage that dramatic events as the entry and exit of firms, which do not reflect the regular adjustment pattern of a frm, are excluded. However, the results may be biased towards larger and successful establishments. To avoid contamination of the results by outliers, firms for which the investment ratio exceeds one for one or more periods (i.e. $I_{t} / K_{t-1}>1, \exists t$ ) are excluded. We end up with 659 firms for which all information is available for the period 1978 to 1992 . The first five years of the sample are used to construct a capital stock measure according to the method described in the appendix to Chapter 3.

To determine whether firms conduct major investment efforts during a particular year so-called relative and absolute spike definitions are used. The former classifies an observation as spike if the imvestment rate exceeds the median investment rate over a certain period by 75 percent (Power 1998); with the latter definition an observation is called a spike if the investment rate exceeds 20 percent (Cooper, Haltiwanger, and Power 1999). Following Sakellaris (2004, we categorise an observation as a positive employment spike if the adjustment rate of employment exceds $10 \%$, and as a negative employment spike if it is smaller than $-10 \%$.

Table 4. 1 displays some descriptive statistics for this sample with respect to the adjustment of employment and capital. The investment rate is about $10 \%$ on average, but with a median of about $6 \%$ it is positively skewed. Average labour adjustment is around zero with only a slight positive skewmess.

\footnotetext{
${ }^{1}$ This chapter was published in Economics letters, vol. 85(2), pp. 145-150.
} 


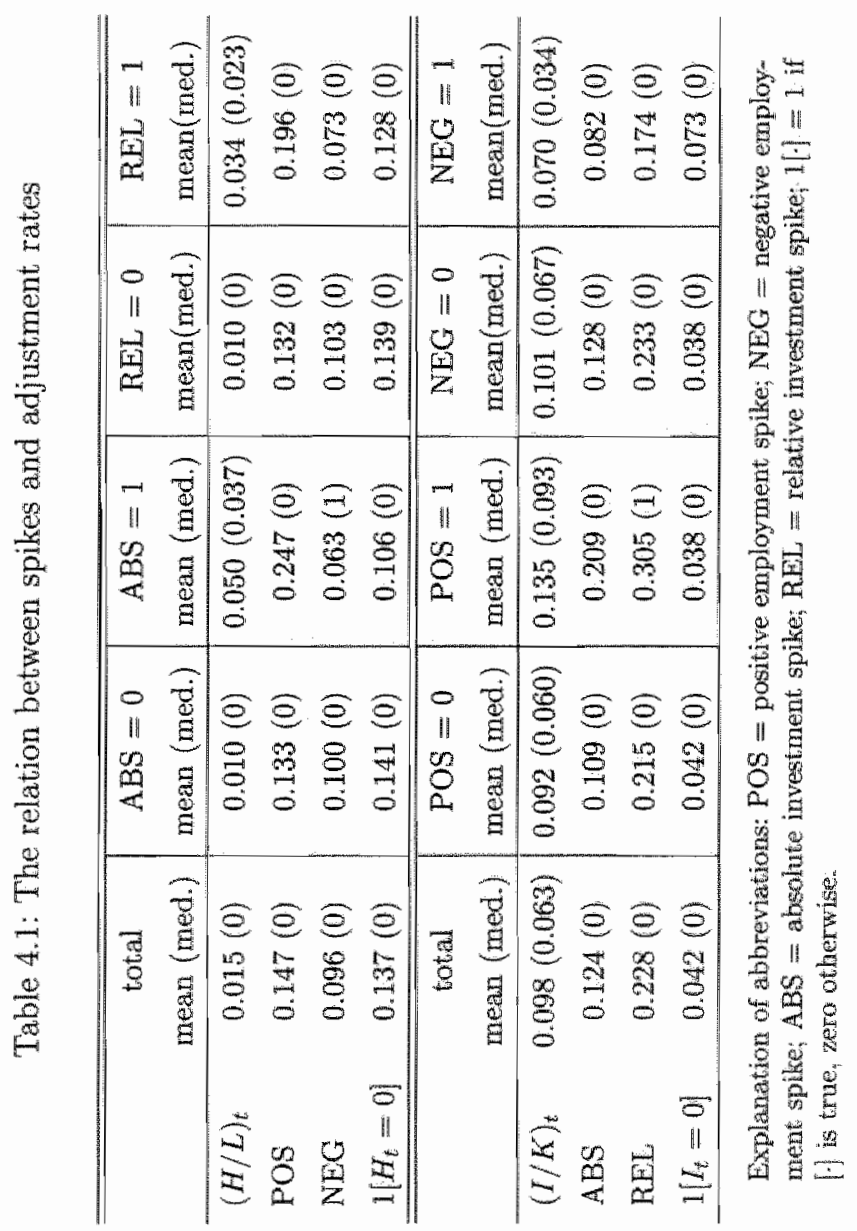


About $12 \%$ are absolute investment spikes, while there are as much as $22 \%$ relative investment spikes. This difference is striking. The percentage zero adjustment is considerably higher for labour than for capital, although this observation is somewhat biased by the fact that only net labour adjustment is observed.

Conditioning on whether a spike occurs in the other production factor or not, large differences are observed. ${ }^{2}$ For instance, if there is an absolute investment spike, labour adjustment increases by $5 \%$ on average. In addition, more positive employment spikes occur if there is an investment spike, and there occur less negative employment spikes. There is also some mild evidence that there is less zero adjustment of labour in times of an investment spike. Turning to capital, it can be seen that in times of a positive employment spike the investment rate is consiclerably higher. It is significantly lower if there is a negative employment spike. Also, there occur more investment spikes if there is a positive employment spike, and less if there is a negative employment spike. Finally, there is more zero investment in times of a negative employment spike.

These statistics show that there is a relation between the adjustment of an input factor and whether or not there is a spike in the other lactor. In other words, they give an indication of the interrelation between the factor demand decisions. Another thing worth mentioning however is the heterogeneity in response. For example, while average employment adjustment increases considerably if there is an investment spike, in $7 \%$ of the observations it is coupled with a negative employment spike. Also, capital and labour do not necessarily "spike togethen"; only about $20 \%$ of the positive employment spikes occur in the same period as an investment spike, for example.

\footnotetext{
${ }^{2}$ The standard errors of the statistics (not reported to save space) show that most differences are highly significant.
} 


\subsection{Lumpiness and interrelation}

The purpose of this section is to investigate how firms adjust the employment level (respectively, capital stock) in periods of investment (respectively, labour adjustment) spikes, and in periods before and after such spikes. ${ }^{3}$ This does not only offer insight into whether there is above average adjustment in times of adjustment spikes, but also gives an idea about the dynamics of the interrelation between investment and employment decisions.

We define indicator variables to represent the timing of lumpy investment episodes (cf. Power (1998)), that is $1_{k} \equiv 1$ [ [investment period $=k$ ] where $k$ $=\{$ next, current, previous, between $\}$. For instance $1_{\text {current }} \equiv 1$ [investment period = current] equals 1 if the firm has an investment spike in the current period, and zero otherwise. The variable 1[investment period = next (previous)] equals 1 if the firm has an investment spike in the next (previous) period, and does not have one in the current or previous (next) period. ${ }^{4}$

To investigate the relation between the timing of a large investment and labour adjustment, the following estimating equation is considered

$$
(H / L)_{i t}=\mu_{i}+\lambda_{t}+\sum_{k} \beta_{k}\left(1_{k}\right)_{i t}+\varepsilon_{i t}
$$

where $\lambda_{t}$ is a year dummy, and $\varepsilon_{i t}$ is an idiosyncratic disturbanoe. The fixed effect $\mu_{i}$ eccounts for a firm-specific average adjustment rate and makes the results robust to any omitted time-invariant variables. Equation (4.1) is firstdifferenced and estimated with least squares. The estimation results are presented in Table 4.2 .

The results indicate that firms hire significantly more people in periods close to investment spikes and the period of the spike itself. "This suggests that the employment and the investment decision are significantly interrelated.

\footnotetext{
${ }^{3}$ See Sakellaris (2004) for a related study.

"A category 'between' is introduced to take account of those observations for which a firm has a spike in the prewious as well as in the next period, while in the current period no spike occurs. Because this is a side category with sometimes very few obserwations, it is omitted from the discussion.
} 
Table 4.2: Effect of investment spikes on employment

\begin{tabular}{lllll}
\hline period of spike & \multicolumn{2}{c}{ absolute spike } & \multicolumn{2}{c}{ relative spike } \\
\hline next & 0.017 & $(0.007)^{*}$ & 0.011 & $(0.054)^{*}$ \\
current & 0.030 & $(0.006)^{* *}$ & 0.030 & $(0.005)^{* *}$ \\
previous & 0.015 & $(0.007)^{*}$ & 0.011 & $(0.055)^{*}$ \\
between & 0.028 & $(0.015)$ & 0.033 & $(0.010)^{* *}$ \\
\hline
\end{tabular}

Dependent variable is $H / L$. Standard errors are reported in parentheses. Thime dummies are included in the estimation but omitted from the results.

* = significant at $1 \%$ level $_{\mathrm{i}}^{*}=$ significant at $5 \%$ level

The fact that investment spikes tend to have a positive effect on employment changes supports the view that labour and capital are mostly complementary. Also, the increase in labour demand in periods right before or after an investment spike indicates that there is a dynamic element in the relation between labour and capital. The fact that firms hire employees in advance of an investment lump may indicate that employees need to be trained. As soon as the new capital arrives these employees can start working with it, or manage the employees that are hired in the same period as the spike. On the other hand the excess hiring in the period after a spike may reflect labour market scarcities, or a learning effect by the firm that it needs more labour to get the work done. The results do not depend on the definition of the investment spike and support those of Sakellaris (2004).

It is also interesting to look at the relation between the investment rate and employment spikes. To investigate this, a similar regression as above is carried out with the investment as dependent variable, that is

$$
(I / K)_{i t}=\mu_{i}+\lambda_{t}+\sum_{k} \beta_{k}\left(1_{k}\right)_{i t}+\varepsilon_{i t}
$$

where the indicator variables $1_{k}$ now reflect whether there was an employment spike in period $k$. The effect of positive and negative spikes is considered 
Table 4.3: Effect of employment spikes on investment

\begin{tabular}{lllll}
\hline \hline period of spike & \multicolumn{2}{c}{ positive spike } & \multicolumn{2}{c}{ negative spike } \\
\hline next & 0.007 & $(0.055)$ & -0.011 & $(0.007)$ \\
current & 0.031 & $(0.005)^{* *}$ & -0.027 & $(0.006)^{* *}$ \\
previous & 0.008 & $(0.005)$ & -0.013 & $(0.006)^{*}$ \\
between & 0.024 & $(0.011)^{*}$ & -0.047 & $(0.011)^{* *}$ \\
\hline \hline
\end{tabular}

Dependent variable is $I / K$. Standard errors are reported in parentheses. "Time dummies were included in the estumation but omitted from the results.

** $=$ sigmificant at $1 \%$ level; * = significant at $5 \%$ level.

separately. The estimation results are reported in Table 4.3. It can be seen that there is significantly more (less) investment in periods of a large positive (negative) employment change. In addition, there is mild evidence that there is more (less) investment in the period after an employment spike. However, it appears that capital adjustment related to a large employment change occurs primarily in the same period.

The results in Table 4.2 and 4.3 should be viewed in the light of the heterogeneity found in the previous section. For example, from Table 4.2 it can be seen that firms hire about $3 \%$ more workers in periods of an - absolute or relative - investment spike on average. At the same time, however, as became clear from Table 4.1, some firms do not adjust employment when there is an investment spike or even exhibit a negative employment spike. A more structural analysis should be able to distinguish between those cases.

\subsection{Concluding remarks}

In this chapter the dynamic interrelation of factor demand decisions is investigated in the context of lumpy adjustment. It is found that the dynamics of employment are significantly related to large investments. In addition, invest- 
ment dynamics are related to large employment changes. Although the results do not necessarily have a causal or structural interpretation, they indicate that in modelling the demand for production factors, the interrelated nature of adjustment decisions should be taken into account. While the traditional literature has investigated this in linear-cuadratic models (Nadiri and Rosen (1969)), no empirical research has been carried out with multiple quasi-fixed input factors where one or more factors are subject to non-convexities. This issue is the main subject addressed in Chapter 5 and 6 . In Chapter 5 the ef fect of investment humps on labour adjustment is investigated in a structural model, where labour adjustment incurs only convex costs but investment costs include a fixed component as well. In Chapter 6 , the Euler equations for labour and capital are derived and estimated, where adjustment costs are interrelated and both factors are subject to non-convexities. 



\section{Chapter 5}

\section{Non-linear investment \\ dynamics and labour demand}

\subsection{Introduction}

Empirical research with micro-level data, reviewed in Chapter 2, has revealed that factor adjustment is not smooth, but is intermittent and 'lumpy'. This type of adjustment behaviour is often attributed to the existence of fixed adjustment costs, see e.g. Abel and Eberly (1994). In this case, firms do not adjust if the gains of adjustment do not exceed the casts. This is in contrast to models with strictly convex adjustment costs, in which adjustment is always optimal. ${ }^{1}$ This explanation seems to meet a broad consensus for investment; but the relevance of fixed adjustment costs for labour is less clear. On the one hand, several studies use the argument of non-convexities to explain lumpy employment dynamics (see e.g. Hamermesh (1989), Caballero, Engel, and Haltiwanger (1997), and Nilsen, Salvanes, and Schiantarelli (2003)). How ever, in line with the literature on interrelated factor demand, ${ }_{2}^{2}$ Abel and Eberly (1998) point out that studying the demand for a production input, in isolation is restrictive. With labour and capital as the main inputs in a pro-

\footnotetext{
${ }^{1}$ See Hamermesh and Pfamn (1996) and Bond and Van Reenen (2002) for overviews of the adjustment costs literature.

${ }^{2}$ This literature originates from the seminal paper by Nadiri and Rosen (1969).
} 
duction function, the demand for both factors should be mutually dependent. Neglecting this interdependence can result in spurious conclusions about the sources of factor dymamics. Abel and Eberly show that if labour is costlessly adjustable but there are fixed investment costs, non-linear employment dynamics arise because of interrelation. This result clearly makes economical serise. Due to the non-convex nature of its adjustment costs, investment is lumpy so that it is either large or nil. Firms generally make a large imvestment becanse they want to expand their capacity, but assuming that labour and capital are complements in the production process, the investment must be accompanied by an increase of the labour force for the additional capacity to take effect. Since firm has full Hexibility in adjusting labour, it will instantaneously make the necessary adjustments in its employment level, leading to a large change in the number of workers.

This chapter investigates empirically the dynamics of investment and labour adjustment when adjustment costs are non-convex for investment but convex for labour. In particular, the question is addressed whether non-linear dynamics can be identified for investment, and if this leads to non-linearity in labour adjustment dynamics. A q model for optimal investment and labour adjustment is employed. ${ }^{3}$ The empirical model that follows from the theoretical framework consists of a regime-type equation for investment in line with $A b e$ and Eberly (1994), in which the regimes and investment rate are determined by capital productivity, and a linear equation relating labour adjustment to labour productivity. Because capital and labour are interrelated through the production technology, the factor demand equations are considered together with the production function. The linearity of the employment. equation implies that lumpy adjustment dynamics for this factor can only arise from lumps in labour productivity. In addition, labour adjustment must

\footnotetext{
${ }^{3}$ The adiustment costs structure is different from Abel and Eberly (1998), who assume labour is costliessly adjustable. Becanse data on the Dutch manufacturing sector is employed, and given the degree of labour market regulation in the Netherlands, the as sumption of fully flexible labour adjustment would be restrictive in this sething. However, while adjusturent is not instantaneons, the specification implies that non-linear employment dynamies camnot be due to the adjustment costs of labour.
} 
be highly sensitive to productivity changes. Essentially, to see if non-linear investment can explain lumpiness in employment dynamics, the strategy in this chapter is to investigate whether large investments have a positive effect on labour productivity, and how labour is adjusted in response to these.

The factor demand equations together with the production function are estimated simultaneousily as a system of Seemingly Unrelated Regressions (SUR), allowing for contemporaneous correlation of the disturbances as well as firm-specific effects. However, the investment equation contains an endogenous thresholds that is determined by $q$. This threshold is estimated in a preceding step. ${ }^{4}$ This is probably the first study to consider simultaneous estimation of the factor demand equations, where investment is subject to non-convexities and both factors are costly to adjust.

To investigate investment and employment dynamics, the effect of different shocks are considered. The effect of these shocks on the clynamic pattern of the adjustment of both factors is analysed by means of an impulse response analysis on the whole system. As a result of the non-linear nature of the investment equation, however, traditional impulse response analysis is unsuitable here. Instead, the Generalised Impulse Response Function (GIRF) approach recently suggested by Koop, Pesaran, and Potter (1996) is used.

The outline of the chapter is as follows. In Section 5.2 the theoretical model is developed. Then the subsample of the data is described briefly in Section 5.3. Section 5.5 gives the estimation results of the system. Subsequently, in Section 5.6 an impulse response analysis is carried out to investigate investment and employment dynamics in response to investment and production shocks of different sizes. Section 5.7 concludes.

\footnotetext{
${ }^{4}$ To be more precise, multiple thresinolds can arise in the investment equation. The estimation framework allows for this possibility.
} 


\subsection{Theoretical model}

Firms are assumed to maximise the expected present value of net profits with respect to gross investment $\left(I_{t}\right)$ and (net) labour adjustment $\left(H_{t}\right)$. The derivation follows that in Chapter 2 , although here both factors are subject to adjustment costs, and the timing assumptions are slightly different. Net profits are given by

$$
\pi_{t}(\cdot)=R\left(A_{t}, K_{t-1}, L_{t}\right)-p_{t} I_{t}-w_{t} L_{t}-C\left(I_{t}, H_{t}, K_{t-1}, L_{t-1}\right),
$$

where, $R(\cdot)$ is the production function, $C(\cdot)$ is the adjustment costs function, and $A_{t}$ anl exogenous stochastic shock to the production process, which is assumed to follow a stationary Markov process and of which the realisation is unknown to the firm at the beginning of period $t$. The price of investment goods and total labour costs per employee are given by $p_{t}$ and $w_{t}$ respectively. Capital $\left(K_{t}\right)$ is subject to depreciation

$$
K_{t}=(1-\delta) K_{t-1}+I_{t}
$$

where $\delta$ is the depreciation rate, assumed to be constant. Like before, $L_{t}=$ $L_{t-1}+H_{t}$. From the production it can be seen that new employees are assumed to become productive immediately (that is at the beginning of period $t$ ), where as capital does not become productive until the end of period $t$. Thus, in year $t$ the firm produces with a capital stock of $K_{t-1}$ and an employment level of $L_{t}$. This timing assumption is discussed further below.

The optimisation problem that the firm faces at the beginning of period $t$ is

$$
V\left(A_{t-1}, K_{t-1}, L_{t-1}\right)=\max _{\{I\}_{t}^{\infty}\left\{[H\}_{t}^{\infty}\right.} \sum_{s=t}^{\infty} \beta^{s-i} E\left[\pi_{s}(\cdot) \mid \Omega_{t-1}\right]
$$

where $\beta$ is a constant discount factor, and $\Omega_{t-1}$ is the information set of the firm at the beginning of period $t$. The Bellman equation is given by 


$$
V\left(A_{t-1}, K_{t-1}, L_{t-1}\right)=\max _{\mathbb{X}_{t}, W_{t}} E\left[\pi_{t}(\cdot)+\beta V\left(A_{t}, K_{t}, L_{t}\right) \mid \Omega_{t-1}\right]
$$

and the first-order conditions can be written

$$
\begin{aligned}
\frac{\partial C}{\partial I_{t}}+p_{t} & =\frac{\partial R}{\partial K_{t}}+\beta \frac{\partial E\left[V\left(A_{t}, K_{t}, L_{t}\right) \mid \Omega_{t-1}\right]}{\partial K_{t}} \\
\frac{\partial C}{\partial H_{i}}+w_{t} & =\frac{\partial R}{\partial L_{t}}+\beta \frac{\partial E\left[V\left(A_{t}, K_{t}, L_{t}\right) \mid \Omega_{t-1}\right]}{\partial L_{t}} .
\end{aligned}
$$

The right-hand side of both equations reflect the total marginal gains of adjusting the concerning factor. These are required to equal total marginal costs for optimality. As in Chapter 2, the right-hand side of equations (5.5) and (5.6) are denoted by respectively $q_{k t}$ and $q_{t t}$. These variables reflect firm expectations about the future gains to adjustment given the information set $\Omega_{t-1}$.

To parameterise the problem, functional forms need to be assumed for the production technology and adjustment costs. The former is assumed to be Cobb-Douglas, that is

$$
R\left(A_{t}, K_{i-1}, L_{i}\right) \equiv Y_{t}=A_{i} K_{t-1}^{\alpha_{k}} L_{t}^{\alpha_{t}}
$$

The adjustment costs function is assumed to be additively separable: $C(\cdot)=$ $C_{\mathrm{cap}}\left(I_{t}, K_{t-1}\right)+C_{\mathrm{lab}}\left(H_{t}, L_{t-1}\right) .5$ The respective cost functions are given by

$$
\begin{aligned}
C_{\text {cap }}\left(I_{t}, K_{t-1}\right) & =\frac{1}{2 \phi_{k}} \frac{I_{t}^{2}}{K_{t-1}}+\left(F K_{t-1}\right)\left[\left[I_{t} \neq 0\right]\right. \\
C_{\text {lab }}\left(H_{t}, L_{t-1}\right) & =\frac{1}{2 \phi_{l}} \frac{H_{l}^{2}}{L_{t-1}}
\end{aligned}
$$

The adjustment costs for investment consist of a quadratic and a fixed component. ${ }^{6}$ The fixed component is proportional to the existing capital stock so

\footnotetext{
${ }^{5}$ This means that there are no cost efficiencies from simultaneons adjustment of capitial and labour, see Chapter 6 for an investigation of this assumption.

${ }^{B}$ Note that with respent to the treatment in Chapten" $2, \phi_{m}=1 / \gamma m, m \in\{k, l\}$
} 
that fxed costs for larger firms are higher. The indicator variable 1.] reflects that fxed costs are only incurred with non-zero investment. Adjustment costs for labour are quadratic in $H_{t}$. Possible non-linear dynamics of the employment level are therefore not explained by the adjustment costs structure of labour.

The optimality conditions $(5.5)$ and $(5.6)$ were derived under the implicit assumption of differentiability of $\pi_{t}(\cdot)$. With the fixed term in $C_{\text {cap }}(\cdot)$ this does not hold for capital, because of a discontinuity at 0 . However, conditional on $1[\cdot]=1$ (that is $L_{t}>0$ ) the optimality condition (5.5) still holds. Therefore, as in Chapter 2 , first an expression for optimal investment, is derived assuming that it is non-zero; with this a condition is derived for when non-zero investment is optimal. Conditional on $1 .[\cdot]=1$, with production and adjustment costs given as above, it is straightforward to derive from (5.5) and (5.6) that

$$
\begin{aligned}
& I_{t} / K_{t-1}=\phi_{k}\left(q_{k t}-p_{t}\right) \\
& H_{t} / L_{t-1}=\phi_{l}\left(q_{t}-w_{t}\right)
\end{aligned}
$$

Naturally, firms only invest if the gains to investing are positive, that is the gains of investing should be larger than those of not investing. Let $K_{t}^{0}=$ $(1-\delta) K_{t-1}$ and $K_{t}^{1}=(1-\delta) K_{t-1}+I_{t}$ respectively be the capital stock under the scenario of zero and non-zero investment. In this model, whether the firm investa in period does not affect labour adjustment in that period. To see this, note that optimal labour adjustment in (5.11) depends on $q$ and $w_{t}$, where qu is the right-hand side in (5.6). This expression shows that qu is affected by lagged capitual, and the expectation about future marginal gains conditional on $\Omega_{t-1}$. As $K_{t}$ is not in the information set at the time of decision masing, $L_{t}$ is not contemporaneously affected by the investment decision. As a consequence $L_{t}$ is the same under both the scenario of zero and non-zero imvestment. While this is a restrictive assumption, it is necessary to derive a structural expression for the different investment regimes. On the other hand, it does not seem more restructive than the common assumption in labour denand models that capital is predetermined. In addition, this 
specification improves on the existing literature by allowing the adjustment of both factors to be costly, with investment subject to fixed costs.

The value of the firm under the respective scenarios of zero and non-zero investment is given by

$$
\begin{array}{r}
V_{0} \equiv R\left(A_{t}, K_{t-1}, L_{t}\right)-w_{t} L_{t}-C_{\mathrm{lal}}\left(H_{t}, L_{t-1}\right)+\beta E\left[V\left(K_{t}^{0}, L_{t}\right) \mid \Omega_{t-1}\right] \\
\begin{aligned}
V_{1} \equiv R\left(A_{t}, K_{t-1}, L_{t}\right) & -p_{t} I_{t}-C_{\mathrm{cap}}\left(I_{t}, K_{t-1}\right)- \\
& -w_{t} L_{t}-C_{\mathrm{lab}}\left(H_{t}, L_{t-1}\right)+\beta E\left[V\left(K_{t}^{1}, L_{t}\right) \mid \Omega_{t-1}\right]
\end{aligned}
\end{array}
$$

That is, $V_{0}$ is the value of the firm if there is no investment, whereas $V_{1}$ is the value of the firm when investment is non-zero. Firms invest if the gains to investing are higher than those when not investing, that is when $V_{1}-V_{0}>0$. From the expressions above this can be written as

$$
\beta E\left[V\left(K_{t}^{1}, L_{t}\right)-V\left(K_{t}^{0}, L_{t}\right) \mid \Omega_{t-1}\right]>p_{t} I_{t}+C_{\text {cap }}\left(I_{t}, K_{t-1}\right)
$$

The left-hand side of (5.12) is the additional value of having $K_{t}^{1}$ over $K_{i}^{0}$. Since the marginal value of a unit of capital is $q_{k t}$, this can be approximated by $q_{k t}\left(K_{t}^{1}-K_{i}^{0}\right)=q_{k t} I_{\xi}$. If this value exceeds the costs, a firm invests. Thus, the criterium for non-zero investment is ${ }^{7}$

$$
\begin{aligned}
\left(q_{k t}-p_{t}\right) I_{t}-C_{\text {cap }}\left(I_{t}, K_{t-1}\right) & >0 \\
& \Leftrightarrow \\
q_{k t}-p_{t} & >\sqrt{2 F / \phi_{k}}
\end{aligned}
$$

where equation (5.14) follows by substitution of the adjustment cost function (5.8) and optimal investment (5.10) into (5.13). ${ }^{8}$ If condition (5.14) is met,

\footnotetext{
"Abel and Eberly (1994) derive an identical condition for non-zero investment in a continuous time framework.

${ }^{8}$ From $(5.13)$ it follows that $\left(q_{k t}-p_{t}\right)^{2}>2 F / \phi_{k}$. Thas also implies a threshold for negative investment, but as only positive investment is observed this solution is ignored here. Because labour adjustment costs are smooth, no condition for non-zero adjustnient is implied for labour.
} 
optimal inwestment is given by (5.10), otherwise it is 0 . Thus, summarising the above, optimal adjustment is characterised by

$$
\begin{aligned}
I_{t} / K_{t-1} & =\phi_{k t}\left(q_{k t}-p_{t}\right) & & \text { if } q_{k t}-p_{t}>\sqrt{2 F / \phi_{k}} \\
& =0 & & \text { otherwise } \\
H_{t} / L_{t-1} & =\phi_{t}\left(q_{t}-w_{t}\right) & &
\end{aligned}
$$

These expressions form the basis for the empirical model in Section 5.4.

\subsection{Data}

A balanced subsample is employed in this chapter, which is convenient in terms of the estimation procedure that will be described in Section 5.4. However, as usual, the results can be biased towards more successful firms, as firms are required to survive throughout the whole sample period. The data span the time period 1983 to $1997 .{ }^{9}$ Ultimately, 603 firms remain that are observed ower the whole sample period. All variables were deflated using two-digit sector level price-index information (base-year 1995).

In Table 5.1 some relevant summary statistics are reported. On average annual investment is just over 6 million Dutch guilders (NLG), and the employment level is about 300 workers. The distributions of both variables are highly skewed however: in 50 percent of the observations investment is smaller than 750 thousand NLG, and half of the firms have less than 84 employees. Also the distribution of the anmal investment rate is skewed with mean of $8 \%$ and a median of $5 \%$. On average the employment level of the firms

\footnotetext{
As before, only positive investment is observed, and the firms sampled have at least 20 enployees. A capital stock measure is not awailiable and therefore five years of presample investment figures are used to construct a proxy with the perpetual inventory method diseussed in the appendix of Chapter 3. Firms that experience investment rates above $100 \%$ were dropped becnuse these observations are likely to be due to either abnormal changes or underestimation of the capital stock. In both cases including these observations will have an distorting effect on the results. In addition, firms with an implausibly high product of capital $(Y / K)$ were dropped.
} 
Table 5.1: Summary statistics

\begin{tabular}{lccc}
\hline variable & mean & std. dev. & median \\
\hline investment & $6,092.13$ & $47,650.9$ & 746.27 \\
employment & 304.84 & 2391.58 & 84 \\
investment rate & 0.08 & 0.10 & 0.05 \\
employment rate & 0.01 & 0.11 & 0 \\
sales-capital ratio & 2.04 & 1.91 & 1.49 \\
sales-labour ratio & 286.65 & 240.38 & 223.17 \\
\hline no. of firms & 603 & & \\
sample period & $1983-1997$ & & \\
\hline \hline
\end{tabular}

Monetary values are real (base-year 1995) and in thousands of Dutch guilders (NLG).

has increased over the sample period by about $1 \%$ but in half of the observations the adjustment rate is zero or negative. The sales to capital ratio is about 2 units of output per unit of capital, while the ratio of sales to labour amounts to 287 . Average investment and employment are relatively high in comparison to the full sample described in Chapter 3 . This is a result of the fact that in the balanced sample there are relatively more large firms.

In Chapter 3 statistical evidence is presented that investment and labour adjustment in the Dutch manufacturing sector is lumpy and intermittent. As mentioned in the introduction, non-convex adjustment costs are a possible explanation. As suggested by Abel and Eberly (1998), however, lumpy labour adjustment can also arise if labour is fully flexible and driven by investment. Chapter 4 shows that there is a statistical dynamic relation between labour adjustment and investment 'spikes' for a similar dataset. In the model presented in Section 5.2 labour adjustment is subject to convex, but not fixed, adjustment costs, while investment incurs convex as well as fixed costs. Thus, there are costs to adjusting labour, but they cannot be the cause of lumpy employment dynamics. In this setting, following the suggestion by Abel and 
Eberly, it will be investigated if lumpy investment dynamics translate to employment dynamics.

\subsection{Empirical model and estimation issues}

In the structural model derived in Section 5.2 the net marginal values of capital and labour, $\left(q_{k t}-p_{t}\right)$ and $\left(q_{t}-w_{i}\right)$, are unobserved. For investment however, the net marginal value can be written as $p_{\ell}\left(q_{k t} / p_{t}-1\right)$, where $q_{k t} / p_{t}$ is marginal $q$. As discussed in Chapter 2 , under some conditions this variable can be replaced by average $q$, which is the firm value divided by replacement value of capital stocks. ${ }^{10}$ If prices do not exhibit large variation over time, it is clear that average $q$ is a sufficient statistic for investment. Given the lack of stock market data, average $q$ for capital can be proxied by average productivity $Y_{t-1} / K_{t-2}$, where - in line with Gilchrist and Himmelberg (1995), Nisen and Schiantarelli (2003), and Letterie and Pfann (2003) - sales are used to measure output. Similarly, $Y_{t-1} / L_{t-1}$ is used as a proxy for average $q$ in the labour equation. ${ }^{11}$

Fon notational convenience, the regime indicator $d_{i t}$ is introduced, which is defined as $d_{i t} \equiv 1\left[Y_{i, t-1} / K_{i, k-2}>\tau\right]$. Thus, $d_{i t}$ is the equivalent of the criterion for non-zero investment in $(5.15)$, with $q$ w $-p_{t}$ replaced by its proxy, and the threshold replaced by a single parameter $\tau$. If $d_{i t}=1$, the frm has positive investment, otherwise it is in the inaction regime. Using the proxies for the qs given above, taking logs of the production function, and introducing a

\footnotetext{
10"The equivalence of marginal and average $q$ was established for the linear case by Hayashi (1982). Necessary conditions for this result are constant returns to scale, perfect competition, and a convex adjustment cost technology. Abel and Eberly (1994) show that the result can be generalised to the case of non-convexities.

${ }^{11}$ Strictly speaking, average factor productivity involves the ratio of value added to capital and labour. However, developments in value added and changes in sales are closely related, and the data show that there is a high correlation between these variables. As such, the sales-capital and sales-labonr ratio will sometimes be referred to as measuring productivity. In addition, note that the q's are predictions on the basis of $\Omega_{t-1}$ - that is, the information awailable at the end of year $t-1$ - hence the lagged average products are the appropriate proxies. Finally, in $t-1$ the firm produces with $K_{t-2}$ and $L_{t-1}$, hence the average productivity of capital is $Y_{t-1} / K_{t-2}$, and $Y_{t-1} / L_{t-1}$ for labour.
} 
subscript $i=1, \ldots, N$ to denote firm $i$, the empirical model becomes

$$
\begin{aligned}
\frac{I_{i t}}{K_{i, t-1}} & =\left(\phi_{k \cdot 1}\left(1-d_{i t}\right)+\phi_{k 2} d_{i t}\right) \frac{Y_{i, t-1}}{K_{i, t-2}}+\omega_{k i t} \\
\frac{H_{i t}}{L_{i, i-1}} & =\phi_{l} \frac{Y_{i, t-1}}{L_{i, t-1}}+\omega_{l i t} \\
\ln Y_{i t} & =\alpha_{k} \ln K_{i, t-1}+\alpha_{l} \ln L_{i t}+\omega_{y i t}
\end{aligned}
$$

with $\omega_{m i t}=\mu_{m i}+\varepsilon_{m i t}(m \in\{k, l, y\})$, where $\mu_{m i}$ is a firm-specific effect in equation $m$, and $\varepsilon_{\text {mit }}$ is an idiosyncratic error term.

In the investment equation, $\phi_{k 2}$ is the sensitivity of the investment rate to changes in "fundamentals" in the positive investment regime, whereas $\phi_{k 1}$ is the sensitivity in the inaction regime. Hence, in theory $\phi_{k i}=0$, that is due to fixed costs firms do not always find it profitable to respond to a change in capital productivity. However, as pointed out in Chapter 3, zero sensitivity may be restrictive because of capital heterogeneity. If certain types of capital have very low (fixed) adjustment costs, aggregate investment will rarely be exactly zero though investment in other types might be irreversible or subject to fixed costs (Eberly (1997)). Therefore, following Banett and Sakellaris (1998) the existence of a true zero-regime is tested rather than imposed. If instead $\phi_{k 1} \neq 0$, a weaker response in the low regime (i.e. $\phi_{k 1}<\phi_{k 2}$ ) still suggests that investment regimes exist but that capital heterogeneity precludes zeroes.

In this model, labour adjustment is linearly related to labour productivity $Y / L$. Lumpy employment dynamics can therefore only arise if changes in labour productivity are subject to lumpiness. One of the main issues in this chapter concerns whether such lumpy changes in $Y / L$ can arise from large investments.

\subsubsection{Estimation of the investment threshold}

The equation for the investment rate given by $(5.17)$ is a panel data model of the threshold type. An estimation framework for this type of models is 
proposed in Hansen (1999). ${ }^{22}$ Barnett and Sakellaris (1998) apply these techniques in the context of non-linear investment models. The idea behind this method is to apply the within-estimator to equation (5.17) given a particular value for $\tau$. By virying $\tau$ the value that gives the best fit can be determined. The within-tiansformed model is given by

$$
\left(\frac{L_{i t}}{K_{i, t}-1}\right)^{*}=\phi^{\prime} x_{i t}^{*}(\tau)+\varepsilon_{k i t}^{*}
$$

where $x_{i t}(\tau)=\left(\left(1-d_{i t}\right) Y_{i, t-1} / K_{i, t-2}, d_{i t} Y_{i t-1} / K_{t-1}\right)^{\prime}$ and $\phi=\left(\phi_{k 1,}, \phi_{k 2}\right)^{\prime}$, and the asterisk (") denotes a variable in deviation from its mean. Note that $x_{i t}$ is denoted as a function of $\tau$ to emphasize that estimation is conditional on a. value for $\tau$. Ordinary least squares (OLS) estimation of (5.20) gives the within estimator of $\phi$. The residuals are given by $e_{i t}(\tau)=\left(I_{i t} / K_{i t-1}\right)^{*}-\hat{\phi}^{\prime} x_{i t}^{*}(\tau)$, and the sum of squared errors is

$$
\operatorname{SSE}(\tau)=\sum_{i t} \sum_{t} e_{i t}^{2}(\tau)
$$

The estimate of $\pi$ minimizes the SSE, that is

$$
\hat{\tau}=\arg \min _{\tau} \mathrm{SSE}(\tau)
$$

The estimate tor $\phi$ is the one associated with $\hat{\tau}$. To implement this estimator one can enumerate all possibilities for the threshold value (i.e. all observed values for $\left.Y_{i-1} / K_{t-2}\right)$, or perform a grid search. Note that for each value of r the withesstimator needs to be determined, so that enumeration is only feasible with a moderate sample size.

Hansen (1996) proposes a bootstrap procedure to perform a likelihood ratio (LR) test for the existence of a threshold. Hansen (2000) shows that $\hat{T}$ is consistent. In addition, although $\hat{\phi}$ depends on the threshold estimate $\hat{\tau}$, inference about $\phi$ can proceed as if $\hat{\tau}$ is the true value. Therefore the common covariance matrix estimate applies.

\footnotetext{
12 See also Hansen $(1996,2000)$.
} 


\subsubsection{Estimation of the system}

Given an estimate of the threshold parameter $\tau$ the equations (5.17)-(5.19) is a system of linear equations. As the error terms of the individual equations are likely to be correlated, Generalised Least Squares (GLS) will give more efficient estimates than OLS on the separate equations. The model is estimated as a system of Seemingly Unrelated Regression (SUR) equations. ${ }^{13}$

To facilitate the discussion the following notation is used. Let

$$
\begin{aligned}
& y_{1}=\left((I / K)_{11},(I / K)_{12}, \ldots,(I / K)_{1 T},(I / K)_{21}, \ldots,(I / K)_{N T}\right)^{\prime} \\
& y_{2}=\left((H / L)_{11}, \ldots,(H / L)_{N T}\right)^{\prime} \\
& y_{3}=\left(\ln Y_{11}, \ldots, \ln Y_{N T}\right)^{\prime}
\end{aligned}
$$

and let $y=\left(y_{1}, y_{2}, y_{3}\right)^{\prime}$. Next let

$$
X=\left(\begin{array}{ccccc}
(1-d(\hat{\tau})) Y / K & d(\hat{\tau}) Y / K & 0 & 0 & 0 \\
0 & 0 & Y / L & 0 & 0 \\
0 & 0 & 0 & \ln K & \ln L
\end{array}\right)
$$

where $Y / K, Y / L, \ln K$, and $\ln L$ are $N T \times 1$ vectors of the suitably lagged explanatory variables in (5.17)-(5.19). The indicator variable $d$ is fully determined given the estimated value for the threshold $\hat{\tau}$. The estimating equations (5.17)-(5.19) can now be conveniently restated as

$$
y=X \beta+\omega
$$

where $\beta=\left(\phi_{k 1}, \phi_{k 2}, \phi_{l}, \alpha_{k}, \alpha_{l}\right)^{\prime}$ and $\omega=\left(\omega_{k}, \omega_{l}, \omega_{y}\right)^{\prime}$ is a $3 N T \times 1$ stacked vector of the disturbances from each equation. With $J_{T}$ denoting a $T \times T$ matrix of ones, the covariance matrix of $\omega$ is given by

$$
\Omega=E\left[\omega \omega^{\prime}\right]=\Sigma_{\mu} \otimes\left(I_{N} \otimes J_{T}\right)+\Sigma_{\varepsilon} \otimes\left(I_{N} \otimes I_{T}\right)
$$

\footnotetext{
${ }^{13}$ See the seminal paper by Zelner $(1962)$, and Baltagi (1995, chapter 6) for a short discussion focusing on panel data. We largely draw upon the latter here.
} 
where $\Sigma_{\mu}$ and $\Sigma_{E}$ are $3 \times 3$ matrices containing the cross-equation covariances of the separtite error components. The spectral decomposition is

$$
\Omega=\Sigma_{\mathbb{I}} \otimes P+\Sigma_{E} \otimes Q
$$

where $\Sigma_{1}=T \Sigma_{\mu}+\Sigma_{\varepsilon,} P=\frac{1}{T}\left(I_{N} \otimes J_{T}\right)$, and $Q=I_{N T}-P^{14}$. Thus,

$$
\Omega^{-1 / 2}=\Sigma_{1}^{-1 / 2} \otimes P+\Sigma_{\varepsilon}^{-1 / 2} \oslash Q
$$

and the (F)GLS estimate of $\beta$ is

$$
\begin{aligned}
\hat{\beta} & =\left[X^{\prime} \Omega^{-1} X^{\prime-1} X^{\prime} \Omega^{-1} y\right. \\
& =\left[X_{*}^{\prime} X_{*}\right]^{-1} X_{*}^{\prime} y_{*}
\end{aligned}
$$

where $z_{*}=\Omega^{-1 / 2} z, z \in\{y, X\}$. This estimate can be obtained by applying OLS to the transformed system $y_{*}=X_{*} \beta+\epsilon_{*}$.

To apply FGLS, $\Omega$ needs to be estimated. Letting $U$ denote a $N T \times 3$ matrix of residuals of a first ronnd estimation, the respective components of the covariance matrix can be estimated by

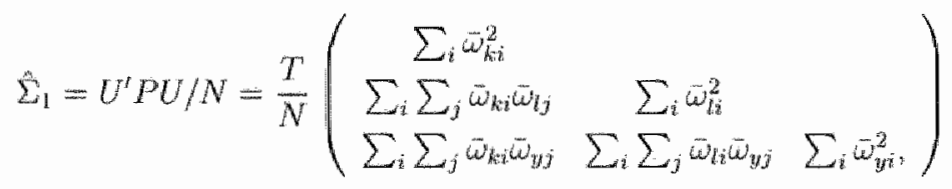

where $\mathrm{w}$ represents the time average of $\omega$. Similarly,

$$
\hat{\Sigma}_{i}=U^{\prime} Q U / N(T-1)
$$

which has the same stucture as (5.26) with the means replaced by the withintransformations. Typically, $U$ is obtained from either OLS or Least Squares Dummy Variables (LSDV, or "within') estimation of the individual equations.

\footnotetext{
${ }^{14}$ See Baltagi (1995), equations $(6.5)$ and $(6.6)$. Note that multiplication of a vector by $P$ maps it into an equally sized vector with averages over time for each unit i. Similarly, nultiplication by $Q$ gives the deviations from these time averages (i.e. the within transformation).
} 


\subsection{Estimation results}

Table 5.2 gives the estimation results of the threshold model. Following Barnett and Sakellaris (1998) and Hansen (1999) additional flexibility is allowed for by testing for multiple regimes. With the bootstrap Likelihood Ratio (LR) test described in subsection 5.4.1 there is evidence for a model with three thresholds. ${ }^{15}$ In line with the theoretical model described in Section 5.2 , we find evidence for a regime in which investment does not respond to fundamentals. This follows from the fact that the coefficient in the first regime is close to zero and strongly insignificant. About one third of the observations fall into this zero-sensitivity regime, which can therefore clearly not be neglected. In the other regimes investment does respond to changes in fundamentals. For each additional unit of output per capital, investment increases by roughly $3 \%$ in the second regime and $4 \%$ in the third. These results underline the existence of lumpy adjustment. For example if $Y / K$ increases from 1 to 2 , investment increases by $8 \%$. Although this is substantial, the estimates do not seem high enough to replicate the 'spikes' found in the data in Chapter 3. Finally, there is a fourth regime in which the coefficient on $Y / K$ is significant but smaller than in the third. That is, if the expectations of future gains to investment rise, response goes down, which seem counterintuitive. Possibly, the fact that the methodology identifies the existence of this regime is a consequence of using capital productivity as a proxy for $q$. A reason for the lower response in the highest regime could be that firms with low capital intensity are sorted in this regime. For these firms $Y / K$ is high but it may not be a good proxy for investment expectations, which will lead

\footnotetext{
${ }^{15}$ An adapted version of the Gauss code that accompanies Hansen (1999) was used, which is available at Hansen's website. To avoid that regimes arise with very few observations the minimum percentage of obserwations per regime was set to $5 \%$ for the single and double threshold model, and $10 \%$ for the triple threshold model. For the LR test 300 bootstrap replications were used. For the single and double threshold the LR test hus a $p$ value of 0.00. The test for the existence of three thresholds has a $p$ value of 0.04. As the significarice of the third threshold is already marginal, it is unlikely that a fouth threshold would be relevant. See Hansen (1996) for details of the LR test.
} 
to a lower response for these firms. 1 .

Given the threshold estimates, model (5.17)-(5.19) is a system of linear regression equations. As mentioned above, if the disturbances are linked, efficient estimation can be carried out by applying FGLS. Following Baltagi (1980), first the LSDV (within) estimator is applied to the equations separately in onder to estimate the transformation matrix $\Omega^{-1 / 2}$ given by (5.23), as discussed in subsection 5.4.2. These results are reported in the third and fourth columns of Tablle 5.3. Estimation by FGLS is equivalent to OLS on the transformed system where each variable is premultiplied by $\Omega^{-1 / 2}$.

The results of the SUR FGLS estimation are given in the fifth and sixth column of Table 5.3. Again there is strong evidence that in the lowest regime investment is not responsive to changes in capital productivity. As $Y / K$ increases and causes a regime-switch, its coefficient becomes significant and positive. In the second regime, an additional unit of capital productivity increases the investment rate by $2.7 \%$. In the third regime the investment rate increases by $3.2 \%$ with an additional unit of output per unit of capital. While there is still a significant difference in response between the second and third regime, the estimate for the third regime is lower than when the investment equation is estimated separately. These estimates are comparable to those obtained in other studies with regime models for investment. ${ }^{17}$ Again, the coeflicient in the highest regime is lower, possibly because firms with low capital intensity are sorted into this regime.

The coefhcient estimates for the other equations are also significant and the signs are conform to a priori expectations. The coefficient on $Y / L$ in the labour adjustment equation is positive and strongly significant. Thus, a higher productivity of labour is associated with a higher adjustment rate. However, the finding that the estimate of $\phi_{l}$ is quite small means that the convex adjustment costs are high, which implies that adjustment to changes

\footnotetext{
16. As mgied by Banett and Sakolliaris (1998) and Abel and Eberly (2002), who use average $q$ from stock market data, this pattern can also result from capital heterogeneity.

17 See e.g. Nilsen and Schiantarelli (2003), Barnett and Sakellaris (1998), Abel and Eberly (2002), and Letterie and Pfranin (2003).
} 
Table 5.2: Results threshold estimation of the investment model

\begin{tabular}{|c|c|c|c|c|c|c|}
\hline regime & & & & coefficient $Y / K$ & (std, err.) & $\%$ of obs. \\
\hline 1 & & $Y / K$ & $<1.006$ & -0.004 & $(0.008)$ & $33 \%$ \\
\hline 2 & $1.006<$ & $Y / K$ & $<1.432$ & $0.028^{* *}$ & $(0,005)$ & $15 \%$ \\
\hline 3 & $1.432<$ & $Y / K$ & $<5.182$ & $0.042^{* *}$ & $(0.002)$ & $45 \%$ \\
\hline 4 & $5.182<$ & $Y / K$ & & $0.032^{* *}$ & $(0.001)$ & $7 \%$ \\
\hline
\end{tabular}

$*=$ significance at $5 \% ; * *$ significance at $1 \%$.

Table 5.3: System estimation results

\begin{tabular}{llcccc}
\hline \hline dep. var. & variable & LSDV & (std. err.) & SUR-FGLS & (std. err.) \\
\hline$I / K$ & $Y / K$ (reg. 1) & -0.004 & $(0.008)$ & 0.005 & $(0.007)$ \\
& $Y / K$ (reg. 2) & $0.028^{* *}$ & $(0.005)$ & $0.027^{* * *}$ & $(0.004)$ \\
& $Y / K$ (reg. 3) & $0.042^{* * *}$ & $(0.002)$ & $0.032^{* *}$ & $(0.002)$ \\
& $Y / K$ (reg. 4) & $0.032^{* *}$ & $(0.001)$ & $0.023^{* *}$ & $(0.001)$ \\
$H / L$ & $Y / L$ & $1.14 \mathrm{e}-04^{* * *}$ & $(1.52 \mathrm{e}-05)$ & $8.43 \mathrm{e}-05^{* *}$ & $(6.48 \mathrm{e}-06)$ \\
$\ln Y$ & $\ln K$ & $0.214^{* *}$ & $(0.013)$ & $0.213^{* * *}$ & $(0.009)$ \\
& $\ln L$ & $0.729^{* *}$ & $(0.015)$ & $0.792^{* * *}$ & $(0.011)$ \\
\hline
\end{tabular}

$*=$ significance at $5 \%$;* significance at $1 \%$

in $Y / L$ are very slow and gradual. This will prove to be important in interpreting the results in Section 5.6. Finally, the coefficients in the production function are also significant and have the expected sign. Recall that in the empirical model marginal $q$ was replaced by average $q$, which required the assumption of constant returns to scale. As the sum of the coefficients on labour and capital is close to one, this assumption appears to be justified.

In summary, there is strong evidence for regime-type investment behaviour, where the regimes are determined by the productivity of capital. This result is in line with other studies on firm investment. However, although a switch to a higher regime leads to a higher investment rate, it does 
not lead to investment lumps of the magnitude found in the data in Chapter 3. Moreover, the adjustrnert of labour to changes in its level of productivity is foumd to be slow. With these results it is now time to see how an exogem nous shock to the system translates to factor adjustment, and in particular If ron-limear labour adjustment can be generated without non-convexities in the adjustment costs specification for labour. As the fourth regime in the investment equation is relatively small, and it is possibly the consequence of the use of capital productivity as a proxy for average $q$, this regime is not considered in the remaining part of this chapter. For this regime, the response of the investment rate to productivity is set equal to that in the third regime.

\subsection{Impulse response analysis}

In this section, the dynamic adjustment implied by the estimated model (5.17)-(5.19) is analysed, by looking at how the variables in the system respond to exogenous shocks. A particular issue of interest is the influence of the non-linear adjustment pattern of capital observed in Section 5.5 on labour adjustment. The effect of two types of shock are investigated. One cause of a lumpy investment cam be a regime-switch in the investment equation, which is determined by the productivity of capital. To trigger a regine-switch for investment, the productivity of capital must increase. Therefore the effect of a large positive shock to the production function in year th considered. In the model, this is simply a realisation of $\varepsilon_{y}$ from the right tail of its distribution. In addition, a direct shock to the imvestment equation itself - a large realisation of $\varepsilon_{k i t}-$ leads to a lump in investment expenditures. Such a shock may for example result from a large cut in the effective price of certain investment goods due to the introduction of a subsidy or abolishment of price increasing taxes. The effect of such a shock will also be investigated. Before turning to the technical analysis, we first look at how the shocks are transmitted through the system. 
In case of a technology shock, output $Y_{\text {, increases, while the capital stock }}$ $K_{t-1}$ and the employment level $L_{i}$ remain unchanged (in fact, these were already determined). Thus, the productivity of capital $\left(Y_{t} / K_{t-1}\right)$ and of labour $\left(Y_{t} / L_{t}\right)$ increases. In the next period $(t+1) Y_{t} / K_{t-1}$ and $Y_{t} / L_{t}$ determine the size of respectively imvestment and labour adjustment. For labour the adjustment is simply proportional to lagged labour productivity, so the ad. ditional adjustment due to the shock is proportional to the shock size. For investment, however, the effect not only depends on the size of the shock but also on how high capital productivity was before the shock. For example, for a firm that was in the zero-sensitivity regime before the shock and remains there after the shock, there is no additional adjustment. In this case the impulse response is zero. On the other hand, firm that switches from the inaction regime to a higher regime because of the increase in $Y / K$ exhibits a 'lump' proportional to lagged capital productivity. The occurrence of a regime-switch therefore depends on whether the shock is large enough and also on whether $Y / K$ is close to a threshold.

In the present model, a possible investment lump does not have a contemporaneous effect on labour. However, via the motion equation (5.2), it leads to an increase in $K_{t+1}$, which in turn results in an increase in output in year $t+2$, that is $Y_{t+2}$. If this increase in output is substantially higher than that of labour in $t+2$, labour productivity $Y_{t+2} / L_{t+2}$ will jump again. As lagged labour productivity determines labour adjustment, this will ultimately lead to an increase in labour demand in year $t+3$. Summarising, the investment lump in year $t+1$ leads to an increase of labour productivity in year $t+2$. This ultimately leads to a higher adjustment rate of labour in year $t+3$. This mechanism therefore allows investment dynamics to influence employment dynamics via a technology shock.

Alternatively, an investment lump can result from a large shock to the investment equation. Such a shock will immediately lead to a lump in investment and an increase in capital stock $K_{b}$. However, again there is no contemporaneous effect of this lump on labour adjustment or production. 
Production increases in year $t+1$, leading to an increase in labour productivity $Y_{t+1} / L_{t+1}$. If this increase is large it will lead to a large adjustment of the employment level in $t+2$. Thus, the effect on labour adjustment of a direct shock to investment shows up one period earlier than does the effect of a technology shock.

\subsubsection{The Generalised Impulse Response Function}

A suitable approach to analyse the effect of a shock is an impulse response analysis. However, in this non-linear setting traditional impulse response analysis is not appropriate. As the shock may cause a regime-switch its effect depends on its size and the values of the relevant variables at the time of the shock. In adclition, the effect also depends on future shocks as these may cause regime-switches as well. In traditional impulse response analysis the effect of a shock is independent of size, state, and future. Therefore we will use the so-called Generalised Impulse Response Function (GIRF) as suggested by Koop, Pesaran, and Potter (1996). In short, this approach involves simulation of the model for as well the case where a shock at time $t$ occurs as the case where no shock occurs. As mentioned above, an investment shock and a technology shock are considered, which are realisations of $\varepsilon_{k i t}$ and $\varepsilon_{y i t}$. For each firm, the GIRF is defined by (dropping the firm index for notational convenience)

$$
\operatorname{GiRF}\left(s, a, \Omega_{t-1}\right)=E\left[X_{t+s} \mid \Omega_{t-1}, \varepsilon_{m i}=a\right]-E\left[X_{t+s} \mid \Omega_{t-1}\right]
$$

$m \in\{k, y\}, X$ is a variable of interest, $s$ is the number of periods after the initial shock (in period $t$ ), and $a$ is the size of a shock. Thus, the GIRF essentially compares the conditional expectation of $X_{t+s}$ given that there was a shock of size $a$ in year $t$, to the same expectation where there is no knowledge about the size of the shock.

The conditional expectations can be determined by Monte Carlo simulation. Consider $R$ replications of the simulation where $X_{t}^{(r)}(\Theta), r=1, \ldots, R$, 
denotes the outcome of the rth replication under 'conditioning set' $\theta^{18} \mathrm{To}$ simulate the model it is assumed, as before, that the disturbances are contemporaneously correlated but independent over time and across firms, and distributed according to a multivariate normal distribution, that is $\varepsilon_{t}=$ $\left(\varepsilon_{k t}, \varepsilon_{t t}, \varepsilon_{y t}\right)^{\prime} \sim N(0, S)$. The covariance matrix $S$ is estimated as the covariance matrix of the FGLS residuals. The simulated disturbance in year $t$ is $\varepsilon_{t}^{(r)}=\left(\varepsilon_{k: t}^{(r)}, \varepsilon_{l t}^{(+)}, \varepsilon_{3 t t}^{(r)}\right)^{y}{ }^{19}$ Under the scenario of an investment shock, $\varepsilon_{k t}^{(r)}$ is replaced by an integer multiple of the standard deviation of $\varepsilon_{k t}$. Likewise, in case of a large productivity shock $\varepsilon_{y t}^{(r)}$ is replaced by an integer multiple of the standard deviation of $\varepsilon_{3 t}$. The simulations are carried out $R=100$ times for each firm, conditional on knowledge of the shock size or not. ${ }^{20}$ Then the GIRF is estimated for each frm by the difference of the averages of the simulations under both conditioning sets

$$
\operatorname{eGIRF}\left(s, a, \Omega_{t-1}\right)=\frac{1}{R} \sum_{r=1}^{R} X_{t+s}^{(r)}\left(\varepsilon_{m t t}=a, \Omega_{t-1}\right)-\frac{1}{R} \sum_{r=1}^{R} X_{t+s}^{(r)}\left(\Omega_{t-1}\right)
$$

where the prefix ' $\mathrm{e}$ ' stands for 'estimated'. By simulating the model one accounts for the different futures that may occur. Essentially, they are averaged out, as the two estimated expectations of the GIRF are both averages over possible different futures. The first, however, is conditional on ashock occurring at time $t$. The difference between the averages is therefore an average of possible effects that the shock might invoke.

The effect of a shock depends on its size and the state of the firm, that is the values of the relevant variables at the time of the shock (summarised in $\Omega_{t-1}$ ). To account for this dependence the GIRF is estimated for different shock sizes $a$ and states. Like in other applications, the shocks are restricted

\footnotetext{
${ }^{18} \mathrm{By}$ 'conditioning set' all the information in the conditional part of the expectation is meant. Thus, it refers to either $\Omega_{t-1}$ and $\varepsilon_{m s}=a_{3}$ or only $\Omega_{t-1}$.

${ }^{19}$ As the date only contain information or positive investments, the investment rate is also not allowed to become negative in the simulations. If a realisation of $\varepsilon_{t}$ makes the investment rate negative, the rate was set to zero.

${ }^{20}$ Realisations from the multivariate normal distribution were drawn according to the method by Scheuer and Stoller (1962), see Law and Kelton (1901, section 8.5.2).
} 
to an integer multiple of the standard deviation of the cortesponding disturbance. $^{2}$ Here the analysis is carried out for shocks to the investment and production equation of 2,4 , and 6 times the standard deviation of the pertinent disturbance. In addition, accounting for different histories is achieved by estimating the GIRF for each individual firm, taking the values for the relevant variables in 1997 as a starting point. While in principle each year can provide the starting values, 1997 is a natural choice as it is the last year of the sample period.

\subsubsection{Results}

For all 603 frms in the sample the GIRF is estimated using the values in 1997 as a starting point. Two types of shocks are considered, namely an investment shock (i.e. a shock to the investment rate equation) and a technology shock (i.e. a shock to the production equation).

Figures 5.1 and 5.2 display the distribution of the estimated GIRFs for year" $t+1$ in the case of a technology shock of twice the standard deviation of $\varepsilon_{y y \text { it }}$. Figure 5.1 nicely illustrates the consequence of the zero-sensitivity regime. For firms that are in this regime and remain there under both the scenarios with and without a shock, investment is zero. The GIRF is then also zero, which means that the investment rate is not higher in case of a shock. This is captured in the figure by the high peak at zero, which represents a good $26 \%$ of the observations. In addition, it can be seen that after the peak at zero the distribution has almost no observations in the interval from 0 to roughly 0.02 . Towards 0.02 the frequency increases again. This shows that the response of investment to a shock in production is in most cases either zero or larger than $2 \%$. In the latter case the investment rate in year $t+1$ is more than $2 \%$ higher if there is a technology shock at time $t$. Although in exceptional cases the investment rate is up to $10 \%$ higher after a technology shock, the differences are generally only very moderate with an average of

\footnotetext{
21 See Balke (1999) and Hoogstrate, Osang, and Slottje (2002) for two studies using non-linear impulse response analysis in different settings.
} 
Figure 5.1: Average responses of $I / K$ to technology shock $(t+1$, size $2 \sigma)$

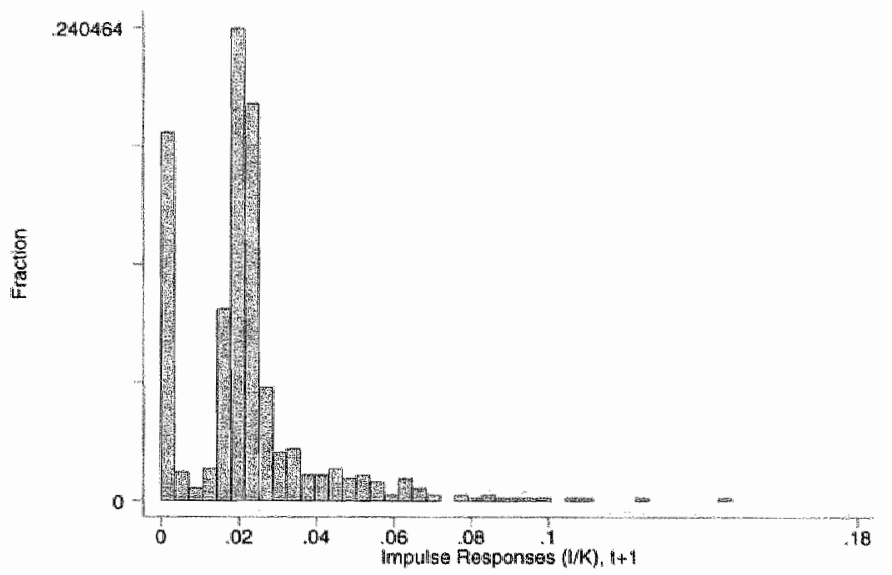

Figure 5.2: Average responses of $H / L$ to technology shock $(t+1$, size $2 \sigma)$

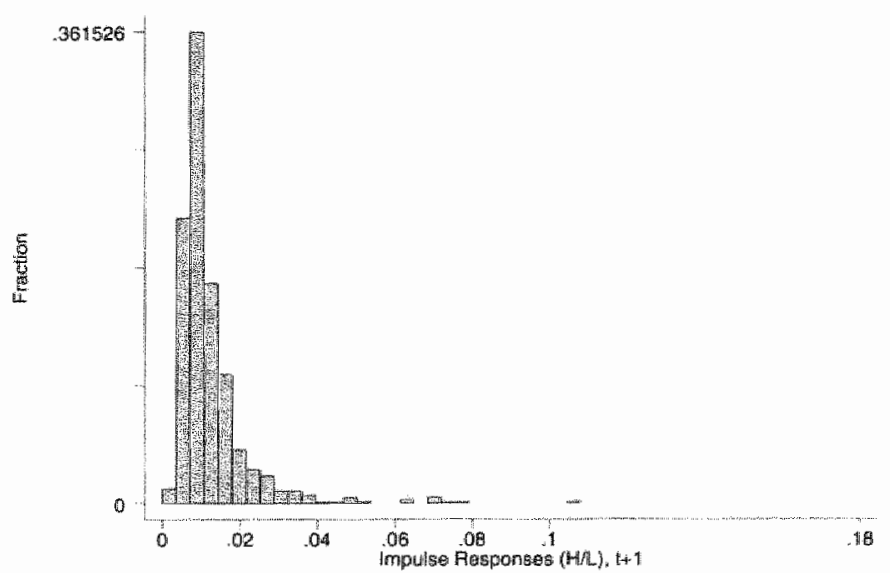


$2.2 \%$

Figure 5.2 gives the distribution of the estimated GIRFs for year $t+$ 1. for labour adjustment. Naturally, the GIRFs are all above zero and the distribution is smooth. The average impulse response over all firms is $1.3 \%$, which means that after a technology shock in year $t$ labour adjustment is on average $1.3 \%$ higher in year $t+1$ than if that shock had not occurred. Note that the distribution is a little skewed to the right because of the initial distribution of $Y / L$.

Table 5.4 reports the average impulse responses of $I / K$ and $H / L$ for period to $t+4$ for different shock sizes. As in Figures 5.1 and 5.2 it can be seen what the technology shock leads to an increase in the adjustment rates in year $t+1$. The responses increase with the size of the technology shock. It should allso be noted that for investment from $t+2$ onwards the average responses are often negative. This results from the fact that after an investment, a firm is less likely to switch to a higher regime in the subsequent periods. In addition, the increase of labour adjustment leads to a reduction in average labonu productivity, causing a slightly negative response in $t+2{ }^{22}$ However, for both the investment rate and the labour adjustment rate, the responses are very small after $t+2$ and never exceed $1 \%$ in absolute value. Thus, be sides a direct effect on labour adjustment in $t+1$, the technology shock only leads to slightly higher labour adjustment via an increase in investment even for very large shocks. There are two reasons for this. Firstly, the estimated coefficient on lagged productivity in the labour equation is very small, which implies very high convex adjustment costs. "Therefore, the estimated model generates labour adjustment that is very show and gradual in response to shocks. Secondly, as became clean from Figure 5.1, the technology shock does not lead to very large increases in the investment rate in $t+1$. Therefore, it can also not be expected that there is a large impact of the higher investment rates on labour adjustment.

Besides a regime-switch, an investment lump can also be the result of a

\footnotetext{
${ }^{22}$ Note that this does not meen that there is negative adjustment under the scenario of al large shock, but that adjustment in period $t+2$ is lower in this case.
} 
Table 5.4: Average Generalised Impulse Responses

\begin{tabular}{|c|c|c|c|c|c|c|}
\hline & \multicolumn{6}{|c|}{ techrology shock } \\
\hline & \multicolumn{3}{|c|}{$I / K$} & \multicolumn{3}{|c|}{$H / L$} \\
\hline & $2 \sigma$ & $4 \sigma$ & $6 \sigma$ & $2 \sigma$ & $4 \sigma$ & 60 \\
\hline t & 0 & 0 & 0 & 0 & 0 & 0 \\
\hline$t+1$ & 2.199 & 5.531 & 10.273 & 1.261 & 3.131 & 5.821 \\
\hline$t+2$ & 0.059 & 0.146 & 0.269 & -0.013 & -0.031 & -0.054 \\
\hline$t+3$ & -0.072 & -0.167 & -0.282 & 0.003 & 0.009 & 0.017 \\
\hline \multirow[t]{3}{*}{$t+4$} & -0.075 & -0.169 & -0.291 & 0.004 & 0.011 & 0.021 \\
\hline & \multicolumn{6}{|c|}{ investment shock } \\
\hline & \multicolumn{3}{|c|}{$I / K$} & \multicolumn{3}{|c|}{$H / L$} \\
\hline$t$ & 15.954 & 32.976 & 49.983 & 0 & 0 & 0 \\
\hline$t+1$ & 0 & 0 & 0 & 0 & 0 & 0 \\
\hline$t+2$ & -0.554 & -0.981 & -1.322 & 0.097 & 0.187 & 0.269 \\
\hline$t+3$ & -0.539 & -0.952 & -1.288 & 0.096 & 0.185 & 0.267 \\
\hline$t+4$ & -0.495 & -0.886 & -1.193 & 0.091 & 0.176 & 0.255 \\
\hline
\end{tabular}

NB. Shock sizes refer to an integer mutiple of the standard deviation of the pertinent disturbance, that is $\varepsilon_{y i t}$ in case of a technology shock and $\varepsilon_{h: t}$ in case of an investment shock. The impulse responses are presented as nominal differences in the adjustment rates. E.g. in period $t+2, T / K$ is on average 0.059 higher after to a technology shock.

large shock to the investment equation. The average impulse responses to this type of shocks are reported in the bottom panel of Table 5.4. Naturally, the effect on the investment rate is direct. Unlike the technology shocks, the investment shocks do generate lumps in investment. Since capital becomes productive after one period, however, it takes until $t+2$ for the shock to affect labour adjustment. Because the differences in the investment rate are much larger than in response to a technology shock, the effect on labour adjustment is also much higher. However, the effects are still moderate; and there is no indication of an adjustment lump in labour whatsoever. Since the investment 
shocks do lead to investment lumps, it can be concluded that the main reason for the small effects that are found is the fact that the convex adjustment costs for labour are estimated to be very high. That is, even if extreme investment lumps occur, adjustment in Labour will still be gradual. "Thus, the model with only convex adjustment costs for labour cannot explain the labour adjustment lumps that were evident in Chapter 3 , even when taking into account the effect of large investments. This suggests the relevance of a richer adjustment costs specification to explain the observed non-linear employment dymamics. ${ }^{23}$

\subsection{Conclusion}

This chapter studies capital and employment dynamics when adjustment costs are non-convex for investment and strictly convex for labour adjustment. In particular, the question whether the observed lumpy employment dynamics can be explained by fixed investment costs is investigated. A structural model for the demand for capital and labour is derived. The factor demand equations are estimated together with the production technology. There is strong evidence for the existence of different investment regimes.

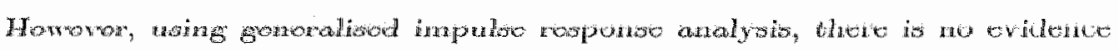
that the resulting investment dynamics infuence enployment dynamics, exen in the case of very lerge investment rates. The reason for this is that the convex labour adjustment costs are estimated to be very high so that adjustment is very slow and gradual. A model with only this type of adjustment costs can therefore not generate the adjustment Jumps for employment that are present in the data, even when taking into account the effect of the lumpiness of investment. This can be interpreted as evidence that a richer adjustment costs specification is required to explain the observed employment dymamics,

\footnotetext{
${ }^{23}$ Also the GIRF distributions conditional on purticular histories were considered. The results presented for the total of firms did not change when distinguishing between the initial investment regines, that, is the regime where the firm is in based on its value for $Y / K$ in 1997 . Finally, conditioning on whether a firm was close to a threshold or not did also not alteir the conclusions.
} 
for instance by including hiring and firing costs and fixed costs of labour adjustment. 


\section{Chapter 6}

\section{Dynamics of labour and capital adjustment - a comparison of Germany and the Netherlands}

\subsection{Introduction}

The ability for firms to adjust employment and capital is infuenced by institutional arrangements and government policies such as labour market regulation, unionisation and taxation. This implies that the dynamics of factor adjustment varies between countries where such constraints differ. For example, in a country with high fring costs one expects to see lower adjustment rates of labour than in a country where such costs are not present." In this chapter Dutch and German manufacturing firms are compared to investigate whether there is an influence of differences in institutions on the dynamics of labour and capital adjustment at the microulevel.

As neighbouring countries in the European Union, Germany and the Netherlands face in some respects similar economic conditions. However, in the last decade there has been a considerable divergence in their respective

\footnotetext{
${ }^{1}$ The theoretical model of Bertola (1999) illustrates the negative impact of dismissal costs on both hirings and firings, though the net effect is ambiguous and depends on functional form assumptions.
} 
labour markets. Unemployment in Germany is now twice as high as it is in the Netherlands; a reversal from the 1980s. Wage stability and the deregulation of temporary work have helped the Netherlands achieve more flexibility. which implies that labour adjustment should be more responsive to economic shocks. The conditions for capital adjustment are not so different since both countries face a similar structure of credit and monetary conditions as imposed by the European Central Bank, though there is some variation in taxation policies. However, considering that factor demand decisions are likely to be interrelated, the differences in the labour markets may also translate to capital adjustment. With this motivation, capital and labour adjustment dynamics in the Netherlands and Germany are investigated, paying specific attention to whether there is any evidence that the institutional differences are reflected in the firm-level decisions regarding dynamic factor demand.

As discussed in Chapter 2, empirical research using micro-data has revealed the importance of non-linearities in factor adjustment, which contradicts the assumption of linear-quadratic adjustment costs typically relied upon in earlier studies. ${ }^{2}$ Common theoretical arguments for this behaviour are non-convexities in the adjustment costs and (partial) irreversibility. However, most of the empirical studies focus on investment using a univariate specification implicitly assuming labour to be fully flexible; see for example, Barnett and Sakellaris (1998), Cooper, Hajtiwanger, and Power (1999), Nilsen and Schiantarelli (2003) and Letterie and Pfann (2003). This assumption is clearly not consistent with the institutional constraints in labour markets, which are evident in countries like the Netherlands and Germany. In strongly regulated markets, labour adjustment costs are considerable and may even be higher than for capital. Thus, rather than assuming that capital is less flexible than labour, the relative magnitude of adjustment costs of these factors should be investigatied empirically.

Another important issue addressed in this chapter is interrelated adjustment costs. To reduce adjustment costs a firm may want to synchronise

\footnotetext{
${ }^{3}$ For an early exposition of a symmetric convex adjustment cost function, see the seminal contribution of Eisner and Strotz (1963).
} 
the timing of the adjustments to the production factors. One reason is that simultaneous adjustment reduces the time of disruption to the production process. Suppose a firm hires new workers, which have to be trained to work with the existing technology within the firm. This invokes training costs and disruption to production because the new workers are not immediately fully productive. If in the next period the firm decides to invest in a new technology, the newly hired workers would have to be retrained. Again training costs are incurred, and production is disrupted. Therefore, it would have been more efficient when the firm had either waited with hiring, or invested earlier. In that way it would have saved on both training and disruption costs. In addition, adjusting one factor may help reduce the adjustment costs of the other. For example, by hiring and training new workers prior to investing, a firm can more easily integrate the new technology. The other way aromin, when a firm invests in a new technology, workers have to be traimed to work with it. The fact that training costs have to be incurred may lead to the situation that some workers are no longer profitable to the firm, so that investment may serve as an incentive to fire these workers in order to save on training costs.

Interrelation was first addressed using sector-level data in a linear setting by Nadiri and Rosen (1969), though this study was not based on a structural model with adjustment costs. Shapiro (1986) expands upon Nadiri and Rosen (1969) and estimates a structural dynamic model of factor demand with interrelation derived from the Euler equations. More recently, Mers and Yashiv (2003) investigate the impact of labour on the market value of the firm using a production-based asset pricing model with frictions in the adjustment of both capital and labour. In this model the interrelation between the two factors is a key determimant of the market value of the firm. However" their paper also restricts the empirical analysis to sector-level data and only considers the relation between gross investment and hirings. The issue of interrelation has not been investigated empirically in the context of non-convex 
adjustinent costs. ${ }^{3}$ Evidence of such costs ane not reflected in sector-level data as investment and employment changes are smoothed by aggregation. Thus, firm-level data is required to explore such behaviour.

This chapter considers a model where capital and labour adjustment are subject to both convex and non-convex adjustment costs. The adjustment cost framework is used to derive a structural model and provides the basis for the empirical strategy. The dynamic models of investment and labour adjustment are estimated using firm-level data for Germany and the Netherlands. Given that Dutch firms are more able to nse flexible work arrangements in response to changes in economic conditions, employment adjustment is expected to be mone frequent and responsive in the Netherlands. Furthermore, interrelated adjustment; costs are considered, which allow the differences in adjustment of labour to infiuence the dynamics of investment.

Section 6.2 compares the institutional structures in Germany and the Netherlands and discusses their implications for the dynamic adjustment of labour and capital by firms in these countries. Section 6.3 discusses the estimation and identification issues. The data and summary statistics are described in Section 6.4 , while the results are presented in Section 6.5 , which includes a discussion about sample selection bias. Finally, Section 6.6 concludes.

\subsection{Institutional background}

To understand the nature of capital and labour adjustment in Germany and the Netherlands, it is useful to briefly describe their economies and institutional structures and how this should be reflected in dynamic factor demand.

\footnotetext{
${ }^{3}$ See Dixit (1997) and Eberly and Van Mieghem (1997) for a theoretical model with kinked-linear adjustment costs. Some empirical studies allow for more general adjustment costs stiuctures with multhple quasinfixed factors while distinguishing between different types of labour; see for example Pfiann and Pam (1993) and Alonso-Borrego (1998). Sakellaris (2004) and Letterie, Pfann, and Polder (2004) - Chapter 4 of this thesis - find that. there is astatistienl relationship between the adjustment dynamics of an input factor and the incidence of an adjustment spike in another factor.
} 
Table 6.1: Macroeconomic indicators

\begin{tabular}{|c|c|c|c|c|c|c|c|c|c|}
\hline & 1992 & 1993 & 1994 & 1995 & 1996 & 1997 & 1998 & 1999 & 2000 \\
\hline \multicolumn{10}{|c|}{ Growth rate of GDP at market prices (\%) } \\
\hline Gemmany & 2.2 & -1.1 & 2.4 & 1.7 & 0.8 & 1,4 & 2.0 & 1.9 & 3.0 \\
\hline Netherlands & 1.7 & 0.9 & 2.6 & 2.9 & 3.0 & 3.8 & 4.3 & 3.7 & 3.5 \\
\hline \multicolumn{10}{|c|}{ Grouth rate of production in industry (\%) } \\
\hline Germany & -2.2 & -8.0 & 3.3 & 0.8 & 0.6 & 3.6 & 4.2 & 1.5 & 6.7 \\
\hline Netherlands & $c^{c}$ & - & - & - & 2.4 & 0.2 & 2.4 & 2.2 & 2.9 \\
\hline \multicolumn{10}{|c|}{ Growth rate of employment in industry $(\%)^{\mathrm{b}, \mathrm{d}}$} \\
\hline Germany & -10.2 & -8.8 & -6.5 & -4.0 & -3.8 & -3.2 & -0.33 & -0.8 & -0.1 \\
\hline Netheriands & -0.8 & -3.7 & -2.8 & -0.4 & -0.7 & 1.3 & 1.3 & 0.4 & 0.3 \\
\hline
\end{tabular}

(Source: Eurostat Yearbook 2002.)

Table notes:

a Working days adjusted.

Excluding construction.

"Data missing for 1992-1995.

d Gross employment.

In general, the economies of these two countries have been characterised as having significant levels of government intervention and coordination between the government, employers and unions. This has been called the 'Rheinland model' in contrast to the 'Anglo-Saxon model', which is still used to describe the economies of the UK and the USA (Delsen and de Long 1998). While Germany and the Netherlands have many institutional similarities, such as their social welfare systems, in the last decacle or so there has been a divergence in their economies, which should translate to differences in the dynamics of factor adjustment in the two countries.

Firstly, as seen in Table 6.1, since the mid-1990s the economy of the Netherlands, as represented by the growth rate in GDP (at market prices), 
has grown faster than that of Germany. However, this difference is largely due to the sectoral composition since the service sector is larger in the Netherlands, while the manufacturing sector is more dominant in Germany. As shown in the middle panel of Table 6.1, the manufacturing sector in Germany labs actually performed better than its Dutch counterpart in some of the years of the late $1990 \mathrm{~s}$, which may result in higher rates of factor adjustment in Geman manufacturing firms during this period.

In contrast; as also displayed in the bottom panel of Table 6.1, from 1992 to 2000 there was negative growth in employment in the German manufacturing sector, which reflects the severe contraction in this sector during this period. The layoff's continued when the sector recovered from 1997 to 2000. In comparison, employment in the Dutch industrial sector decreased from 1992 to 1996 and then started increasing at a smali rate. Thus, the macro data suggests that there was considerable restructuring in botl countries, particularly in Germany, and this should be reflected in labour adjustment. Related to this situation, Germany has been suffering from a persistently high unemployment rate since the mid-1990s. As of 2001 , unemployment in Germany stood at $7.9 \%$ compared with $2.4 \%$ in the Netheriands, a reversal of the situation a decade before. The growth in Dutch employment over this period has mainly come from the service sector, and specifically from the increase in part-time jobs, which accounted for $42.2 \%$ of total employment in 2001. In contrast, there has not been a similar growth in part-time work in the German labour market; as of 2001 , only $20.3 \%$ of jobs were part-time (Eurostat 2002). One reason for the high percentage of part-time workers in the Netherlands is the higher participation rate of women. Although in terms of strictness of employment protection, the Netherlands rank slightly above Germany for regular employment: (OECD 1999), regulations of fixedterm contracts and temporary work agencies have been liberalised far more than in Germany. This implies that frms in the Netherlands can more easily rely on flexible work arrangements when responding to changes in economic conditions. 
Another relevant issue in this context is the relative weakness of the unions in the Netherlands compared with Germany, which made it easier to deregulate the Dutch labour market, particularly in the use of temporary and fxed-term workers. Moreover, during the post-unification years, there was considerable wage inflation in Germany as the result of demands by unions, something that was not evidert in the Netherlands. Between 1991 and 1995 labour costs increased in Germany by $3.2 \%$, compared to only $0.6 \%$ in the Netherlands. As a consequence, there was a loss of competitiveness for the German industry, which contributed to a fall in exports, an important source of revenue for both economies. Real wages have been in fact decreasing in the Netherlands, helping increase exports and growth (Delsen and de Long 1998).

With regard to the influence of the institutional structures in Gemany and the Netherlandls on the dymamics of investment, the differences are less obvious. Firstly, while some aspects of the capital markets vary in the two countries, they are more alike compared to Anglo-Saxon countries. Secondly, monetary policy is determimed at the European Union level and the similar structure of the credit market implies that monetary transmission should not differ significantly. Thirdly, the Deutsche Mark (DM) and the Dutch Guilder (NLG) were closely related since the introduction of the Exchange Rate Mechanism. In 1999 the conversion rates were fixed as part of the introduction of the Euro. Finally, the financial stiucture of firms is found to be similar in both countries, in the sense that investments terd to be fnanced primarily from internally generated funds as opposed to extermal sources of credit (Hoogduin and Huisman 1998).

Apart from the higher growth rate for Geman manufacturing during some years of the 1990 s, these macroeconomic and institutional issues suggest. that one expects to see higher rates of labour adjustment in the Netherlands. In terms of capital adjustment, it is not clear a priori how the rates of investment should differ between the two countries. If labour adjustment and investment are interrelated, differences in labour market flexibility could also translate to capital adjustment. 


\subsection{Econometric model and identification}

To derive the econometric specification, it is assumed that firms maximise their net present value at the beginning of period $t$ with respect to labour and capital. The dynamic optimisation problem - and hence the Euler equations - is similar to that discussed in Chapter 2, but here it is assumed that adjustment is costly for both factors, and there are interrelated adjustment costs. Initially, the role of non-convexities in adjustment costs is ignored; this issue is addressed in Sections 6.4 and 6.5. Hence, under the assumption of convex adjustment costs for both factors, this yields two linear dynamic firstorder conditions, or Euler equations, including expectation terms for period $t+1$. Assuming rational expectations, these equations can be used as the basis for Generalized Method of Moments (GMM) estimation as first proposed by Hansen (1982) and later extended to efficient panel data estimators by such studies as Arellano and Bond (1991) and Blundell and Bond (1998).

The optimisation problem can be represented as the following Bellman's equation (cf. for example Bond and Meghir (1994))

$$
\begin{aligned}
V\left(A_{t-1}, K_{t-1}, L_{t-1}\right) & =\max _{\left\{I_{t}, H_{t}\right\}}\left[F\left(A_{t}, K_{t}, L_{t}\right)-p_{t} I_{t}-w_{t} L_{t}\right. \\
& \left.-A C\left(K_{t}, I_{t}, L_{t}, H_{t}\right)+\beta E_{t} V\left(A_{t}, K_{t}, L_{t}\right)\right]
\end{aligned}
$$

where $A_{t}$ is a strictly-exogenons Markov process that captures productivity and technology shocks in period $t ; K_{t}$ is the capital stock; $L_{t}$ is the number of workers employed; $I_{t}$ is total investment; $p_{t}$ is the price of unvestment goods; $w_{t}$ is the total wage, including bonuses and social security payments; and $0 \leq \beta \leq 1$ is the discount rate. Capital is subject to the equation of motion $K_{t}=(1-\delta) K_{t-1}+I_{t}$ where $\delta$ is a constant discount rate. Since only net employment changes are observed, labour adjustment is denoted by $H_{i}=L_{t}-L_{t-1}$. Note that capital and labour are assumed to become immediately productive. The production function is assumed to be CobbDouglas 


$$
Y_{t} \equiv F\left(A_{t}, K_{t}, L_{t}\right)=A_{t} K_{t}^{\alpha_{k}} L_{t}^{\alpha_{t}}
$$

and the adjustment costs function is given by

$$
A C\left(K_{t}, I_{i}, L_{t}, H_{t}\right)=\frac{\gamma_{t}}{2}\left(\frac{I}{K}\right)_{t}^{2} K_{t}+\frac{\gamma}{2}\left(\frac{H}{L}\right)_{t}^{2} L_{t}+\theta I_{t} H_{t}
$$

where $\gamma_{k}, \gamma_{t}$ and $\theta$ are adjustment cost parameters. Besides direct purchase costs and additional wage payments, firms incur strictly convex costs of investment, which are intended to capture costly disruptions to production and other forms of internal adjustment costs. This implies that firms have an incentive to spread adjustments over time to avoid increasing marginal costs. The last term in the adjustment costs specification captures the interrelation between capital and labour adjustment costs. As explained in the introduction, simultaneous adjustment of factors can be cost efficient, and adjustment of one factor can reduce adjustment costs in the other. It should be noted that compared to an interaction term in rates, this specification has the advantage that it yields a more tractable econometric specification. An alternative specification is discussed in Section 6.5.

As argued in previous chapters, firms also incur fixed costs when adjusting capital or labour, which are not specified in (6.3). However, the assumption of convex adjustment costs remains valid when conditioning on the optimality of non-zero adjustment in the maximisation of (6.1). As argued in Chapter 2, Section 2.5, fixed costs only have an impact on the decision whether or not to adjust, but conditional on adjustment, the convex costs determine the level of demand for the factors of production. As discussed in that section, this implies that the optimality conditions derived here apply only to a subsample of the data.

Therefore, conditional on the decision to adjust capital and labour and given the production function (6.2) and the adjustment cost function (6.3), 
the following system of Euler equations can be derived from $(6.1)^{\text {t }}$

$$
\begin{aligned}
p_{t}+\gamma_{k}\left(\frac{I}{K}\right)_{t}-\frac{\gamma}{2} & \left(\frac{I}{K}\right)_{t}^{2}+\theta H_{t}-\alpha_{k}\left(\frac{Y}{K}\right)_{t} \\
& =(1-\delta) \beta E_{t}\left[p_{t+1}+\gamma_{t}\left(\frac{I}{K}\right)_{t+1}+\theta H_{t+1}\right] \\
w_{t}+\gamma_{t}\left(\frac{H}{L}\right)_{t}-\frac{\gamma}{2} & \left(\frac{H}{L}\right)_{t}^{2}+\theta \Gamma_{t}-\alpha_{t}\left(\frac{Y}{L}\right)_{t} \\
& =\beta E_{t}\left[w_{t+1}+\gamma\left(\frac{H}{L}\right)_{t+1}+\theta I_{t+1}\right]
\end{aligned}
$$

The Euler equations (6.4) and (6.5) have the standard interpretation as intertemponal optimality conditions: firms adjust their factors of productions such that the marginal adjustment costs less the marginal product of the factor in period (left-hand side) is equal to the discounted expected value of the marginal adjustment costs in period $t+1$ (right-hand side). "The expectations in the Euler equations (6.4) and (6.5) are unobserved, but can be replaced with their realisations, which under the assumption of rational expectations introduces a forecast error that is onthogonal to all variables in the information set at the time of the decision. Making this substitution, and mapping the structural parameters to reduced form, the following econometric specification for investment can be derived

$$
\begin{aligned}
\left(\frac{I}{K}\right)_{i t}= & a_{1}\left(\frac{I}{K}\right)_{i, t-1}+a_{2}\left(\frac{I}{K}\right)_{i, t-1}^{2}+a_{3}\left(\frac{Y}{K}\right)_{i, t-1} \\
& +a_{4} p_{i t}+a_{5} p_{i, t-1}+a_{\theta} H_{i t}+a_{i} H_{i, t-1}+w_{k i t}
\end{aligned}
$$

and similarly, for labour adjustment

$$
\begin{aligned}
\left(\frac{H}{L}\right)_{i t}= & b_{1}\left(\frac{H}{L}\right)_{i, t-1}+b_{2}\left(\frac{H}{L}\right)_{i, i-1}^{2}+b_{3}\left(\frac{Y}{L}\right)_{i, l-1} \\
& +b_{4} w_{i t}+b_{5} w_{i, t-1}+b_{6} I_{i t}+b_{\pi} I_{i, t-1}+w_{i t i}
\end{aligned}
$$

where $\omega_{\text {kit }}$ and $\omega_{\text {it }}$ are disturbance terms such that $E\left[\omega_{m i t} \mid \Omega_{i, t-1}\right]=0, m \in$ $\{k, l\}$, and $\Omega_{i, t w 1}$ is the information available at the beginning of period $t$. The

\footnotetext{
"See Chapter 2 for the derivation. Note that the adjustment costs function has been angmented with an intenction term to capture internelation.
} 
structural technology and cost parameters in (6.4) and (6.5) can in principle be recovered from the non-linear relations between the reduced-form and structural parameters using a Minimum Distance procedure. However, the focus in this chapter is on the estimation of the reduced-form results for the German and Dutch samples. This approach still allows for a comparison of state dependence in the dynamics, how responsive investment and labour adjustment are to economic variables in these two countries, and whether there is any evidence of interrelation. Note that $H_{i t}$ and $H_{i, t-1}$ enter the investment equation (6.6), whereas $I_{\text {th }}$ and $I_{i, t-1}$ are included in the labour adjustment equation (6.7), to capture interrelation between the adjustment decisions.

The error terms are specified such that $\omega_{\text {mat }}=\mu_{\text {mi }}+\varepsilon_{\text {mit }}$, where $m \in$ $\{k, l\}$, and $\mu_{m i}$ is a firm-specific and $\varepsilon_{m i t}$ an idiosyncratic error term. Timespecific effects can be modelled by including year dummies. Estimation is complicated by the presence of the nuisance parameters $\mu_{m i}$, which are correlated with the lagged dependent variable, and endogenous or predetermined explanatory variables. To eliminate this firm-specific effect, equations (6.6) and (6.7) are first-differenced. Although the differenced dependent variable (and possible endogenous or predetermined explanatory variables) is still correlated with the differenced error term $\Delta \varepsilon_{m i t}$, it can now be instrumented with suitable lags of the corresponding levels." This results in the GMM estimator proposed by Arellano and Bond (1991).

However, first-difference GMM estimators such as that of Arellano and Bond (1991) have been found to have large finite sample bias and poor precision when the lagged levels are weak instruments for the differenced variables. As discussed in Blundell and Bond (1998) and Arellano and Bover (1995), it can be shown that under the assumption of stationarity, lagged differences of the variables in the levels equation are uncorrelated with the fixed effect. This yields additional moment restrictions for GMM estimation. The use of

\footnotetext{
${ }^{5}$ This is appropriate if the notransformed arror term is serialy uncorrelated. For andogenous variables, $t-2$ and earlier lags are velid instruments, while for predetermined variables we can use $t-1$ and earlier. Exogenous variables can instrument themsel wes.
} 
Both the moment restrictions based on the differenced specification as well as those resulting from the levels equation leads to the so-called System GMM estimator. The GMM estimator of Blundell and Bond (1998) is implemented in this chapter.

As discussed in Chapter 2 and above, the Euler equations are intertemporal marginal conditions of optimality and are derived under the assumption that adjustment is optimal in adjacent periods. Therefore they only apply to observations where firms adjust in two consecutive periods, which implies that the estimation of equations (6.6) and (6.7) needs to be restricted to the subsample where firms adjust in two adjacent years. Moreover, as also discussed in Chapter 2, since the decision to adjust factor levels in these models is endogenous, using this subsample is likely to result in biased estimates. Firms with higher adjustment costs are less likely to adjust, and therefore, estimates of adjustment costs should be biased downwards when using the subsample where adjustment is non-zero. In Section 6.4 summary statistics with respect to the different adjustment regimes are presented, which provide evidence of the extent of censoring and how this is correllated between investment and labour adjustment. Section 6.5 investigates the impact of sample selection bias on the estimation results.

\subsection{Data and summary statistics}

To ensure that the results reflect underlying economic differences, two comparable data sets are used that span the period from 1992 to 2000 . The German data is sourced from the Mannheim Innovation Panel (MIP), collected by the Centre for European Economic Research (ZEW) in Mannheim, Germany, while the Dutch data combines the Investment Statistics (IS) and

Production Statistios (PS) administered at Statistics Netherlands (CBS) by the Center for Research of Economic Microdata (CEREM). The German data set is at the firm-level consisting of mostly single location operations, 
while the Dutch data is at the plant-level. ${ }^{6}$ The sample of the MP is based on a stratified random sample and firms participate voluntarily in the survey. On average between 2000 and 2500 firms respond each year, whough attrition rates have been high. In the Netherlands, as mentioned in Chapter 3, firms are required by law to participate in the surveys, which explains why the Dutch sample is much larger than the German sample. The focus is exclusively on firms in the manufacturing sector. ${ }^{7}$ Both data sets indude information on annual investment, though this is restricted to non-negative values, employment level, total labour costs and sales. A measure for the capital stock is available in the MIP and this is used in the first year as a starting value, with capital for the remaining years constructed using the perpetual inventory method. In the case of the Dutch data, a measure for capital stock is not available. Therefore, for each firm five years of reported investment are used to construct a capital stock proxy as described in Letterie and Pfann (2003) and in the appendix to Chapter $3^{8}$ In terms of employment, since only levels are observed, the changes in employment are net. Furthermore, only total employment is considered as full- and part-time workers are not separately identified in the Dutch data. Finally, investment and capital stock are deflated by the two-digit sector-level price index for investment goods, and sales are deflated by the two-digit producer price index."

The following summary statistics provide a preliminary indication of sample characteristics, and in particular, of the rates of capital and labour adjustment. As seen in Table 6.2, the average (median) annual investment for German firms is 8 (0.8) million Deutsche Mark (DM), and for their Dutch coun-

\footnotetext{
SSee www zew de and Janz, Ebling, Gottschalk, and Niggemann (2001) for wone information on the MIP. See www wabs.m and Chapter 3 for more information on the IS and PS.

${ }^{7}$ The samples consist of establishnents in sectors 15 to 36 according to the NACE Rev. 1 classification.

${ }^{8}$ For this exercise, 1987 was taken as the first year of observation for each firm, unless a firm enters the panel in a later year, in which case the first observation is the year in which it enters.

The base-year is 1995. See the German Statistical Office, www.destatis.de, and the CBS, www.cbs.n.l, for more information regarding the German and Dutch sector-lewel time series data.
} 
Table 6.2: Summary statistics

\begin{tabular}{|c|c|c|c|c|c|c|}
\hline & \multicolumn{3}{|c|}{ Germany } & \multicolumn{3}{|c|}{ Netherlands } \\
\hline & mean & std. dev. & median & mean & std. dev. & median \\
\hline cotall investment & 8.04 & 55.79 & 0.80 & 2.96 & 27 & 0.44 \\
\hline eniployment & 474 & 1997 & 91 & 151 & 807 & 61 \\
\hline sales $^{\text {a }}$ & 148.55 & 713.48 & 17 & 59.4 & 293 & 14.5 \\
\hline$I / K$ & 0.180 & 0.186 & 0.125 & 0.068 & 0.083 & 0.044 \\
\hline$H / L$ & -0.015 & 0.204 & 0 & -0.013 & 0.142 & 0 \\
\hline$Y / K^{b}$ & 6.521 & 18.925 & 3.026 & 2.573 & 8.571 & 1.399 \\
\hline$Y / L^{\mathrm{e}}$ & 253.38 & 428.17 & 179.72 & 311.74 & 405.79 & 226.08 \\
\hline wage & 62.825 & 39.563 & 59.503 & 63.360 & 20.058 & 62.267 \\
\hline no, of obs. & 18,147 & & & 25,109 & & \\
\hline
\end{tabular}

${ }^{2}$ Millions of DM for German firms; millions of NLG for Duteh firms.

b Real sales per unit of capital stock.

- Thousands of DM and NLG per worker for German and Dutch firms, respectively, and includes all labour costs such as social security contributions and bonuses.

terparts it is considerably lower at 3 (0.44) million Dutch guilders (NLG). ${ }^{10}$ The data also show that the German fims are on average larger in terms of employment and sales, though the medians are more comparable. The investment statistics translate to an average (median) annual investment rate of $18.0 \%$ (12.5\%) for German firms and $6.8 \%$ (4.4\%) for Dutch frms. The German results are larger than typically found in micro data for other conntries, though this figure still includes outliers that are later dropped for estimation. Moreover, this iss consistent with the ligher growth rates of the manufacturing sector in Germany as displayed in Table 6.1." The labour adjustment rate is slightly below zero for both countries, showing that on average German and Dutch firms have been downsizing in terms of employment over this

\footnotetext{
${ }^{10}$ The conversion rate is $1 \mathrm{DM}=1.12674 \mathrm{NLG}$.

${ }^{11}$ However, differences in the construction of the capital stock measure could also play a role here.
} 
period. $^{12}$

The summary statistics in Table 6.2 also show that the average capital productivity is higher in German firms, while the average labour productivity is higher in the Dutch sample. Differences in the sectoral distribution may be one cause of this variation. In the German sample the largest sector is the machinery industry with around $18 \%$ of observations, followed by the metal products and rubber and plastic goods industries with around $12 \%$ and $8 \%$. In the Dutch sample the machinery and metal products are the dominant industries, with $14 \%$ and $15 \%$ of the observations. However; the food industry and publishing and printing are also strongly represented with $13 \%$ and $10 \%$. Finally, the annual labour costs per worker are higher on average in Germany, which is consistent with the stronger union wage demands in this country. ${ }^{13}$

In. Figures 6.1 and 6.2 the distributions of the investment rate for the German and Dutch samples are compared. Consistent with the summary statistics in Table 6.2, the observations in the Dutch sample are much more concentrated at the lower end of the distribution than is the case with the German data, which are more dispersed. As illustrated in Figures 6.3 and 6.4, both distributions for the labour adjustment rate are centred around zero but in the German case the observations are again somewhat more dispersed.

The percentage of observations where firms do not adjust provides an indication of the importance of censoring in capital and labour adjustment. Table 6.3 shows that investment in the German data is zero in almost $10 \%$ of investment observations. In the case of labour adjustment, the rate of censoring is higher; in over $15 \%$ of observations, German firms are not adjusting their stock of employment. In comparison, Dutch firms adjust capital more often with only about $4 \%$ of observations where investment is zero. Surprisingly, labour adjustment is carried out less frequently in the Dutch sample with about $18 \%$ of observations for zero labour adjustment. However, the

\footnotetext{
${ }^{12}$ For the sample used for estimation, outliers where the labour adjustment rate is below $-100 \%$ were dropped, as well as other observations which were deened to be exceptional.

${ }^{13}$ Using the conwersion rate $1 \mathrm{DM}=1.12674 \mathrm{NLG}$, the average labour cost per worker in the Netherlands is DM 56,233 .
} 
Figure 6.1: Investment rate distribution (Germany)

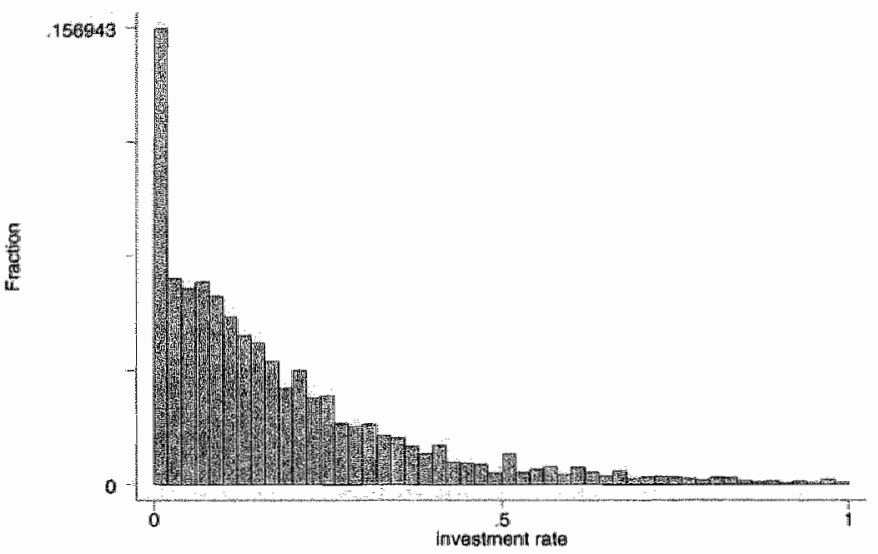

Figure 6.2: Investment rate distribution (Netherlands)

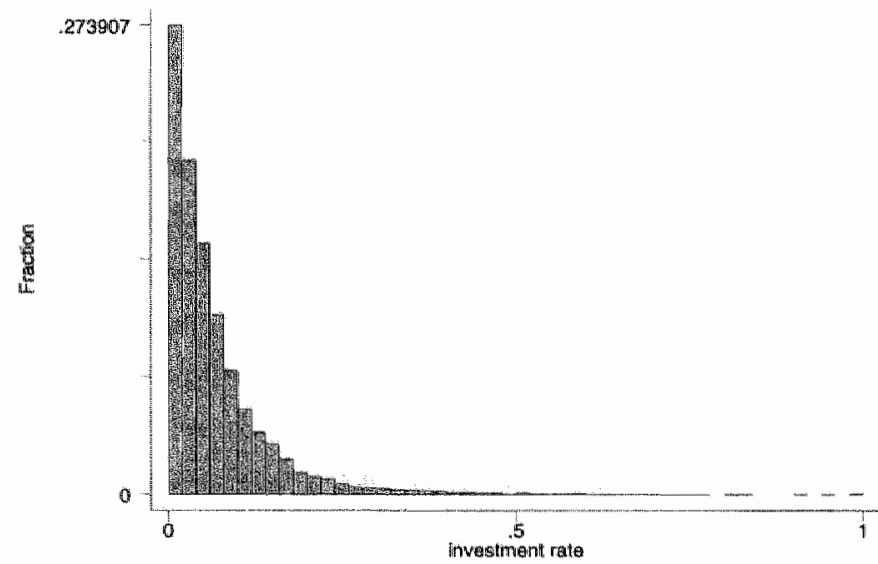


Figure 6.3: Labour adjustment rate distribution (Germany)

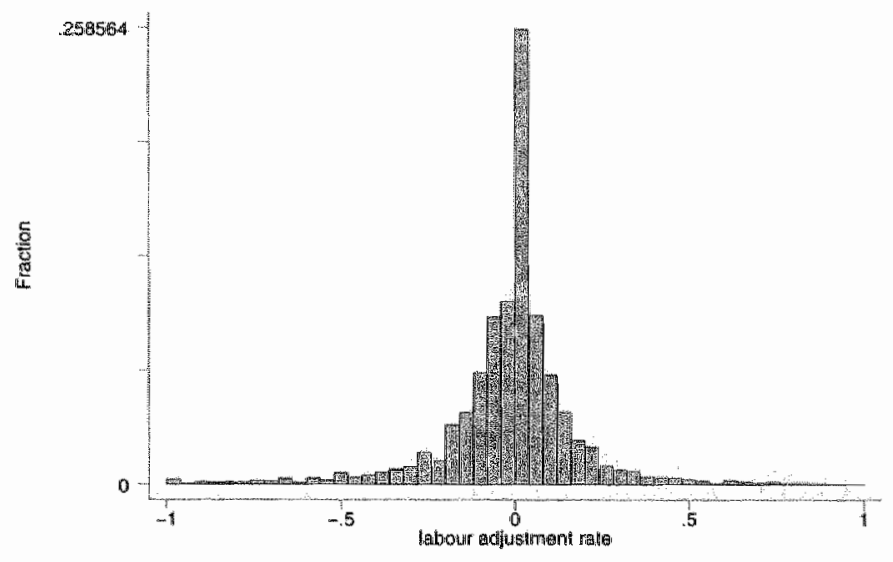

Figure 6.4: Labour adjustment rate distribution (Netherlands)

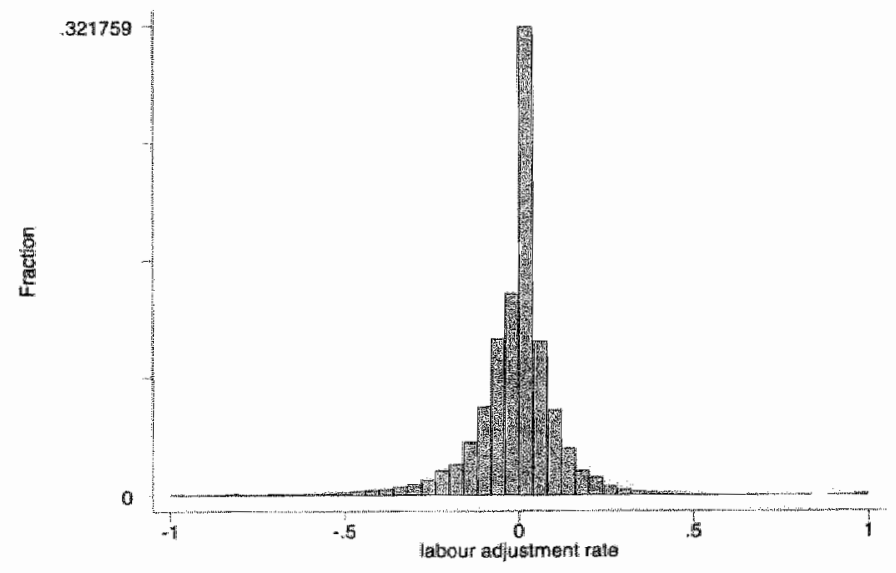


Table 6.3: Censoring of investment and labour adjustment rates

\begin{tabular}{lcc}
\hline & Germany & Netherlands \\
\hline$(I / K)_{t}=0$ & 9.75 & 4.23 \\
$(I / K)_{t}=0,(I / K)_{t-1}=0$ & 10.04 & 6.14 \\
$(H / L)_{t}=0$ & & \\
$(H / L)_{t}=0,(H / L)_{t-1}=0$ & 27.12 & 1.28 \\
\hline
\end{tabular}

vate of censoring in the Dutch case is driven by a high percentage of zero adjustment in 1995 to 1997 where the rate is approximately $25 \%$ of observations. The average for the other years is around $13 \%$. In contrast, the rate of censoring in the German data is relatively constant, over the whole period.

These results are primary evidence that frms adjust capital stock more often than their employment levels. In terms of the literature on non-convex adjustment costs, this implies that these costs are higher for labour than for capital. This is contrary to what is typically assumed in theoretical models where labour is fully flexible and capital is (quasi-) fixed. ${ }^{14}$ The differences in censoring are so large that this claim is likely to remain valid even if gross employment flows were olbserved. Together with the evidence displayed in Figures 6.1 to 6.4, Dutch firms can be seen to carry out smaller investments, but invest mone frequently. This suggests that German firms incur higher fixed costs for capital adjustment, or altermatively, Dutch fims face larger convex costs so that it is beneficial for them to spread investments over time. Labour adjustments in the Dutch data are also smaller and occur less frequently than in the German data This runs counter to the idea that the German firms are less flexible with respect to employment adjustment as angued above in Section 6.2. However, as already noted in that section, the

\footnotetext{
${ }^{14}$ However, as noted in Chapters 2 and 5 aggregation over different capital goods with different degrees of nonwourex costs is likely to prevent investment from becoming truly zero.
} 
Table 6.4: Adjustment regimes

\begin{tabular}{cccc}
\hline \hline Germany & Netherlands \\
\hline$>0$ & $H / L$ & $\%$ & $\%$ \\
\hline$>0$ & $\neq 0$ & 79.33 & 80.52 \\
$>0$ & $>0$ & 38.22 & 36.62 \\
$>0$ & $<0$ & 41.12 & 43.89 \\
$>0$ & $=0$ & 14.15 & 15.47 \\
$=0$ & $\neq 0$ & 5.19 & 3.11 \\
$=0$ & $>0$ & 2.01 & 1.07 \\
$=0$ & $<0$ & 3.19 & 2.03 \\
$=0$ & $=0$ & 1.31 & 1.00 \\
\hline \hline
\end{tabular}

availability of part-time and temporary workers plays an important, role in the Netherlands, which enables the Dutch firms to adjust their workforce without hiring or firing permanent employees. Unfortunately, these types of secondary workers cannot be identified in the data.

As mentioned in Section 6.3, the estimation sample for the Euler equam tions only consists of those observations where firms adjust in two consecutive periods. This selection results in a censoring of observations where adjustment is zero in either the current, previous or both periods. As apparent from the percentages reported in Table 6.3 , this censoring occurs in around $10 \%$ of the German sample for the investment equation, but is only about $6 \%$ in the Dutch data. In the observations for the estimation of the labour equation, almost $27 \%$ of the observations in the German case are censored in this way over the two periods, and around $30 \%$ for the Netherlands. The possible bias resulting from this sample selection is discussed in further detail in Section 6.5.4.

Another interesting aspect of the raw data is the correlation of capital and labour adjustment. If both factors face non-convex adjustment costs or (partial) irreversibility, adjustment is characterised by different regimes, sim- 
ilar to the model of Dixit (1997) who assumes kinked-linear adjustment costs. As displayed in Table 6.4, the similarity of the distribution of the observations over the regimes in the two samples is striking. The proportion of cases Where firms adjust both capital and labour is about $80 \%$ of observations in both the German and Dutch samples. This shows that adjustment is mostly simultaneous, which supports the argument of interrelated adjustment in the theoretical model. Furthermore, for both countries some heterogeneity is observed with respect to the direction of labour adjustment when firms invest. Given that a frm invests, negative labour adjustment is slightly more likely than positive adjustment to employment, and hence, firms invest while simultaneously downsizing their workforce. This heterogeneity is also reflected in the observations where firms do not invest but adjust employment, although this occurs much less frequently. ${ }^{15}$ Finally, firms do not adjust either factor in only around 1\% of observations. This means that in both samples firms almost always adjust the capital stock or employment level.

\subsection{Results}

The investment and labour adjustment equations (6.6) and (6.7) are estimated separately using the subsample where firms make non-zero adjustments to capital and employment in two adjacent periods. The Blundell-Bond System GMM estimator for dynamic linear panel data models (Blundell and Bond 1998) is implemented using Ox, version 3.30 (Doornik 2002), and the DPD packge, version 1.21 (Doonik, Arellano, and Bond 2002). Standard exrors are robust to heteroskedasticity and corrected for finite sample bias using the correction by Windmejer (2000).

\footnotetext{
15Fhese statistics can also be compared to those obtained for the full Dutch sanple period 1984 to 2000 in Chapter 3, Table 3.6, where it is found that positive labour adjustment is shightly more likely than negative adjustment. In addition, accounting for the fact that investment may serve replacement only, the results there indicate that in the case of expansion investments complementarity of labour and capital is more likely than substitution.
} 


\subsubsection{Investment equation}

The results for the investment rate equation (6.6) are displayed in Table 6.5. Columns (1) and (3) report the estimates for the German and Dutch samples without controling for sample selection bias. The results for the specification with the sample selection correction are discussed in Section 6.5.4.

For the German sample as denoted in column (1) of Table 6.5, the coeificient on the lagged dependent variable is positive and significant at the $1 \%$ level. This indicates that there is substantial positive state dependence in investment, which implies that German firms spread investment over a longer period. The quadratic term is negative and significant suggesting that the effect of the investment rate in the last period is positive but declining. The investment rate is increasing with the average product of capital in the previous period. The price index for capital goods in both the current perod and its lag are insignificant, which is likely to result from the lack of variation in the sector-level price index. There is no evidence of interrelation between the investment rate and changes to employment in the current and previous period. The Sargan test statistic does not reject the validity of the instruments, and there is no indication of second-order autocorrelation.

Column (3) of Table 6.5 reports the results for the Dutch sample. As with the German estimates, there is evidence of positive but declining state dependence, though the coefficients are of a smaller magnitude. This indicates that Dutch firms concentrate investment more than their German counterparts. Investment is again increasing with the average product of capital in the previous period. In contrast to the German results, the coefficients on the price index for capital goods and its lag are significant at the $5 \%$ level. They indicate that investment is negatively correlated with the current price but positively correlated with the price in the previous period, which suggests that firms delay investment to the current year when prices are higher in the previous one. Though not found in the German sample, there is some evidence in the Dutch results of a positive relation between the investment rate and net employment adjustment in the previous period. However, in terms 
Table 6.5: Estimation results Fuler equation (capital)

\begin{tabular}{|c|c|c|c|c|}
\hline & \multicolumn{2}{|c|}{ Germany } & \multicolumn{2}{|c|}{ Netherlands } \\
\hline & (1) & (2) & (3) & (4) \\
\hline \multirow[t]{2}{*}{$(I / K)_{i t-1}$} & 0.404 & $0.411 * *$ & $0.111 * *$ & 0.064 \\
\hline & $(0.091)$ & $(0.092)$ & $(0.052)$ & $(0.067)$ \\
\hline \multirow[t]{2}{*}{$(I / K)_{i L-1}^{2}$} & $-0.386^{2}$ & 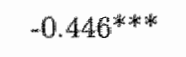 & -0.150 & -0.142 \\
\hline & $(0.118)$ & $(0.152)$ & $(0.150)$ & $(0.141)$ \\
\hline \multirow[t]{2}{*}{$(Y / K)_{i, t-1}$} & $0.005^{3} x^{2}$ & $0.003^{\text {水将 }}$ & 0.007 * & 0.002 \\
\hline & $(0.002)$ & $(0.001)$ & $(0.002)$ & $(0.004)$ \\
\hline \multirow[t]{2}{*}{$p_{i t}$} & 0.032 & 0.021 & $-0.003^{* *}$ & $-0.013^{*}$ \\
\hline & $(0.055)$ & $(0.033)$ & $(0.001)$ & $(0.007)$ \\
\hline \multirow[t]{2}{*}{$p_{i, t-i}$} & -0.032 & -0.021 & $0.012^{*}$ & 0.037 \\
\hline & $(0.056)$ & $(0.033)$ & $(0.006)$ & $(0.024)$ \\
\hline \multirow[t]{2}{*}{$H_{i t}$} & $-4.37 e-08$ & $3.71 \mathrm{e}-04$ & $-1.04 \mathrm{em} 05$ & $3.290-04$ \\
\hline & $(7.35 \mathrm{e}-06)$ & $(3.17 \mathrm{e}-04)$ & $(1 . .53 \mathrm{e}-0.5)$ & $(2.00 \mathrm{e}-04)$ \\
\hline \multirow[t]{2}{*}{$H_{i, t-1}$} & $5.99 \mathrm{e}-07$ & $1.04 \mathrm{e}-04$ & $5.41 \mathrm{e}-00^{*}$ & $5.08 \mathrm{e}-05$ \\
\hline & $(1.00 \mathrm{e}-05)$ & $(1.05 \mathrm{e}-04)$ & $\left(3.00 \mathrm{e}-06^{2}\right)$ & $(6.32 \mathrm{e}-0.5)$ \\
\hline \multirow[t]{2}{*}{$\lambda_{k i t}$} & - & 0.007 & - & .0 .018 \\
\hline & & $(0.032)$ & & $(0.040)$ \\
\hline instruments $^{a}$ & $t-2, t-3$ & $t-2-t-4$ & $t-2, t-3$ & $t-2, t-3$ \\
\hline Sargan test & 44.33 & 53319 & 70.90 & 79.35 \\
\hline AR(1) test & -6.008 * & 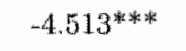 & $-11.99 * * *$ & $-4.650 * *$ \\
\hline $\mathrm{AR}(2)$ test & -0.440 & -1.448 & 1.375 & -0.357 \\
\hline no. of obs. & 2646 & 1792 & 8799 & 5420 \\
\hline
\end{tabular}

Dependent warable is $I / K$. Two-step results from the Blundel-Bond GMM Estimaton are reported. *** - signifieant at 1\% * - at $5 \%$; and $*-10 \%$ level. Monetary variables are in thousands of DM or NLG, and real. Specifications for both countries indude year dummes and a dummy for East Germany is included in the German specification. $a$ - Variables in levels used as instruments for transformed equations: $I / K,(I / K)^{2}$, and $Y / K$ (German sumple): $I / K,(I / K)^{3}, Y / K, H$, and current and lagged $p$ (Duteh sample). Variables in differences used as instruments for level equations: $I / K$, $(I / K)^{3}, Y / K$, and dummies (German sample); $I / K,(I / K)^{2}, Y / K, H$, and dummies (Dutch sample). Standard errors are reported in parentheses. 
of the magnitude of the coefficient, the effect of this interrelation term on the investment rate is negligible. The validity of the instruments and the absence of second-order autocorrelation are also not rejected in the Dutch sample.

As discussed in Section 6.2 one expects to see fewer differences in the dynamics of investment in the two countries than in labour adjustment. The results from columms (1) and (3) show that, while the investment behaviour is indeed similar, German firms spread their investments more over time. This indicates that German frms incur higher convex adjustment costs for capital than the Dutch businesses. However, the summary statistics in Section 6.4 reveal that in certain periods investment is zera, which is only consistent with some form of non-convexity in adjustment costs or partial irreversibility. Therefore, the results from both the discrete decision to invest and the continuous decision regarding the investment rate suggest that firms face both convex and non-convex adjustment costs, which is consistent with the assumptions of the model. All estimated coefficients on the current and lagged employment changes are of a negligible magnitude, and the only significant interrelation tem is the lagged employment change in the Dutch case. Hence, there is no evidence that changes in the employment level affect capital adjustment. Consequently, there is no indication that differences in the employment dynamics between the two countries are reflected in the investment profile.

\subsubsection{Labour adjustment equation}

The estimation results for the labour adjustment equation (6.7) are displayed in Table 6.6. As in the case of inwestment, the estmates for the German and Dutch samples without controlling for sample selection bias are reported in column (1) and (3). The German results indicate that in contrast to investment, there is evidence of negative state dependence. This is an indication. of high non-convex adjustment costs. In this case periods of intensive adjustment are alternated with periods of inaction, leading to a regative serial correlation in the labour adjustment rate. Although the "zeroes" have 
been elminated from the estmation, it is well possible that this argument still holds. Instead of alternating periods of heavy adjustment with inaction, firms may altemate heavy adjustment with periods of only moderate adjustment. That is, athough fixed costs play a role in the dynamics of labour, the theoretical prediction of actual zero adjustment may empirically turn out to be too restrictive. A first reason for this is that the data concern net employment changes. Within the time span of a year it is not unlikely that some employees guit or retire. This is a natural way for firms to downsize without having to lay-off workers. Thus, even if a firm does not fire workers, the net change in employment from year to year may not be exactly zero. In addition, worker heterogeneity may play a role here. High-skilled workers are often hited on an individual basis, rather than 'en gros'. Such incidental hirings can also prevent annual employment changes from being zero. A pattern of periods with intensive adjustment followed by periods of low adjustment will still lead to negative autocorrelation in the net hirings series "see e.g. Cooper, Haltiwanger, and Willis (2004).

The insignificance of the labour cost variables as also reported in Table 6.6 could reflect the wage rigidity resulting from the high degree of unionisation in Germany. The coefficient on the current, investment level is negative and significant at the $10 \%$ level, while the coefficient on the lagged variable is positive but not significant. The negative sign is consistent with the high percentage of observations in the regime with $I / K>0$ and $H / L<0$ given in "Table 6.4. However, simillar" to the effects of interrelation in the investment. equation, the coefficients are very small. The other coefficients are insignificant, and therefore, according to this specification, it is state dependence that largely drives current labour adjustment in German firms. The validity of the instruments and the absence of second-order antocorrelation are not rejected.

The estimates for the Dutch sample are compiled in column (3) of Table 6.6, and in contrast to the Garman results, there is evidence of positive state dependence. Hence, although the coeficient is small, Dutch firms spread the 
Table 6.6: Estimation results Euler equation (1abour)

\begin{tabular}{|c|c|c|c|c|}
\hline & \multicolumn{2}{|c|}{ Germany } & \multicolumn{2}{|c|}{ Netherlands } \\
\hline & (1) & (2) & (3) & (4) \\
\hline \multirow[t]{2}{*}{$(H / L)_{i, t-1}$} & $-0.133^{*}$ & $-0.160 * *$ & $0.066^{* * *}$ & 0.021 \\
\hline & $(0.069)$ & $(0.078)$ & $(0.031)$ & $(0.024)$ \\
\hline \multirow{2}{*}{$(H / L)_{i, t-1}^{2}$} & -0.083 & -0.069 & 0.103 & 0.021 \\
\hline & $(0.140)$ & $(0.157)$ & $(0.074)$ & $(0.055)$ \\
\hline \multirow[t]{2}{*}{$(Y / L)_{i, t-1}$} & $1.21 \mathrm{e}-05$ & $1.03 \mathrm{e}-06$ & 3.520 .05 & $4.62 \mathrm{e}-05 *$ \\
\hline & $(2.85 e-05)$ & $(2.28 \mathrm{e}-05)$ & $(2.510=05)$ & $(1.94 \mathrm{em} 05)$ \\
\hline \multirow[t]{2}{*}{$w_{\text {it: }}$} & $1.74 \mathrm{e}-04$ & $3.78 \mathrm{e}-04$ & $-0.006^{3}$ & 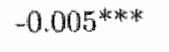 \\
\hline & $(5.90 \mathrm{e}-04)$ & $(6.40 \mathrm{e}-04)$ & $(0.000)$ & $(4.70 \mathrm{e}-04)$ \\
\hline \multirow[t]{2}{*}{$w_{i, t-1}$} & $3.52 \mathrm{e}-04$ & $4.410-04$ & $0.004^{* 2 * 2 *}$ & 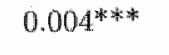 \\
\hline & $(3.25 e-04)$ & $(3.72 \Theta-04)$ & $(0.001)$ & $(0.001)$ \\
\hline \multirow[t]{2}{*}{$I_{i t}$} & $-9.15 \mathrm{e}-07^{*}$ & $-7.29 \mathrm{e}-07^{*}$ & $-7.71 \mathrm{e}-08$ & $-7.84 \mathrm{em} 08$ \\
\hline & $(4.780-07)$ & $(5.08 \mathrm{e}-07)$ & $(7.26 \mathrm{e}-08)$ & $(7.42 \mathrm{e}-08)$ \\
\hline \multirow[t]{2}{*}{$I_{i_{\mathrm{r}} t-1}$} & $1.71 \mathrm{e}-06$ & $1.30 \mathrm{e}-06$ & $1.05 \mathrm{e}-07^{* * *}$ & $7.43 \mathrm{e}-08^{* * *}$ \\
\hline & $(1.05 e-06)$ & $(1.12 e-06)$ & $(4.60008)$ & $(3.41 \mathrm{e}-08)$ \\
\hline \multirow[t]{2}{*}{$\lambda_{\text {lit }}$} & - & 0.021 & - & 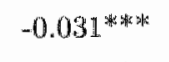 \\
\hline & & $(0.024)$ & & $(0.010)$ \\
\hline instruments ${ }^{a}$ & $t-2 t-3$ & $t-2, t-3$ & $t-2, t-3$ & $t-2, t-3$ \\
\hline Sargan test. & 62.37 & 62.90 & 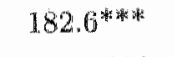 & $126.0^{2}$ \\
\hline AR(1) test & $-4.229^{* * * * *}$ & 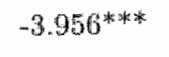 & $-12.566^{2}$ & $-12.43^{* * * * * 3}$ \\
\hline AR (2) test & -1.197 & -1.038 & 0.527 & -1.005 \\
\hline no. of abs. & 1402 & $129 \pi$ & 11,659 & 8517 \\
\hline
\end{tabular}

Dependent wariable is $H / L$. T wo-step results from the BIndel-Bond GMM Estimator are reported.** - significant at $1 \% * *$ - at $5 \%$; and $-10 \%$ level. Monetary variables are in thousands of DM or $\mathrm{NLG}$, and real. Specifications for both countries include year dummies and a dummy for East. Germany is included in the Gerran specification. a - Variables in levels used as inetruments for transformed equations: $H / L, H / L^{2}, Y / L$, $u$, and $r$. Variables in differences used as instriments for level equations: $H / L, H / L^{2}$, $Y / L, w_{2} I$, and dummies. Standard errors are reported in parentheses. 
adjustment of employment over time. Moreover, though not present in the German results, the coefficient on the per worker wage in the current period is negative and significant. The sign reverses for the lagged value, which suggests that firms delay adjustment to employment to the current period when labour costs are higher than in the previous one. The signs of the coefficients for the current and previous level of investment are the same as in the German sample, negative and positive, respectively, but only the lagged variable is significant. The coefficient estimates are also very small and imply that an increase in investment in the previous period has a positive, but only marginal, impact on the labour adjustment rate in the current period. With respect to the specification tests, there is no evidence of second-order autocorrelation. However, although the same instrument set is used as in the German specification, the Sargan test statistic points to a rejection of the validity of these instruments. To investigate if this rejection results from a particular instrument, the sensitivity of the Sargan test statistic to various instrument sets was checked and the rejection is lound in all specifications. One reason for the rejection of the instrument validity could be sample selection bias, which is investigated in the next section. Atternatively, simplifying assumptions in the theoretical model may lead to rejection in the Dutch subsample. ${ }^{16}$

Unlike the summary statistics in Section 6.4, these results illustrate that the dynamics of labour adjustment in the two countries differ. Furthermore, the finding that labour adjustment is more responsive to changes in wages and capital stock is consistent with the more flexible labour market in the Netherlands versus the stricter regulations in Germany. Similar to the results for investment, the combination of descriptive statistics and the estimation results for labour adjustment reveal that firms in both countries are likely to incur both conwex and non-convex costs when adjusting the level of employ-

\footnotetext{
${ }^{4}$ It is not turcommon in the Euler equation approach that overidentifying restrictions are rejected, see e.g. Whited (1998). Bond and Meghir (1994), and Shapiro (1986). In particular, allowing for asymmetric adjustment costs appears a valuable extension in this context, see Pfann and Palm (1993).
} 
ment. As argued above, the negative state dependence for Gamany suggests that, non-convex costs appear to be higher in the Geman case.

\subsubsection{An alternative specification for interrelation}

The identification of interrelation relies on the specifications of equations (6.6) and (6.7), and in particular, how interrelation enters the adjustment cost function (6.3). As presented in Section 6.3, the effect of interrelation on adjustment costs is assumed to be in levels, though the dependent and other explanatory variables are stated in rates. This may result in that the variables that are supposed to capture interrelation possibly also pick up scale effects. Therefore, to check the walidity of the levels assumption, equations (6.6) and (6.7) are re-estimated using the interrelation terms in rates instead of in levels, though such a specification cannot be derived from a structual. model. That is, the changes in lagged and current employment $H_{\text {it }}$ and $H_{i, t-1}$ in the investment equation (6.6) are replaced by $(H / L)_{\text {it }}$ and $(H / L)_{i_{2} t-1}$, and likewise, $(I / K)_{i t}$ and $(I / K)_{i, t-1}$ are used instead of the investment levels $I_{i t}$ and $I_{i, t, 1}$ in the labour demand equation $(6,7)$. The results are reported in Tables 6.7 and 6.8 .

Interestingly, when the interrelation tems in the investment equation. are specified in rates, both the current and lagged labour adjustment ratic are significant for Germany. The coefficient estimates are respectively 0.171 and 0.124 , implying quite strong interrelation. For example, if employment increases with $10 \%$, investment goes up by $1.7 \%$ in the current year, and with an additional $1.2 \%$ in the next. In contrast, there is no evidence that the labour adjustment rate affects investment in the Dutch sample. On the other hand, Table 6.8 shows that the lagged investment rate significantly affects the labour adjustment rate in the Dutch case. The estimated coeficient; of 0.097 , implies that employment goes up by $1 \%$ for each $10 \%$ increase in investment. The fact that in this specification there is evidence that the German firms take labour costs into account when making the investment decision -... While there is no evidence for this in the Dutch sarmple - - is 
Table 6.7: Estimation results with interrelation in rates (capital)

\begin{tabular}{lcc}
\hline & Gernany & Netherlands \\
\hline$(I / K)_{i, t-1}$ & $0.403^{* * *}$ & 0.063 \\
& $(0.106)$ & $(0.046)$ \\
$(I / K)_{i, t-1}^{2}$ & $-0.336^{*}$ & -0.046 \\
& $(0.198)$ & $(0.117)$ \\
$(Y / K)_{i, t-1}$ & $0.004^{* *}$ & $0.007^{* * *}$ \\
& $(0.002)$ & $(0.001)$ \\
$p_{i t}$ & -0.007 & -0.0016 \\
& $(0.041)$ & $(0.001)$ \\
$p_{i, t-1}$ & 0.008 & 0.002 \\
& $(0.041)$ & $(0.009)$ \\
$(H / L)_{i t}$ & $0.171^{*}$ & 0.045 \\
& $(0.096)$ & $(0.057)$ \\
$(H / L)_{i, t-1}$ & $0.124^{* *}$ & 0.006 \\
& $(0.052)$ & $(0.007)$ \\
\hline instruments ${ }^{\alpha}$ & $t-2, t-3$ & $t-2, t-3$ \\
Sargan test & 48.29 & 85.83 \\
AR(1) test & $-7.184^{* * *}$ & $-13.43^{* * *}$ \\
AR(2) test & -1.723 & 1.727 \\
\hline no. of obs. & 2443 & 10.779 \\
\hline \hline
\end{tabular}

Dependent wariable is $\mathbb{I} K$. Two-step results from the Blundell-Bond GMM Jstimator are reported. ${ }^{*}$ * significant at $1 \%$; - at $5 \%$; and $-10 \%$ lavel. Monetary variables are in thousands of DM or $\mathrm{NLG}$ and real. Specm Ifications for both countries include year dummies and a dummy for East Germany is included in the German specification, $a$-Variables in levels used as instruments for transformed equations: $I / K,(I / K)^{2}$, and $Y / K$ (Germen sample): $/ / K,(I / K)^{2}, Y / K, H / L$, and current and lagged $p$ (Dutch sample). Variables in differences used as instruments for level equations: $I / K$, $(I / K)^{3}, Y / K$, and dummies (German sample); $I / K,(I / K)^{2}, Y / K, H / L$, and dummies (Dutch sample). Standard errors are reported in parentheses. 
Table 6.8: Estimation results with interrelation in rates (labour)

\begin{tabular}{|c|c|c|}
\hline & Germany & Netherlands \\
\hline \multirow{2}{*}{$(H / L)_{i, t-1}$} & $-0.169^{*} * *$ & $0.065^{*}$ \\
\hline & $(0.060)$ & $(0.028)$ \\
\hline \multirow[t]{2}{*}{$(H / L)_{i, t-1}^{2}$} & -0.120 & 0.033 \\
\hline & $(0.126)$ & $(0.053)$ \\
\hline \multirow[t]{2}{*}{$(Y / L)_{i, t-1}$} & $7.68 \mathrm{e}-05$ & $2.32 \mathrm{e}-0.5$ \\
\hline & $(292 e-05)$ & $(3.33 \mathrm{e}-05)$ \\
\hline \multirow[t]{2}{*}{$w_{i t}$} & $5.72 e-04$ & $-0.006 * * *$ \\
\hline & $(7.790-04)$ & $(0.000)$ \\
\hline \multirow[t]{2}{*}{$w_{i, t}, i$} & $6.90 e-04^{*}$ & $0.006 * * *$ \\
\hline & $(3.98 e-04)$ & $(0.001)$ \\
\hline \multirow[t]{2}{*}{$(I / K)_{i t}$} & 0.136 & 0.155 \\
\hline & $(0.344)$ & $(0.190\rangle$ \\
\hline \multirow[t]{2}{*}{$(I / K)_{i, k-1}$} & 0.023 & $0.097^{7 * *}$ \\
\hline & $(0.123)$ & $(0.033)$ \\
\hline instruments ${ }^{a}$ & $t-2, t-3$ & $t-2, t-3$ \\
\hline Sargan test: & 59.92 & $139.2^{*}$ \\
\hline AR(1) test & $-4.217^{* * * * *}$ & $-11.52^{*} * *$ \\
\hline AR(2) testo & $-1,099$ & 0.135 \\
\hline no. of obs. & 1219 & 8024 \\
\hline
\end{tabular}

Dependent, variabie is H/L. Two-step resulte from the Bluradi-Bond GMM Estimator are reported. ${ }^{*}$ - significart at $1 \%$ - at $5 \%$, ard * 10\% level. Monetary variables are in thousands of DM or NLG, and real. Specifications for both countres inchude year dumming and a dummy for East Germany is inchded in the German specification. a - Varables in levels used as instruments for tranformed equations: $H / L, H / L_{3}^{2}, Y / L, w$, and $I / K$. Varables in differences wased as instrumenta for level oquations: $H / L, H / L^{2}, Y / L, z, I / K$, and dumming Standard errors ate roporhe in penentheses. 
another indication of the higher adjustment costs to labour in Germany. That labour is affected by investment in the Netherlends shows that this input is more flexible in this country. Finally, given that these results are intuitively appealing, the specification of the cross-terms in levels in the theoretical model does not appropriately capture interrelation, and a more general model may be needed to properly identify the correlation between the dynamic adjustment of factors.

\subsubsection{Sample selection bias}

In this section the effect of selection bias on the results is discussed, an important issue that has not received much attention in this literature. As clear from the summary statistics in Section 6.4 , there are a significant number of observations in the datia where investment or labour adjustment is zero. In estimating equations (6.6) and (6.7), only those observations are used where a firm adjusts its level of an input factor in two consecutive periods. As discussed in Section 6.3, this introduces the problem of sample selection. bias since the conditioning event is endogenous. To assess the sensitivity of the results to this bias, following Aguirregabiria (1997) and Alonso-Borrego (1998), the Fuler equations are estimated using a two-step approach similar to the sample selection model of Heckman (1979). This approach involves the estimation of a probit model for both investment and labour adjustment in a first-stage, where the dependent variable is a binary indicator variable that equals one when adjustment of capital or labour is mon-zero in two consecutive years and zero otherwise. From the first-stage estimates, correction. terms are constructed as per Heckman's two-step estimator. These correction terms are an estimate of the additive bias which is the (conditional) expectation of the respective error terms given selection. This additive bias may invalidate the orthogonality conditions used in the GMM estimation. "This is solved by using the bias correction term as additional regressors in equations (6.6) and (6.7).

The results for the first-stage probit models for investment and labour ad- 
justment are reported in Tables 6.9 and 6.10. The explanatory variables are the same as those determining the size of the investment and labour adjustment rates in period $t$ and $t-1$ as per equations (6.6) and (6.7). Twice-lasged variables determine adjustment in period $t-1$ and are by assumption uncorrelated with the differenced error term $\Delta \varepsilon_{\text {mit: }}, n \in\{k, l\}$. Hence, these variables serve as natural exclusion restrictions in period t. As shown in Tables 6.9 and 6.10 , the adjustment rates and their squares in perioc $t-1$ are highiy significant in all cases. The significance of the other variables differs between the specifications. Turning to the exclusion restrictions, in the investment selection equation, as denoted in Table 6.9, the twice-lagged squared investment rate and sales-capital ratio are significant in the German sample, while the twice-lagged investment rate, its square and the price of capital goods are significant in the Dutch specification. The lagged and twice-lagged price of capital goods are not included in the German specification as these variables are highly collinear with the price in the current period. In the labour adjustment selection equation as shown in Table 6.10, the twice-lagged sales-worker ratio, per worker cost of labour and the investment level are significant in the German sample, while only the twice-lagged labour adjustment rate is significant in the Dutch specification. The significance of these exclusions restrictions is important in terms of identifying the selection bias in the estimation of the investment and labour adjustment, equations (6.6) and (6.7). However, due to the definition of the binary dependent variable there is no natural interpretation of the coefficient estimates.

Columns (2) and (4) in Table 6.5 list the results for the investment equation when the correction term $\left(\lambda_{k i t}\right)$ is added as an additional variable in the German and Dutch specifications. ${ }^{17}$ The correction term in the German sample is positive but not significant. Most parameter estimates go down, but all estimates are within one standard error of the initial oness. For the Netherlands the correction term is negative but also highly insignificant. The fact that all coefficients except the current price are insignificant in this spec-

\footnotetext{
${ }^{17}$ Standard enrors were not corrected for the use of predicted values but such a corregtion is unlikely to alter the condusions.
} 
Table 6.9: Probit results two-period selection model (investment)

\begin{tabular}{|c|c|c|}
\hline & Germany & Netherlands \\
\hline$(I / K)_{i, i-1}$ & $\begin{array}{c}10.723^{* * * *} \\
(0.893)\end{array}$ & $\begin{array}{c}13.672^{*} \\
(0.926)\end{array}$ \\
\hline$(I / K)_{i, \ell-1}^{2}$ & $\begin{array}{c}-13.080 * * \\
(1.189)\end{array}$ & $\begin{array}{c}-23.842^{* * *} \\
(1.834)\end{array}$ \\
\hline$(Y / K)_{i, t-\pi}$ & $\begin{array}{c}-0.056^{* * * *} \\
(0.011)\end{array}$ & 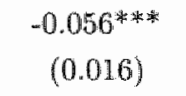 \\
\hline$p_{i t}$ & $\begin{array}{l}0.089^{*} \\
(0.046)\end{array}$ & $\begin{array}{c}0.042 \\
(0.027)\end{array}$ \\
\hline$p_{i, k-1}$ & - & $\begin{array}{c}0.033 \\
(0.043)\end{array}$ \\
\hline$H_{i t}$ & $\begin{array}{c}2.76 \mathrm{e}-05 \\
(5.62 \mathrm{e}-04)\end{array}$ & $\begin{array}{c}4.24 \mathrm{e}-05 \\
(3.24 \mathrm{e}-04)\end{array}$ \\
\hline$H_{i_{s} t-1}$ & $\begin{array}{c}3.61 \mathrm{e}-04 \\
(3.36 \mathrm{e}-04)\end{array}$ & $\begin{array}{l}-0.001 \\
(0.001)\end{array}$ \\
\hline$(I / K)_{i, t-2}$ & $\begin{array}{c}0.830 \\
(0.731)\end{array}$ & 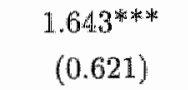 \\
\hline$(I / K)_{i, t-2}^{2}$ & $\begin{array}{c}-2.504^{*} \\
(0.990)\end{array}$ & $\begin{array}{c}-2.978 * * * \\
(0.941)\end{array}$ \\
\hline$(Y / K)_{i, l-2}$ & $\begin{array}{c}0.017^{* * *} \\
(0.007)\end{array}$ & $\begin{array}{l}-0.005 \\
(0.016)\end{array}$ \\
\hline$p_{i, t-2}$ & - & $\begin{array}{c}-0.063^{* *} \\
(0.031)\end{array}$ \\
\hline$H_{i, k-2}$ & $\begin{array}{l}-1.70 \mathrm{e}-04 \\
(2.97 \mathrm{e}-04) \\
\end{array}$ & $\begin{array}{r}-1.56 \mathrm{e}-04 \\
(3.57 \mathrm{e}-04)\end{array}$ \\
\hline no. of obs. & 2255 & 7688 \\
\hline Log Likelihood & -483.569 & -1359.87 \\
\hline
\end{tabular}

Dependent wariable is $\left.\mathcal{I}(I / K)_{i r} \neq 0,(I / K)_{i, t-1} \neq 0\right)$ where $\mathcal{I}$ is an indicator variable and equals 1 if the condition inside the parentheses is fulfilled and 0 otherwise. *** - significant at $1 \%$; ** - at $5 \%$; and ${ }^{*}-10 \%$ level. Monetary variables are in thousands of DM or NLG, and real. Specifications for both countries include yenr dummies and a dummy for East Germany is included in the German specification. Standard enrors are reported in parentheses. 
Table 6.10: Probit results two-period selection model (labour adjustment)

\begin{tabular}{|c|c|c|}
\hline & Germany & Netherlands \\
\hline$(H / L)_{i, t-1}$ & $\begin{array}{c}0.634^{\text {*3* }} \\
(0.236)\end{array}$ & $\begin{array}{c}0.800^{\text {* }} \\
(0.139)\end{array}$ \\
\hline$(H / L)_{i, t-1}^{2}$ & $\begin{array}{c}2.085^{* * *} \\
(0.486)\end{array}$ & $\begin{array}{c}3.311^{* * * *} \\
(0.329)\end{array}$ \\
\hline$(Y / L)_{i, t-1}$ & $\begin{array}{c}4.90 \mathrm{e}-0.4 \\
(4.71 \mathrm{e}-04)\end{array}$ & $\begin{array}{c}1.39 \mathrm{e}-04 \\
(1.24 \mathrm{e}-04)\end{array}$ \\
\hline$u_{i t}$ & $\begin{array}{c}4.75 e-04 \\
(0.013)\end{array}$ & $\begin{array}{c}0.004 * * \\
(0.002)\end{array}$ \\
\hline$w_{i, t-1}$ & $\begin{array}{c}0.002 \\
(0.001)\end{array}$ & $\begin{array}{c}0.005^{*} \\
(0.002)\end{array}$ \\
\hline$I_{i t}$ & $\begin{array}{l}-4.92 \mathrm{e}-06 \\
(5.08 \mathrm{e}-06)\end{array}$ & $\begin{array}{c}1.700 \mathrm{e}-05^{* * * *} \\
(2.00 \mathrm{e}-06)\end{array}$ \\
\hline$I_{i_{\mathrm{s}} t-1}$ & $\begin{array}{l}-1.61 \mathrm{e}-06 \\
(7.73 \mathrm{e}-06)\end{array}$ & $\begin{array}{c}-1.00 \mathrm{e}-06^{*} \\
(4.23 \mathrm{e}-07)\end{array}$ \\
\hline$(H / L)_{:, t-2}$ & $\begin{array}{c}0.030 \\
(0.179)\end{array}$ & $\begin{array}{l}0.220^{* *} \\
(0.102)\end{array}$ \\
\hline$(H / L)_{i, t-2}^{2}$ & $\begin{array}{l}-0.162 \\
(0.357)\end{array}$ & $\begin{array}{c}0.255 \\
(0.204)\end{array}$ \\
\hline$(Y / L)_{i_{n} t-2}$ & $\begin{array}{r}-9.08 \mathrm{e}-04^{*} \\
(4.84 \mathrm{e}-04)\end{array}$ & $\begin{array}{l}-0.001 \\
(0.001)\end{array}$ \\
\hline$w_{i, t-2}$ & $\begin{array}{l}0.004^{*} \\
(0.002)\end{array}$ & $\begin{array}{l}-0.002 \\
(0.002)\end{array}$ \\
\hline$I_{i, t-2}$ & $\begin{array}{l}424 \mathrm{e}-04 \\
(8.93 \mathrm{e}-06)\end{array}$ & $\begin{array}{l}-1.00 \mathrm{e}-06 \\
(4.24 \mathrm{e}-07) \\
\end{array}$ \\
\hline $\begin{array}{l}\text { no. of obs. } \\
\text { Log Likelihood }\end{array}$ & $\begin{array}{r}241.7 \\
-1381.701 \\
\end{array}$ & $\begin{array}{c}11,842 \\
-7170.526 \\
\end{array}$ \\
\hline
\end{tabular}

Dependent wariable is $\mathcal{I}\left[(H / L)_{\text {it }} \neq 0,(H / L)_{i, t-1} \neq 0 !\right.$ where $\mathcal{I}$ is an indicator wariable and equals 1 if the condition inside the parentheses is fulfilled and 0 otherwise. *** - significant at $1 \%$; ${ }^{*} *$ - at 5\%, and * $-10 \%$ level. Monetary variables are in thousands of DM or NLG, and real. Specifications for both countries inchude year dummies and a dummy for East Germany is inciuded in the German specification. Standard erron are reporterd in parentheses. 
ification, indicates multicollinearity problem, an issue common to sample. selection models. Nonetheless, for both samples there is no clear evidence that estimates are biased due to sample selection.

The results for the labour adjustment equation with correction for sample selection bias are denoted in columns (2) and (4) of Table 6.6. As in the case of investment, the coefficient on the correction term $\left(\lambda_{\text {lut }}\right)$ is positive and insignificant in the German sample. However, the coefficient is again negative and now also significant in the Dutch sample. Most of the Dutch results remain the same but interestingly the lagged dependent variable becomes insignificant while the average product of labour becomes significant. The Sargan test statistic still leads to a rejection of the validity of the instruments used for the Dutch results, suggesting that it is not selection bias that drives rejection of the overidentifying restrictions. ${ }^{18}$ Based on the Ger man results, howewer, there is also no indication that selection bias alters the main conclusions for labour.

As discussed in Chapter 2, the method of controlling for selection adopted here is somewhat ad hoc. This is due to the fact that the selection variable is defined over two periods, where the formulation by Heckman (1979) is based on a selection in a single period. In addition, the original two-step estimator is formulated for a static model with only exogenous regressors. Given the lack of appropriate econometric techniques, however, this approach seems justified as robustness check. In Chapter 7 the economic model is restricted to a simple partial adjustment model, so that selection can be approptiately controlled for using an Asymptotic Least Squares procedure due to Arellano, Bover, and Labeaga (1999).

\footnotetext{
${ }^{18}$ The walue of the Sargan statistin is lower than without controlling for selection, but this is largely due to the decrease in the number of observations.
} 


\subsection{Conclusion}

How firms adjust employment and capital is influenced by institutional arrangements and government policies such as labour market regulation and unionisation. This implies that the dynamics of labour and capital adjustment should also vary between countries where such constraints and policies differ. Moreover, it has long been assumed that capital is adjusted less frequently than labour. This assumption is inconsistent with the observed patterns of factor adjustment in countries where labour markets are subject to significant intervention such as in Germany, and to a lesser extent, in the Netherlands. Thus, it can expected that the differences in the labour markets in Germany and the Netherlands are also reflected in the adjustment of employment. Furthermore, factor adjustment costs at the frm-level are likely to be interrelated which means that the acjustment of one factor affects the adjustment of another. This implies that the constraints on employment are possibly translated to investment dynamics.

To address these issues, structural dynamic investment and labour adjustment equations are estimated, accounting for interrelation between the two factors. The dynamic linear System GMM estimator of Blundell and Bond (1998) is implemented to take account of the endogeneity of variables. Moreover, the impact of sample selection bits on the estmation results is addressed, an issue that has not been widely addressed in the literature.

Using Dutch and German frmmlevel data, it is found that while the dynamies of investment are relatively similat in the two countries, the Germen firms spread their adjustments to capital over a longer period. Secondly, there is a stronger difference in the dynamics of labour adjustment with the Germ man firms exhibiting negative state dependence, while the labour adjustment. rate of the Dutch firms is positively correlated to the adjustment in the previous period. The negative relationship in the German sample could be driven by higher fixed costs resulting from such policies as dismissal protection for regular workers and the stricter regulation of flexible work arrangements. Furthermore, the dymanics of labour adjustment in the German sample is 
largely determined by this process. In contrast to Germany, labour adjustment in the Netherlands is also highly responsive to wages. These results reflect that adjustment to employment is more flexible in the Netherlands. Thirdly, secifying the cross-tems in rates, there is evidence that factor adjustment is interrelated. German firms take into account labour costs when making an investment clecision, while investment influences labour adjustment in the case of Duteln frms. This also indicates that labour incurs higher adjustment costu in Germany, and is more flexible in the Netherlands.

Finally, using Heckman's twomstep estimator, there is no indication that endogenous sample selection alters the main conclusions, although controlling for selection bias leads to multicollinearity in the Dutch investment equation. This approach is ad hoc because selection is defned over two periods, instead of one period as in the original framework. In addition, the original approach does not consider dynamics and endogenous regressors. As discussed in Chapter 2 , however, given that controlling for selection in non-linear panel data models with endogenous regressors is the topic of ongoing research, such an ad hoc approach is reasonable as a robustness check. In a comparable setting, Chapter 7 imposes theoretical restrictions so that the empirical model reduces to an AR(1) model without additional regressors. For this model, selection can be controlled for by means of an Asymptotic Least Squares procedure. 


\section{Chapter 7}

\section{Estimating the speed of labour adjustment: a problem of selection}

\subsection{Introduction}

One of the main reasons for studying factor demand dynamics is the interest in how fast firms can adapt to changing economic circumstances. In earlier chapters, we have seen that for both labour and capital, acjustment at the micro-level responds non-linearly to economic shocks, due to non-convexities in the costs of adjustment. In Chapter 2 theoretical models to explain this behaviour are reviewed, along with evidence from existing empirical reseatch. From the empirical evidence in the literature and that in this thesis, it is clear that to estimate the speed of factor adjustment from micro-data it is necessary to rely on non-linear models.

The implications of these non-linear firm-level clynamics for the aggregrate adjustment of production factors are the subject of an interesting debate. Despite the strong evidence of non-linearity at the micro-level, macro-economic research is often based on lineam time series models to estimate the adjustment speed of labour - and other economic variables - to policy changes 
and other economic shocks. The underiying argument is that linear partial adjustment models provide a useful approximation to the actual dymamics, as non linearities at the micro-level "smooth out" with aggregation. Support for this clain comes from Calvo (1983) and Rotemberg (1987), who - in the context of price adjustment - show that in the limit the aggregate dymamics following from a model in which firm-level adjustment is subject to a constant fixed cost, are indistinguishable from those arising from a model in which adjustment costs are quadratic. Recently, Hall (2004) estimates linear Euler equations for factor demand with sector-level data, and finds no evidence that his estimates are biased by the presence of fixed adjustment costs or aggregation over firms. On the other hand, many of the empirical studies discussed in Chapter 2 claim that better understanding the raicrofoundations of adjustment also leads to increased understanding of aggregate fuctuations. In addition, in analysing the Calvo-Rotemberg model Caballero and Engel (2004) find that if a variable is adjusted in a lumpy way at the micro-level, estimating its adjustment speed with a linear dynamic model leads to a severe bias. Although the bias decreases with aggregation, convergence is very slow so that a substantial bias remains even when inferring the adjustment speed of a variable from economy-wide data for a country as large as the United States.

Given the discussion above, it does not sem inappropriate to revisit the partial adjustment model (PAM) to estimate the speed of adjustment of employment. This chapter addresses the question whether, though the model clearly does not fully characterise adjustment at the micro-level, the PAM can still be used to make inferences about the adjustment speed of labour. That is, can the PAM be used to estimate the response of aggregate labour to an economic shock? As mentioned above, estimating the PAM witl aggregate data can lead to severe bias. However, as argued in this chapter, using microdata a linear time series model can still be used to determine - in the words of Caballero and Engel (2004) - the 'first-order dynamics' of adjustment. In line with Calvo (1983) and Rotemberg (1987), these first-order dynamics 
can be interpreted as the 'average' adjustment over all firms, which are the same as the aggregate dynamics.

The main insight in this chapter is that the estimation problem of the adjustment parameter at the micro-level is subject to sample selection. The PAM can be wiewed as the first-order condition of an optimisation problem in which the frm minimises the costs of adjustment. With a fixed cost component a corner solution at zero exists because non-zero adjustment is not always optimal. This is not consistent with a linear policy function like the PAM. However, as we saw in previous chapters, given that adjustment is worthwhile, the policy function is linear. In this sense, the fixed adjustment. costs component essentially acts as a censoring mechanism. The PAM still applies to the non-zero observations, so that estimation of the adjustment parameter can still be carried out on the basis of this subsample. Since ad. justment costs are higher in the neglected subsample, however, this clearly leads to a selection bias. But controlling for this bias will in principle provide an unbiased estimate of the adjustment speed.

This raises an intexesting econometric problem, namely that of controlling for selection in a dynamic panel data model. The literature on this issue is very recent and although much progress is being made (see Arellano and Honore (2001) for an overview) the number of available estimators is limited. "To my knowledge, no estimatom has been proposed that can deal with a lagged latent dependent variable as well as additional endogenous righto hand side variables. As any explanatory variables in a dynamio labour demand model are necessarily endogenous, ${ }^{2}$ I rely on a specification with only a lagged dependent variable on the right-hard side. In this model it is possible to control for selection bias using an Asymptotic Least Squares (ALS) procedure, in line with insights from Arellano, Bover, and Labeaga (1999). This approach is employed to estimate the adjustment speed of labour. The estimate is compared with those obtained from estimation without controlling

\footnotetext{
${ }^{1}$ A similar point is raised by Whited (1998) in the context of the Euler equation for investmenty see also Chapter 6 .

${ }^{2}$ This is the case in Chapter 6 .
} 
for selection and those using more aggregated data.

The outline of this chapter is as follows. Section 7.2 illustrates how the problem of selection arises in the context of estimating the PAM based on micro-data. Section 7.3 explains the details of the ALS estimation procedure to correct for the selection bias. A short description of the data is provided in Section 7.4 . The results are presented in section 7.5. Section 7.6 concludes and provides some ideas for future research.

\subsection{The selection problem in the PAM}

The partial adjustmenti model is typically derived from a dynamic optimisation problem in which firms mimimise a loss function under uncertainty with respect to the control variable. In the case of labour adjustment, the following loss function can be defined

$$
\mathcal{L}=\sum_{s=0}^{\infty} \beta^{s} E\left[\phi_{1}\left(L_{t+s}-L_{t+s}^{*}\right)^{2}+C\left(L_{t+s}, L_{t+s-1}\right)\right]
$$

where the control variable $L_{t}$ is the employment level at time $t, C$ is the adjustment costs function, $\beta$ a constant discount factor, and $L_{t}^{*}(s=0,1, \ldots)$ is the optimal level of employment for period $t$. To allow adjustment to occur gradually as well as lumpy, $C$ is specified as

$$
C\left(L_{t}, L_{t-1}\right)=\phi_{2}\left(L_{t}-L_{t-1}\right)^{2}+1\left[H_{i t} \neq 0\right] F^{\prime}
$$

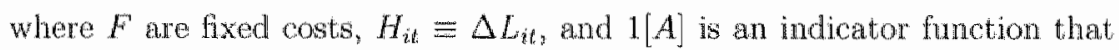
equals 1 if $A$ is true. Due to the quadratic component of the adjustment cost function, marginal costs are increasing in the size of adjustment. Thereby, spreading adjustment over time is more efficient than immediate adjustment. In contrast, the fixed component does not vary with the adjustment size and these costs are only incurred when adjustment is non-zero. This gives the firm an incentive to concentrate adjustment. The interplay between the two adjustment costs components is the source of the adjustment dynamics in 
the model. Without loss of generality $\phi_{2}$ is set to 1 .

The partial adjustment model can be derived under the assumption of no fixed costs, that is $F=0$. The consequences for assuming $F$ unequal to zero are discussed below. The first-order conditions when there are no fixed casts are

$$
E\left[\beta L_{t+s+1}-\left(1+\beta+\phi_{1}\right) L_{t+s}+L_{t+s-1}\right]=-\phi_{1} E\left[L_{t+s}^{*}\right], \quad \forall s \geq 0
$$

This leads to the following optimal policy at time

$$
\Delta L_{t}=(1-\alpha)\left[(1-\beta \alpha) \sum_{s=0}^{\infty}(\beta \alpha)^{s} E\left[L_{t+s}^{*}\right]-L_{t-1}\right]
$$

where $0<\alpha<1 .{ }^{3}$

To arrive at the common partial adjustment structure, suppose that firms regard changes to the (actual) target level as random shocks with zero mean, i.e. $E\left[L_{t+s}^{*}\right]=L_{t}^{*}, \forall s>0 .{ }^{4}$ Then equation $(7.3)$ mednces to the fundamental PAM

$$
\begin{aligned}
\Delta L_{t} & =(1-\alpha)\left(L_{t}^{*}-L_{t-1}\right) \\
& \Leftrightarrow L_{t}=\alpha L_{t-1}+(1-\alpha) L_{t}^{*}
\end{aligned}
$$

In principle, it is possible to parameterise the target level. For example, a static labour demand equation can be derived from a production function, which can be interpreted as a long-run equilibrium or the desired employment: level that would arise if there were no "friction" (see e.g Caballero and Engel (1993)). However, this will necessarily lead to including endogenous wariables in the estimating equation, like output, wages, and the demand for other in put factors. With an eye on the fact that this is a dynamic (panel data) model with selection, this is undesirable. As pointed out in the introduction there are no techniques available that appropriately accomt for the endogeneity

\footnotetext{
${ }^{3}$ See Nickell (1985). More speciffeally, a is a root of the quadratic function $f(\rho)=$ $\beta p^{2}-\left(1+\beta+\phi_{1}\right) \rho+1$, and arises from a factorisation of the lefthand side of equation $(7.3)$.

${ }^{4}$ It is also implicitly assumed that the target employment lovel for period $t, L_{t}^{*}$, is observed. This is not essential, but it is convenient for the exposition.
} 
(or predeterminedness) of other variables than the lagged dependent variable. Therefore, following Caballero and Engel (2004), it is assumed that the firm 's expectations about the target employment level are time-invariant, that is $E_{E}^{*}\left[L_{i+*}^{*}\right]=L_{i}^{*}=L^{*}, \forall s>0$. Then, taking first-differences of (7.4),

$$
H_{i t}=\alpha H_{i t-1}+\mu_{i}+\varepsilon_{i t}
$$

introducing a subscript $i$ to denote the firm, and where, as before, $H_{i t}=$ $\Delta L_{\text {it }}$. Besides the idiosyncratic disturbance $\varepsilon_{\text {tit }}$, the specification allows for a frm-specific effect $\mu_{i}$. Finally, the adjustment speed of labour is given by $\lambda \equiv 1-\alpha$. Thus, as $\alpha \rightarrow 0, \lambda \rightarrow 1$ and adjustment occurs instantaneously.

The clerivation of the PAM relies on the absence of fixed costs. The probability of zero adjustment in the model is infinitesimal. As such, it is not consistent with a probability mass at zero that is typically found in microw data. This so-called inaction regime can be modelled by allowing $F \neq 0$. Technically speaking, allowing $F \neq 0$ introduces a corner solution to the minimisation of $\mathcal{L}$, leading to a mass point at zero. The interpretation in economic terms is straightforward: if the benefits of adjusting are not high enough to overcome the costs, a firm does not adjust. This generates a regime of inaction, and in addition, if fixed costs are high, adjustment becomes lumpy:

Given that non-zero adjustment is optimal, how much does a firm adjust? As we saw in earlier chapters, fixed costs only affect the extensive margin of adjustment. If adjustment is non-zero, $1\left[H_{i t} \neq 0\right]=1$ in $(7.2)$, and because $f$ does not depend on $L_{t}$, the same marginal optimality condition applies. In fact, conditional on $1\left[H_{i t} \neq 0\right]=1$ the derivation remains unchanged, thus given non-zero adjustment the PAM can still be used to describe adjustment

\footnotetext{
${ }^{5}$ In this sense, the lack of theoretical model, as it rules out more realistic assumptions about the expectation formation process of firms, like for example rational expectations. Future research into correction techniques for sample selection in dyamic panel data morles is therefore most desirable.

"Note that fixed costs are assumed to be symmetric, which implies that the extent of left and right censoning is the same. Although not considered here, asymmetric adjustment costs are an interesting extension to the model.
} 
dynamics. In this sense, the fixed costs can be viewed as a censoring mechanism. That is, in principle the linear partial adjustment model applies to all observations, but in some instances labour adjustment is 'censored' and set to zero due to the presence of fixed costs. Thus, letting $\tilde{H}_{6}$ denote the uncensored variable, equation (7.5) should be adjusted to

$$
\tilde{H}_{i t}=\alpha \tilde{H}_{i t-1}+\mu_{i}+\varepsilon_{i t}
$$

However, instead of the latent variable $\tilde{H}_{i t}$, the variable $H_{i t}$ is observed; $H_{i t}$ is equal to $\tilde{H}_{i t}$, except when adjustment is not profitable in which case it. equals zero. Thus, $H_{i t}$ is effectively a censored version of $\tilde{H}_{i t}$.

Equation (7.6) only applies to those observations where $H_{i t} \neq 0$. For estimation, therefore, all zero observations should be discarded. Adjustment costs are likely to be higher for these observations, so that the censoring is obviously non-random. That is, estimation based on the non-zero observations would bias the estimate of the adjustment parameter $\alpha$ of labour downwards, and would overestimate the adjustment speed. This relates the estimation of equation (7.6) to the problem of sample selection bias in dynamic panel data models. A similar problem arises in Chapter 6. In that chapter, further complications arise because of additional endogenous regressors, and a somewhat acl hoc approach is adopted to take account of sample selection bias. In the context of the PAM in the current chapter, selection bias can controlled for more appropriately because, besides the lagged dependent variable, it does not involve any additional regressors.

\subsection{Controlling for selection bias}

In the absence of a selection rule for observing $H_{i t}$, equation (7.6) is a standard linear dynamic panel data model with a fixed effect $\mu_{i}$. By definition this nuisance parameter is correlated with the lagged dependent variable so that OLS will give an inconsistent estimate of the parameter of interest $\alpha$. A standard approach is to eliminate the fixed effect by estimating the model 
Wh first differences. However, in the presence of censoring, it is not clear how to difference out the fxed effect. The literature on controlling for sample selection in dymamic panel data models is very recent, and although progress is being made (see Arellano and Honore (2001)) the number of estimators. avallable is limited. In this chapter an approach along the lines of Arellano, Bover, and Labeaga (1999) is employed. ${ }^{7}$ The estimator can be qualified as Asymptotic Least Squares (ALS, see Gourieroux and Monfort (1995)), and combines the insights of Arellano and Bond (1991) and Chamberlain (1984) with the popular Heckman two-step estimator (Heckman 1979). In short, the estimator proposed makes use of the fact that the orthogonality conditions used by the Generalised Method of Moments (GMM) estimator of Arellano and Bond (1991) can be expressed in terms of the coefficients of the linear projection of the (uncensored) dependent variable on its lags. These coefficients can be estimated consistently (asymptotically) with Heckman's two-step estimator. With these estimates, the only unkmown in the orthogo nality conditions is the adjustment parameter, which can then be identified by means of a minimum distance procedure.

\subsubsection{Moment conditions}

First, orthogonality conditions are derived for the latent model (7.6), as per Arellano and Bond (1991). That is, taking first-differences eliminates the fixed effect $\mu_{i}$. The diterenced lagged dependent wariable $\Delta \tilde{H}_{i t}$ is correlated with the diflerenced enror term $\Delta \varepsilon_{i}$, but higher lags $\tilde{H}_{i, t, j}(j=2, \ldots, t-1)$ can be used as instruments, yelding the orthogonality conditions

$$
\begin{aligned}
E\left[\tilde{H}_{i,-j} \Delta \varepsilon_{i t}\right] & =0 \\
& \Leftrightarrow E\left[\tilde{H}_{i, t, j, j}\left(\Delta \tilde{H}_{i t}-\alpha \Delta \tilde{H}_{i, i-1}\right)\right]=0
\end{aligned}
$$

\footnotetext{
'A semi-parametric estimator has been proposed in Hu (2002), that relies on 'sym" rnetrical trimmings' in the fashion of Powell (1986) and Honore (1993). Unfortunately, we cannot present the selection rule as a Type I Tobit model (Amerniya 1984) as is required for this estimator, because there is no single, observable cutioff point above which $\tilde{H}_{i \text { is }}$ is not censored.
} 
In the absence of censoring, that is if there would be no fixed adjustment costs, these conditions cond be used for GMM estimation of $\alpha$.

Consider the following two linear projections of $\tilde{H}_{i t}$ on its lags:

$$
\begin{array}{ll}
\tilde{H}_{i l}=\pi_{t 1} \tilde{H}_{i 1}+\ldots+\pi_{t, t-1} \tilde{H}_{i, t-1,1}+u_{i t}^{(1)} & (t=2, \ldots, T) \\
\tilde{H}_{i t}=p_{t 1} \tilde{H}_{i 1}+\ldots+p_{t, t-2} \tilde{H}_{i, t-2}+u_{i t}^{(2)} & (t=3, \ldots, T)
\end{array}
$$

where $u_{i t}^{(\cdot)}$ are normally distributed zero-mean ID disturbences. That is, equation $(7.8)$ gives the linear projection of $\tilde{H}_{i t}$ on all its lags, while equation (7.9) gives the projection on its lags up to $t-2$. The key insight of the estimator proposed is that the moment conditions can be written in terms of the vectors of coefficients $\pi_{i}$. Let $x_{i t}=\left(\tilde{H}_{i 1}, \ldots, \tilde{H}_{i t}\right)$. The coefficients in (7.8) and (7.9) take the form

$$
\begin{aligned}
& \pi_{t}=\left(x_{i, t-1} x_{i, t-1}^{\prime}\right)^{-1} x_{i, t-1} \ddot{H}_{i t} \\
& p_{t}=\left(x_{i, t-2} x_{i, t-2}^{\prime}\right)^{-1} x_{i, t-2} \ddot{H}_{i t}{ }^{*}
\end{aligned}
$$

In addition, using $x_{i, t-2}$ to denote the vector of instruments, the monent conditions in (7.7) can be written as

$$
E\left[x_{i, t-2}\left(\tilde{H}_{i t}-\tilde{H}_{i, t-1}\right)\right]=\alpha E\left[x_{i, t-2}\left(\tilde{H}_{i, t-1}-\tilde{H}_{i, t-2}\right)\right]
$$

Multiplication of both sides by $\left(x_{i, t-2} x_{i, t-2}^{t}\right)^{-1}$ shows that the orthogonaity conditions can be written in terms of the coefficients in the best linear prediction,

$$
E\left[p_{t}-\pi_{i-1}\right]=E\left[\alpha\left(\pi_{t-1}-e_{i-2}\right)\right] \quad(t=3, \ldots, T)
$$

where $e_{t-2}$ is a vector with element $t-2$ equal to 1 and zeroes elsewhere. Note that this vector arises because the term $\left(x_{i, 1-2} x_{i, t-2}^{t}\right)^{-1} x_{i, t-2} \tilde{H}_{i, t-2}$ is equivalent to the coefficient vector of a regression of $\tilde{H}_{i,-2}$ on its lags and on itself. Naturally, setting the coefficient of $\vec{H}_{i, t \rightarrow 2}$ itself to one, and setting all the other coefficients to zero, gives the best linear predictor in this case. The coefficient vector is therefore equal to $e_{\ell-2}$. 


\subsubsection{Asymptotic Least Squares}

With consistent and asymptotically normal estimates $\pi=\left(\hat{\pi}_{3}^{\prime}, \ldots, \hat{\pi}_{T}^{\prime}\right)^{\prime}, \alpha$ is the only unknown in (7.13), and can be identified from this set of equations if $T \geq 3$. A minimum distance type estimate for $\alpha$ can then be obtained as

$$
\hat{\alpha}=\arg \min _{\alpha} m(\hat{\pi}, \alpha)^{\prime} W m(\hat{\pi}, \alpha)
$$

where $m(\hat{\pi}, \alpha)$ is the $\frac{1}{2} T(T-1) \times 1$ vector of stacked moment conditions from (7.13) with $p_{t}$ and $\pi_{t-1}$ replaced by their estimates, and $W$ is a weighting matrix. The optimal weighting matrix is given by (Gourieroux and Monfort 1995)

$$
W^{*}=\frac{\partial m}{\partial \pi^{\prime}} \Omega \frac{\partial m^{\prime}}{\partial \pi}
$$

where $\Omega$ is the asymptotic covariance matrix of $\sqrt{N}(\hat{\pi}-\pi)$. An estimate of $W^{*}$ can be obtained by replacing $\Omega=\hat{\Omega}$ from the estimation of $(7.8)$, and evaluating the derivative $\partial m / \partial \pi^{\prime}$ at a preliminary consistent estimate of $\alpha{ }^{8}$

\subsubsection{Estimation of the linear projections}

To estimate the reduced form equations (7.8), Hecknan (1979)'s two-step estimator can be applied. The expectation of $u_{i t}^{(1)}$ conditional on selection in $(7.8)$ is non-zero, which causes the parameter estimates to be inconsistent. Heckman's two-step estimator estimates this conditional expectation by making parametric assumptions. In this case, consider the following probability modal for observing a non-zero adjustment

$$
\operatorname{Pr}\left[H_{i t} \neq 0\right]=\operatorname{Pr}\left[\gamma_{i} w_{i t}+\xi_{\text {it }}>0\right]
$$

The vector of variables $w_{i t}^{\prime}$ includes $x_{i, t-1}$ and possible additional variables. To capture that non-zero adjustment can be positive or negative, also quadratic

\footnotetext{
"Arelleno, Bover; and Labeagn (1.999) suggest using weighting matrix $W=$ $\operatorname{diag}\left(M_{1}, \ldots, M_{T-2}\right), M_{t}=\sum_{i=1}^{N} h_{i, T-2} x_{i t} x_{i,}^{\prime}$ to obtain a preliminary consistent estimator:
} 
terms are considered. The central assumption is that $u_{i t}^{(1)}$ and $\xi_{\text {it }}$ are jointly normally distributed. It follows that (7.16) is a probit model and it can be shown that

$$
E\left[u_{i t}^{(1)} \mid H_{i t} \neq 0\right]=\rho\left[\phi\left(\gamma_{t}^{\prime} w_{i t}\right) / \Phi\left(\gamma_{t}^{\prime} w_{i t}\right)\right]=\rho \lambda_{i t}
$$

where $\rho=\operatorname{cov}\left(u_{i t}^{(1)}, \xi_{i t}\right) / \sigma_{\xi}^{2}$, and $\phi(\cdot)$ and $\Phi(\cdot)$ are respectively the normal density and distribution function. Adding $\lambda_{i t}$ as an additional regressor creates a zero-mean disturbance, and the linear projection (7.8) for year $t$ $(t=2, \ldots, T)$ can be estimated using the subsample where $h_{i t} \equiv 1\left[H_{i_{t} t-s} \neq\right.$ $0, s=0, \ldots, t-1]=1.9$

Heckman's two-step estimator is a common approach to control for sample selection. Its virtues are mainly that it has a straightforward interpretation, and that it is easy to implement. Its performance has been questioned however, see e.g. Puhani (2000). To avoid collinearity of the correction term with other regressors, for instance, the probit model should include enough wariables that are different from those in the primary equation, so-called exclusion restrictions. It is usually cumbersome to find variables that affect selection, but do not occur in the primary equation. This is less of a problem in this case, because the PAM has a lagged dependent variable as the only regressor, so that it is not difficult to find variables that are likely to influence the decision. whether or not to adjust, and that do not appear in the primary equation. It has also been claimed that the results are sensitive to the assumption of the joint normality (Little and Rubin 1987). Semi-parametric alternatives are availlable, see e.g. Powell (1986) and Newey, Powell, and Walker (1990), though the application of these estimators in this context is left for future work.

\footnotetext{
${ }^{5}$ Note that, assuming that $u_{i t}^{(1)}$ is not antocorrelated, $\operatorname{cov}\left(u_{i t}^{(1)}, \tilde{H}_{i, t-s}\right)=0, \psi_{s}>0$ so that the subsample where $h_{i, t-1}=1$ can be treated as exogenous. The only source of endogeneity bias - controlled for by Heckman's lambda - is that of using the non-zero observations of $H_{i x}$ instead of $\ddot{H}_{i t}$.
} 
Table 7.1: Summary statistics

\begin{tabular}{lccc}
\hline & mean & std. dev, & median \\
\hline employment level $\left(L_{t}\right)$ & 158.74 & 287.85 & 66 \\
net hiring $\left(H_{t}\right)$ & 0.56 & 49.94 & 1 \\
hiring rate $\left(H_{t} / L_{t-1}\right)$ & 0.02 & 0.15 & 0 \\
\hline
\end{tabular}

\subsection{Data}

The data used in this chapter are a balanced subsample of the CEREM data ${ }^{10}$ for the period 1983 to 1992 . The use of a balanced subsample greatly facilitates the estimation procedure, but as usuct could bias the results towards larger and successful firms. The number of firms quickly declines with the length of the sample period. The length of the sample period is chosen such that both the time and cross-section dimension of the data are reasonably large. The number of firms is 1199 , representing 11990 firm-year observations. ${ }^{11}$ Some summary statistics for this particular sample are reported in Table 7.1. The average firm in the sample employs 159 workers. However, half of the firms has 66 employees or less, which shows that the size distribution is highly skewed to the right. Net hirings appear symmetric with a mean and median around 1. The hinng rate, however, has a slightly positive skewness, with a mean of $2 \%$ and a median of $0 \%$.

Table 7.2 displays the annual percentage of observations where net hiring is zero. These observations are used in the probit estimation in order to estinate the bias correction term, but do not enter in the estimation of the

\footnotetext{
${ }^{10}$ See Chapter 3 for an extensive description and analysis of the full data set.

${ }^{11}$ Firms with employment growth above 200 percent in one or more years were dropped. lu addition, one firm was dropped because it had zero employment in one year. The two largest firms in the sample were excluded as well, as these were heavily downsizing during the sample period and found to strongly infuence the results. Note that the mumber of firms is different than for the same period in lietterie and Pfann (2003), and hence Chapter 4, becanse they consider less sectors and their balanced subsample is conditional on the avallability of some additional veriables.
} 
Table 7.2: Zero net hiring per year

\begin{tabular}{ccc}
\hline \hline year & \# obs. $H_{t}=0$ & $\%$ \\
\hline 1985 & 154 & 12.8 \\
1986 & 144 & 12.0 \\
1987 & 166 & 13.8 \\
1988 & 151 & 12.5 \\
1989 & 136 & 11.3 \\
1990 & 155 & 12.9 \\
1991 & 159 & 13.3 \\
1992 & 183 & 15.2 \\
\hline \hline
\end{tabular}

linear projections. For the period under consideration, censoring is about $13 \%$ on average, and appears reasonably constant over time.

\subsection{Results}

\subsubsection{Reduced form estimates}

To obtain consistent estimates of the reduced form parameters from the linear projections (7.8) and (7.9), an estimate of the correction term $\lambda_{i t}$ is required. This is achieved via estimation of equation (7.16), which under the marginal normality of $\xi_{i t}$ is a probit model. As a result of poor identification in the estimations for individual years, the estimation is carried out for the pooled data set. This implies that the restriction $\gamma_{t}=\gamma$ is imposed, such that the coefficients in the probit equations are time-invariant. Year effects are accounted for by dummies, howewer, but only the dummy for 1985 turns out to be significant. The results are reported in Table $7.3 .{ }^{12}$ To avoid multicollinearity the number of lags is restricted to one.

The specification of the probit is the result of experimentation with dif-

\footnotetext{
12The probit routine in Stata 7.0 was used for this estimation.
} 
Table 7.3: Probit estimation results

\begin{tabular}{lcc}
\hline & coefficient $(\gamma)$ & (std. error) \\
\hline$H_{t-3 .}$ & 0.0019 & $(0.0014)$ \\
$H_{t-1}^{2}$ & $0.0001^{* * *}$ & $(0.0000)$ \\
$Y_{t} / L_{t}$ & $0.0002^{*}$ & $(0.0001)$ \\
$\left(\Delta\left(Y_{t} / L_{t}\right)\right)^{2}$ & $-4.06 \mathrm{e} 07^{*}$ & $(-2.09 \mathrm{e} 07)$ \\
$w_{t}$ & $-0.0229^{*}$ & $(0.0136)$ \\
$w_{t}^{2}$ & $0.0002^{*}$ & $(0.0001)$ \\
$\Delta w_{t}$ & $-0.0086^{*}$ & $(0.0052)$ \\
$\left(\Delta w_{t}\right)^{2}$ & $0.0019^{* * *}$ & $(0.0005)$ \\
\hline \hline
\end{tabular}

Dependent wariable is $1\left[H_{i t} \neq 0\right]$. The estimation also includes a constant term and a dummy for the year 1985. Sector dummies and other year dummies are not included because of insigmificance. ${ }^{* * *}$ significance at $1 \%$, ** significance at $5 \%, "$ significance at $10 \%$.

Table 7.4: Bias-conrected OLS estimation of reduced forms

\begin{tabular}{|c|c|c|c|c|c|c|c|c|}
\hline & 1985 & 1986 & 1987 & 1988 & 1989 & 1990 & 1991 & 1992 \\
\hline$H_{i-1}$ & 0.090 & -0.492 & -0.775 & -0.333 & 0.1113 & 0.064 & -0.541 & -0.239 \\
\hline$H_{i-2}$ & & 0.151 & $-0.037^{\prime}$ & 0.172 & 0.115 & -0.029 & 0.086 & 0.457 \\
\hline$H_{k-3}$ & & & -0.358 & 0.327 & $0.086^{t}$ & 0.161 & 0.085 & $0.016^{\dagger}$ \\
\hline$H_{t}, 4$ & & & & 0.2415 & 0.453 & 0.124 & -0.091 & $0.06 \pi$ \\
\hline$H_{t-5}$ & & & & & 0.158 & -0.209 & 0.166 & 0.027 \\
\hline$H_{t-6}$ & & & & & & -0.190 & $-0.040^{t}$ & -0.121 \\
\hline$H_{i-7}$ & & & & & & & -0.061 & $-0.066^{t}$ \\
\hline$H_{t-8}$ & & & & & & & & $-0.047^{1}$ \\
\hline$\lambda_{t}$ & 42.09 & -143.81 & 117.83 & 110.77 & 181.71 & $11.50^{\dagger}$ & -105.50 & 142,68 \\
\hline
\end{tabular}

Variables that are insignificant at the $10 \%$ lewel are indicated by t." 
ferent variables and various transformations. Whereas lagged net hiring is not significant at $10 \%$, its square is strongly significant. This reflects that the hiring distribution is two-sided. The probability of non-zero adjustment. increases when there is either more firing or biring in the previous period. This illustrates that although fixed costs give firms an incentive to concentrate adjustment, they may not always succeed to complete it in one calendar year. Firms with a higluer labour productivity have a higher probability of adjusting. However, the probability decreases with square of the change of labour productivity. The probability of adjustment is convex in labour costs per capita, so that high labour costs have a positive effect. It is also convex in the change in labour costs, where the squared term is strongly significant. Thus, larger changes in the labour costs increase the probability of adjustment.

With $\hat{\gamma}$ from the probit estimation, $\lambda_{i t}$ is estimated as given in equation (7.17). Subsequently, as described in Section 7.3 .3 , the reduced forms in (7.8) are estimated by year with least squares using the subsamples where $h_{i t} \equiv$ $1\left[H_{i, t-s} \neq 0, s=0, \ldots, t-1\right]=1$, adding $\hat{\lambda}_{i t}$ as an additional regressor to control for endogenous selection. The results are reported in Table 7.4.13 Although for each year most standard errors are very low, the estimated coefficient on the different lags differ quite strongly in magnitude and even in sign. The same holds for the coefficient on $\lambda_{\text {it }}$, which is an estimate of the negative of $\rho=\operatorname{cov}\left(u_{i t}^{(1)}, \xi_{i t}\right) / \sigma_{\xi}^{2}$. These estimates for $\pi_{t}, t=2, \ldots, T=9$, are the basis of the $(T-2)(T-1) / 2=28$ moment restrictions of the form $(7.13)$.

\subsubsection{Partial adjustment model}

Table 7.5 reports various estimates of the PAM for different types of data and estimation methods. The estimates for the adjustment parameter differ strikingly in magnitude and sign. First the adjustment parameter was ast-

\footnotetext{
13ote that two years of observations are lost doe to the fact that met hiring is obluthed from first differencing the employment level (that is, $H_{i t}=\Delta L_{i t}$ ), and that $H_{i, t \sim 1}$ cannot be calculated for 1984 .
} 
mated on the basis of the entire balanced sample. As pointed out in Section 7.2 the resulting estimates are subject to the fact that the PAM does not hold for the observations in which arijustment is zero. The OLS results show a negative correlation between current net hiring and lagged net hiring. This is clearly at odds with the resticiction on a from the PAM $(0 \leq \alpha \leq 1)$. However, it is not unnatural in this context to find a negative estimate. Theoretieal models with fixed adjustment costs predict that firms will alternate periods of large adjustment with periods of inaction. This results in a negative corretation between consecutive observations of labour adjustment (cf. Caballero and Eingel (2004), Cooper, Haltiwanger, and Willis (2004)). Thus, when fitting a linear model to this adjustment pattern, a negative autocorrelation may result, and this result can be interpreted as indirect evidence of non-corvexitics. The problem persists when accounting for the presence of fixed effects with the Arellano-Bond estimator. ${ }^{4}$

Subsequently, the estimations are based on the subsample of observations where net hiring is non-zero. In principle, the PAM is walid for all these observations but, as pointed out above, estimation is subject to endogenous selection. The estimates with OLS and Arellano-Bond do not differ much from those based on the full sample. The negative state dependence can be interpreted in a similar way as above. ${ }^{15}$ Although now the observations in which there is inaction are not considered, instead of altemating periods of heavy adjustment with inaction - that is, periods where adjustment is exactly zero - firms may alternate heavy adjustment with periods of only moderate adjustment. That is, although fixed costs play a role in the dynamics of labour, the theoretical prediction of actual zero adjustment may empirically turn out to be too restrictive. A first reason for this is that the data concern net employment changes. Within the time span of a year it is not unlikely that some employees quit or retire. This is a natural way for" firms to downsize without having to lay-off workers. Thus, even if a firm does

\footnotetext{
${ }^{14}$ The xtabond routine in Stata 7.0 was vised to olytain the estimates, see Stata (2001).

15 In Chapter 6 a similar interpretation is given for the negative state dependence found for labour adjustment in Germany.
} 
Table 7.5: Estimation results of the Partial Adjustment Model

\begin{tabular}{lccc}
\hline \hline & $\hat{a}$ & $($ s.e.) & Sargan-statistic (df) \\
\hline all observations & & & \\
OLS & -0.253 & $(0.010)$ & \\
Arellano-Bond & -0.323 & $(0.011)$ & $1600.34(35)$ \\
subsample $H_{\text {it }} \neq 0$, no bias-correction & & & \\
OLS & -0.255 & $(0.011)$ & \\
Arellano-Bond & -0.330 & $(0.013)$ & $1314.79(35)$ \\
subsample Hit $\neq 0$, bias-corrected & & & $1293.24(27)$ \\
ALS & 0.094 & $(0.016)$ & \\
ALS (iterated) & 0.148 & $(0.015)$ & $1022.19(27)$ \\
aggregated data & & & \\
two-digit industry (OLS) & -0.483 & $(0.079)$ & \\
total industry (OLS) & 0.078 & $(0.545)$ \\
\hline \hline
\end{tabular}

Standard errors in parentheses. OLS and Arellano-Bond regressions ijclude year dummies, and the sector regression also inchudes sector dummies. Onestep results are reported for the Arellano-Bond estimator.

not fire workers, it is passible that the net change in employment from year to year may not be exactly zero. In addition, worker heterogeneity can also play a role here. High-skilled workers are often hired on an individual basis; rather than 'en gros'. Such incidental hirings car also prevent annual employment changes to be zero. As before, a pattern of periods with so-called 'adjustment spikes' followed by periods of low adjustment rates will lead to negative autocorrelation in the net hirings series.

In contrast, the bias-corrected estimates from the ALS procedure outlined in Section 7.3 are positive. As mentioned there, the estimation re quires a preliminary consistent estimate of $\alpha$. Following Arellano, Bover, and Labeaga (1999), the weighting matrix $W=\operatorname{diag}\left(M_{1}, \ldots, M_{T-2}\right), M_{t}=$ 
$\sum_{i=1}^{N} h_{t ;} T-2 x_{i t} x_{i}^{\prime}$ is used to obtain this preliminary estimate. Subsequently; this estimate is used for calculation of the optimal weighting matrix $W^{*}$ given by equation (7.15). The resulting estimate of the adjustment parameter $\alpha$ is 0.094. However, the preliminary estimate turns out to be -0.1.16, which is outside the admissible range for $\alpha$. Alternatively, I treated the obtained estimate of 0.094 as a starting value, and obtaned a new estimate. Iterating in this way, the procedure converges to an estimate for of of $0.148 .^{16}$

To investigate the influence of aggregation on the estimates, the PAM was also estimated for two-digit sector-level data. According to the macroeconomics literature, aggregation smooths out non-linearities at the microlevel, and the adjustment speed of aggregate variables can be estimated with linear models, see e.g. Hall (2004). Caballero and Engel (2004) show that the bias from using a linear instead of a non-linear adjustment model decreases with the level of aggregation. However, the results in Table 7.5 shows that the negative autocorrelation persists after aggregation to two-digit sector-level. ${ }^{17}$ Thus, the estimate for $\alpha$ from the sector data is outside the admissible range. It is interesting that the serial correlation obtained by fully aggregating the data is 0.078 , implying an adjustment time of 0.072 . This indicates that the bias of the adjustment parameter may indeed decrease with aggregation. This correlation is within the admissible range and closer to the bias-corrected ALS estimate than the other estinates. However, although the time series dimension is only 8 years, the results indicate that the adjustment speed obtained from aggregated data can still differ substantially from that obtained from micro-data. The results for both the two-digit and total industry data point out that aggregation does not make the estimation immune to the existence of non-comvexities.

Compared to the other estimates the ALS procedure is the only one to provide an estimate within the required interval between 0 and 1 . As such,

\footnotetext{
16 Estumation with preliminary values along the grid $\{0,0.05,0.10, \ldots, 1\}$ shows that point estimates for $\hat{\alpha}$ range from 0.121 to 0.165 .

${ }^{7}$ For the sectoral aggregates all firm observations within a two-digit inclustry in the bahnced sample were added up.
} 
the method appears to correct appropriately for selection bias arising from using only the observations with non-zero adjustment. In addition, the ALS estimates appear less sensitive to the problem that adjustment may not be exactly zero due to the natural motion of employment or worker heterogeneity as discussed above. A reason for this could be that the method axploits moments of the data that are based on the best linear prediction based on all available lags, rather than estimating the adjustment parameter diredly from the data. The estimated adjustment speed is relatively high. Based on the iterated estimation the time until full adjustment is $\alpha /(1-\alpha)=0.174$, which implies that adjustment is completed within less than a quarter of a year.

The overidentifying restrictions in the ALS procedure can be tested with a Sargan statistic. It is calculated as the sample size times the criterion function in (7.14) evaluated at $\hat{a}$, and has a chi-square distribution with degrees of freedom equal to the number of overidentifying restrictions. As can be seen in Table 7.5, the Sargan test rejects the validity of the overidentifying restrictions in the ALS estimation at any conventional significance level. ${ }^{18}$ This, on the other hand, is also true for the orthogonality conditions exploited by the Arellano-Bond estimator. This finding reflects the restrictive nature of the PAM. However, the overiclentifying restrictions are often also rejected for more realistic models like the Euler equation, see Bond and Meghir (1994), Whited (1998), and Chapter 6. Relaxing the assumption of symmetry between hiring and firing decisions, however, appears to lead to improvement, see e.g. Pfann and Palm (1993) and Alonso-Borrego (1998).

\subsection{Conclusions}

Although there is evidence on the non-linearity of labour adjustment at the micro-level, linear partial adjustment models remain popular in macto-

\footnotetext{
${ }^{18}$ I experimented with different subsets of the moment restrictions. In all casess the results did not vary much from those presented.
} 
economic to estimate the adjustrnent speed of labour. At the aggregate level non Linearities smooth out, but convergence is very slow so that estimates of adjustment parameters at ty pical levels of aggregation are subject to substanthal bias (Caballero and Engel 2004). In this chapter, it is shown that with non-convex adjustment costs, the partial adjustment model can be estimated with micro-data only for the subsample of non-zero observations. In addition, as this subsample is non-random, selection bias needs to be control].ed for to infer the adjustment speed of labour.

The partial adjustment model is estimated with and without controlJing for selection, and for different levels of aggregation. The estimates that account for selection bias are obtained from an Asymptotic Least Squares procedure, suggested by Arellano, Bover, and Labeaga (1999). It is found that estimation with firm-level data and controlling for selection bias gives an estimate within the admissible range (i.e. between 0 and 1). The estimate implies that labour adjustment occurs within less than a quarter of a year. In contrast, estimates based on the sample including the zeromobservations and those not corrected for selection bias are negative, which arises from the adjustment pattern of spikes and (relative) inaction. Moreover, inferring the adjustment parameter from sectoral data also leads to a negative estimate, which shows that aggregation does not make the estimation immune to the existence of non-convexities.

The analysis in this chapter can be extended in number ways. Most prominently, the available econometric techniques for controlling for endogenous selection in dymanic panel data models do not allow for additional endogenous explanatory variables. This restricts the expectation formation process of the firms to being static. Given the availability of such a technique in the future, it is most promising to infer the adjustment speed of Labour from an Euler equation with rational expectations by firms. ${ }^{19}$ Within the framework of this chapter, it is worthwhile to look at semimparametric

\footnotetext{
${ }^{19}$ Chapten 6 presents estimates of the Euler equation for labour adjustment as well as investment. There an ad hoc approach based on Heckman's two-step approach is adopted to account for nou-convexities.
} 
altematives to Heckman's two-step approach in the estimation of the linear projections, e.g. Powell (1986) and Newey, Powell, and Walker (1990). In addition, treating hiring and firing decisions asymmetrically is likely to result in an improvement of the model. In particular, the symmetric treatment of negative and positive adjustment could be one of the reasons that the Sargan statistic is rejected. Finally, in tems of data, it is desirable to be able to distinguish between types of labour, for example by skill level or occupation. Typically, different types of workers are found to be quite heterogenous with respect to their adjustment dynamics. 



\section{Chapter 8}

\section{Conclusion}

The dynamics of capital and labour adjustment can be characterised as lumpy and intermittent, meaning that firms alternate periods of heavy adjustment with periods of only moderate changes to factor levels, or even inaction. This is the conclusion from recent micro-level empirical research on dynamic factor demand. This finding is consistent with non-convexities in the adjustment cast structure, that are due to economies to scale. Unlike the neoclassical model that assumes strictly convex adjustment costs, economies of scale predict that adjustment is not always optimal. In addition, non-convexities often captured by a fixed adjustment costs component - give the firm an incentive to concentrate adjustment. A common finding is that a specification including non-convex components provides a better description of the data than the traditional linear-quadratic formulation.

The thesis is centred around two main themes. Firstly, it aims to reinforce the empirical evidence on lumpy and intermittent factor dynamics using plant-level data from the Dutch manufacturing sector. The second main theme is to investigate the interrelation between capital and labour in the presence of non-convexities. Although intuition suggests that decisions on investment and labour adjustment should be mutually dependent, this line of research has sofar received little attention in this context. However, as alleady pointed out by Nadiri and Rosen (1969), considering a univariate specifica- 
tion for the demand for production factors may lead to sparious inferences concerning the dynamics and the driving forces of these. In addition, in the econometric analyses of the structural models, recently developed techniques. are employed, in particular from the literature on estimation and inference in linear and non-linear dynamio panel data models. In most cases, their application has not been considered in the context of factor demand models, so that this can also be considered a contribution to this literature.

In Chapter 3 a descriptive statistical analysis is carried out, providing prelinimary insights into the two central themes. The results are in line with various well-known studies pertorming similar analyses. In particular, it is shown that for many firms, a small number of observations accounts for a large share of total adjustment over the sample period. This indicates that firms alternate years of intensive adjustment with years of moderate adjustment, and confirms that adjustment of capital and labour is lumpy. In addition, the interrelation between the factors is studied by considering the probabilities of different adjustment regimes, both unconditional and conditional on the regime of the other factor. These regimes arise from the fact that adjustment of either factor can be positive, negative or zero. "The finding that the probabilities differ substantially when conditioning on the regime of the other factor, suggests that the adjustment decisions are not independent. This supports the relevance of the second research theme. Finally, lumpy adjustment dymamics at the micro-level are found to affect the time series Auctuation of aggregate adjustment, especially for investment. This finding is an indication that in studying aggregate series, non-linearities at the microlevel should be taken into account.

Chapter 4 contimus the statistical analysis of interrelated factor demand in Chapter 3. Firstly descriptive statistics suggest that labour adjustment is significantly higher in periods of large investments, so-called 'spikes'. Investment, in turn, is higher if there is a positive employment spike, and lower if there is a negative spike. Subsequentily, the analysis is extended to indude dynamics. A simple linear reduced form panel data regression is used for both 
factors to relate the rate of adjustment to the timing of adjustment spikes in the other factor. The results from this analysis show that the labour adjustment rate is higher in the same period as an investment spike, but also in the period before. Similarly, there is mild evidence that investment is highen in the period after an employment spike. These findings suggest that there is a dymamic element in the interrelation of production factors. For example, the result that additional labour adjustment occurs before a large investment can indicate that firms anticipate the time that employees need to be trained.

In Chapter 5 to 7 the dynamics and interiatation of capital and labour are investigated by means of structural models of adjustment. The central question in Chapter 5 is whether non-convex adjustment costs of investment can be the cause of the non-linear labour adjustment dynamics observed in Chapter 3. This question is motivated by the theoreticall study of Abel and Eberly (1998) who suggest that non-linear employment dynamics can arise due to interrelation in a model where labour is fully flexible but investment is subject to fixed costs. In Chapter 5 , investment is subject to non-convex adjustment costs, and a non-linear $Q$ model is derived for this input. Since the assumption of full flexibility in the model by Abel and Eberly is likely to be restrictive in the Dutch case, labour adjustment is assumed to be subject to convex costs, and a linear $Q$ model is derived for this production factor. The interrelation in this model tuns completely via the production technology. In the resulting empirical model, the question whether investment can be the cause of non-linear employnent dynamics boils down to whether investment lumps cause lumps in labour productivity. Because labour adjustment is proportional to labour productivity in the empirical model, this would result in lumpy employment dynamics. The estimation results point out that there is strong evidence for the non-linearity of investment. However, in this model, large shocks to investment do not carry over to labour adjustment. The reason is that the coefficient on productivity in the labour adjustment equation is estimated to be very low. This implies that adjustment is slow, and that adjustment in response to an economic shock is spread over a long period. 
Thus, a rrodel with only convex adjustruent costs does not generate lumps in labour adjustment, even when accounting for the lumpiness of investment. This should be interpreted as evidence that a richer adjustment costs specification - including non-convexity - is required to explain employment dynanics.

The ablity for firms to adjust employment and capital is influenced by institutional arrangements and government policies such as labour market regulation, unionisation and taxation. The institutional setting therefore has an important effect on the costs of adjusting factor levels. It follows that differences between countries should lead to differences in factor dynamics. To investigate this, a comparison between Dutch and German manufacturing firms is made in Chapter 6. For this purpose, the Euler equations for investment and labour adjustment are estimated, accounting for non-convex and interrelated adjustment costs. The findings are consistent with the hypothesis that Germany has a stricter regulation of the labour market, and show that this translates into high fixed adjustment costs for this factor. In addition, determinents of labour adjustment like labour productivity and wages are insignificant. In contrast, the Dutch labour market is characterised by more flexible arrangements with respect to part-time and temporary work. This is confirmed by the fact that, unlike in Germany, labour adjustment in the Netherlands is responsive to wage changes. While the labour markets in both countries are characterised by different degrees of Hexibility, the capital markets are quite similar. Indeed, the results of estimating the Euler equation for investment, shows that investment dynamics are roughly similar. With the initial specification of interrelation in levels there is also no evidence that differences in employment dynamics carry over to investment. While the cross-terms in levels are likely to also pick up scale effects, interrelation is also specified in rates, although such a specification cannot be derived from a structural model. Newertheless, wh interrelation specified in rates, labour adjustment aftects investment in Germany but not vice versa. This is a futher indication that labour adjustment is relatively costly in Germany, 
as it suggests that German firms take labour adjustment into account when making an investment decision. For the Netherlands, labour adjustment is responsive to investment. The fact that employment is responsive to changes in capital shows again that it is relatively flexible in the Netherlands. Because of fixed adjustment costs, the Euler equations apply only to the observations where adjustment is non-zero. This subsample is non-random, however, because selection depends on adjustment costs. Therefore, Heckman's two-step type estimator is used to check the sensitivity to possible selection bias, and there is no evidence that the results are altered. This approadn to contiol for selection is somewhat ad hoc, however, becanse selection is defined over two periods, instead of one as in the original formulation of the estimator. On the other hand, given the lack of appropriate estimation techniques to deal with censoring in this type of model, the use of an ad hoc approach does not seem unreasonaljle.

While there is strong evidence on the non-linear dynamics of capital and employment in the micro-economic literature, the implications of these findings for the aggregate adjustment of production factors is the subject of an interesting debate. Since non-linevrities are clained to smooth out with aggregation, macro-economic research often relies on limear time-series models to estimate the speed of adjustment of economic variables to policy changes and other economic shocks. Caballero and Engel (2004), however, show that: the estimates obtained from aggregate data using linear partial adjustment model are subject to a severe bias. Within the framework of the partial adjustment model it is shown in Chapter 7 that there is a problem of selection similar to that in the Euler equation in Chapter 6 . Unilike in that chapter, some restrictions are imposed to be able to write the partial adjustment model as an AR(1) panel data model, thus eliminating the problem of endogenous regressors. It is then possible to control for selection using an Asymptotic Least Squares procedure, after Arellano, Bover, and Labeaga (1999). The estimated adjustment speed implies that labour adjustment is completed within less than a quarter of a year. In contrast, estimation based 
on the complete data set that is, including the observations where adjustment is zero) and estimation without controlling for selection bias, lead to estimates of the adjustment speed that are negative. This is likely to be due to the alternation of adjustment humps and relative inaction, which causes a negative serial conrelation in labour adjustment. In addition, the estimated speed from sector-level data is also negative. This shows that aggregation does not make estimation immune to the existence of non-convexities at the micro-level.

In summary, retuming to the two main themes of the thesis, I find the following. Firns in the Dutch manufacturing exhibit lumpy and intermittent factor demand dynamics, both for capital and labour. This can be concluded from statistical evidence presented in Chapter 3 , as well as from the results of a structural modes of factor adjustment in Chapter 5. These results are consistent with the existence of non-convex adjustment costs. In addition, the costs of adjustment are affected by institutional factors, as becomes clear from the international comparison in Chapter 6. Statistical evidence in Chapter 3 and 4 shows that factor demand is interrelated, in the sense that the dynamics of an input factor are related to adjustments in the other. In Chapter 5, however, there is no evidence that lumps in investment generate lumps in labour adjustment when it is assumed that the costs of labour adjustment are convex. This indicates that fixed costs to adjusting the employment level are bikely to play a role. Interrelated adjustment costs, due to cost efficiencies of simulaneous adjustment of factors, are hard to identify. In Chapter 6 the results of an intutively appealing specification, where the investment rate affects the labour adjustment rate and vice versa, show that this kind of interrelation is plausible. However, such a specification camnot be derived in a structural way, and therefore further research should focus on how to capture adequately interrelated adjustment costs in a structural model. Chapter 7 shows that non-comvexities in the adjustment costs for labour should be accounted for when estimating the adjustment speed of this production factor. 
The study can be extended in various ways. Firstly, the use of additional data can potentially strengthen the analysis. The avalability of a capital stock measure, for instance, would avoid the use of a proxy for this variable, and reduce the impact of measurement error. The availability of capital stock also gives the opportunity to look at disinvestment, which would provide a more complete picture of the adjustment decisions by firms. For labour it would be desirable to have information on gross flows. Firms are likely to carry out negative and positive adjustments to the labour force within a certain time period, but when only net flows are observed the costs of these adjustments cannot be identified separately. In addition, the results in various chapters indicate the importance of the heterogeneity within capital and labour. Information on the flows of the different types within both factors is desirable, because each type is likely to face different adjustment costs resulting in heterogeneous dynamics. For capital different types of investment goods can be considered, as well as a distinction between expansionary and maintenance investment. For labour a distinction can be made between production and non-production workers, temporary versus permanent workers, and according to skill-level. Firms are also likely to control working hours in addition to the employment level. As the ability to vary working hours will have consequences for labour dynamics, data on this decision variable would also useful. Finally, adjustment decisions may not be made at a yearly basis, so that higher frequency (e.g. quarterly) data can possibly sherl more light on the timing of adjustment decisions.

An important direction for future research is the development of a structural model that is able to describe the discrete choice between adjustment and non-adjustment, as well as the continuous choice of the adjustment size for both factors. Such a model should include non-convexities for both capital and labour. This is in line with the results of Chapter 5 where it is found that lumps in labour adjustment cannot be generated from a model with only non-convex costs for investment. However, it is not clear at this point if such a model has a closed-form solution that can be translated to a tractable 
empirical model.

Another promising line of research is the estimation of Eulex-type equatons conditional on mon-zero adjustment. Controlling for the sample selection What results from fixed adjustment costs, the structural parameters that affect the continuous decision can in principle be estimated. In Chapter 7 it is found that such an approach leads to a plausible first-order approximation of the adjustment speed of labour from a simple partial adjustment model. In contrast, the estimates based on the full sample and those that are not corrected for selection bias, suffer from the fact that non-convexities are not thaken into consideration, and produce inadmissable estimates.. Given these results it seems worthwhile to extend the analysis to a more realistic economic model like the Euler equation. This requires the development of estimation techniques that allow for endogenous explanatory variables - in addition to the lagged dependent variable -.- in panel data models with selection.

The findings in this thesis are also relevant for policy making. The results im Chapter 6 can be taken as evidence that the institutional setting, for a large part related to government policies, has an effect on the dynamics of capital and labour. In addition, from the statistical evidence in Chapter 3 and the structural analysis in Chapter 5 it can be learned that adjustment to policy changes occurs in a non-linear way. This implies that to assess or predict the effect of a certain policy, knowledge is required about the underlying distribution of fundamentals. If, in addition, factor dynamics are inter related, the effect of policy change with respect to one factor on the dynamics of another should be taken into account. Finally, Chapter 7 reveals that it is doubtitul that estimates of the response to economic shocks by firms can be based on aggregate data. The study of firn level dynamics should therefore be a vital aspect in the analysis of macro-economic policy. 
. 


\section{Bibliography}

ABEL, A., AND O. BLANCHARD (1986): "The present walwe of profits and cyclical movements in investment," Econometrica, 54, 249-273.

ABEL, A., AND J. EBERLY (1994): "A unified model of investment under" uncertainty," The American Economic Review, 84, $1369-1384$.

(1998): "The mix and scale of factors with irreversibility and fixed costs of investment," Carnegie-Rochester Conference Series on Public Policy, 48, 101-135.

(2002): "Investment and $q$ with fixed costs: an empirical analysis" working paper.

ADDA, J., AND R. COOPER (2003): Dynamic Economics - Quantitative Methods and Applications. "The MTT Press, Cambridge, Massachusetts.

Aguirfegabiria, V. (1997): "Estimation of dynamic programming models with censored dependent variables," Investigaciones Economicas, 21(2), $167-208$

AKERLOF, G. (1970): "The market for lemons; quality uncertainty and the market mechanism," Quarterly Jourmal of Economics, 84, 488-500.

AlONSO-Borreco, C. (1998): "Demand for labour inputs and adjustment costs: evidence from Spanish manufacturing firms," Labour Economics, 5 , 475-497. 
AMEMIYA, T. (1984): "Tobit models: a survey," Journal of Econometrics, $24,3-63$

ARELLANO, M., AND S. BOND (1991): "Some testis of specification for panel data: Monte Carlo evidence and an application to employment equations," Review of Economic Studies, pp. 277-297.

ARELlano, M. AND O. BOVER (1995): "Another look at the instrumentalvariable estimation of error-components Models," Joumal of Econometrics, $68,29-52$.

Arellano, M., O. BOVER, AND J. LABEAGA (1999): "Antogressive models with sample selectivity for panel data," in Analysis of panels and limited dependent variable: essays in honour of G.S. Maddala, ed. by C. Hsiao, K. Lahiri, C.F. Lee, and M. Pesaran. Cambridge University Press, Cambridge (UK).

Arellano, M. Ano B. Honore (2001): "Panel data models: some recent developments," in Handbook of econometrics, volume V, ed. by J. Heckman, and E. Leamer. North-Holland, Amsterdam.

BALKE, N. 1999): "Credit and economic activity: credit regimes and nonlinear propagation of shom $\mathrm{ss}_{\text {" }}$ "The Review of Economics and Statistics, pp. 344348 .

BALTAGI, B. (1980): "On seemingly unrelated regressions and enor components," Ecomometica, 48, $1547-1552$.

(1995): Econometric Analysis of Panel Data.. John Wiley \& Sons, Chichester, England.

BARNETT, S., AND P. SAKELLARIS (1998): "Nonllinear response of firm investment to $Q$ : testing a model of convex and non-convex adjustment costs," Journal of Monetary Economics, 42(2), 261-288. 
Bentolila, S., And G. Bertola (1990): "Firing costs and labour denand: how bad is Eurosclerosis?" Review of Economic Studies, 57(3), 381-402.

BertolA, G. (1999): "Microeconomic perspectives on aggregate labor mar" kets," in Handbook of Labor Economics, ed. by O. Ashenfelter, and D. Card, vol. 3, pp. 2985-3028. Elsevier Science.

Blundell, R., AND S. BOND (1998): "Initial conditions and monent restrictions in dynamic panel data models," Journal of Econometrics, 87 , $115-143$.

BOND, S., AND C. MEGHR (1994): "Dynamic investment models and firm's financial policy," Review of Economic Studies, 61, 197-222.

BOND, S., AND J. VAN REENEN (2002): "Microeconometric models of investment and employment," manuscript.

Broersma, L., and P. Gautier (1997): "Job flows in Dutch manufacturing, 1979-1993 - empirical evidence and theoretical implications," De Economist, 145(1), 47-64.

CABALLERO, R. (1999): "Aggregate investment," in Handbook of Macroeconomics, vol. 1B, ed. by I. Taylor, and M. Woodford. NorthHolland, Amsterdam.

CABAllero, R., AND E. ENGEL (1993): "Microeconomic adjustinent hatards and aggregate dynamics," Quarterly Journal of Economics, pp. 359383.

—_ (1999): "Explaining investment dynamics in U.S. manufacturing; a generalized $(\mathrm{S}, \mathrm{s})$ approach," Econometrica, 67(4), 783-826.

(2004): "Adjustment is much slower than you think," working paper.

Caballero, R, E Engel, and J. Haltiwanger (1995): "Plant-level adjustments and aggregate investment dynamies," Brookings papers on economic activity, 2, 1-54. 
L___ (1997): "Aggregate employment dynamics: building from microeconomies, The American Economic Review; 87, 115-137.

CABALLERO, R., AND J. LEAHY (1996): "Fixed costs: the demise of marginal q." NBER working paper 5508.

CALvo, G. (1983): "Staggered prices in a utility-maximizing framework," Journal of Monetary Economics, 22, 383-398.

Chamberlain, G. (1984): "Panel data," in Handbook of Econometrics, volume II, ed. by Z. Griliches, and M. Intrilligator. Elsevier Science, Amsterdam.

ChIrINKo, R. (1993): "Business fixed investment spending: modelling strategies, empirical results and policy implications," Journal of Economic Literature, 31, 1875-191.1.

Cooper, R., and J. Haltiwanger (2002): "On the nature of capital adjustment costs," working paper.

Cooper, R., J. Haltiwanger, and L. Power (1999): "Machine replacement and the business cycle: lumps and bumps," The American Economic Review, 89(4), 921-946.

COOPER, R., J. HALTIWANGER, AND J. Willis (2004): "Dynamics of labor demand: evidence from plant-level data and aggregate implications," working paper.

COOPER, R., AND J. WILlis (2001): "The economics of labor adjustment: mind the gap," working paper.

Davis, S., J. Haltiwanger, and S. SCHuH (1996): Job Creation and Destruction. MIT Press, Cambridge, Massachusetts.

Dellsen, L., And E. De Long (eds.) (1998): The German and Dutch Economies: Who Follows Whom? Physica-Verlag, Heidelberg, Germany. 
DixiT, A. (1997): "Investment dynamics in the short run and long run," Oxford Economic Papers, 49, 1-20.

DixIT, A., AND R. PINDYCK (1994): Investment Under Uncertainty. Princeton University Press, Princeton, New Jersey.

Doms, M., And T. Dunne (1998): "Capital adjustment patterns in manufacturing:" Review of Economic Dynamics, 1, 409-429.

DoorNIK, J. (2002): Object-Oriented Matrix Programming Using Ox. Timberlake Consultants Press, London, 3rd edn.

Doornik, J., M. ArellaAno, and S. Bond (2002): "Panel Data Estimation Using DPD for Ox," DPD package manual.

EBERLY, J. (1997): "International evidence on investment and fundarnentals," European Economic Review, 41, 1055-1078.

ERerly, J., AND J. VAN Mieghem (1997): "Multi-factor factor investment under uncertainty," Journal of Economic Theory, 75, 345-387.

EISNER, R., AND R. STROTZ (1963): "Determinants of business investment, part I," in Impacts of Monetary Policy, ed. by Commision on Money and Credit, pp. 59-233. Prentice-Hall, Englewcod-Cliffs, New Jersey.

Eurostat (2002): Eurostat Yearbook 2002. Eur-Op, Linxembourg.

Gilchrist, S., and C. Himmelberg (1995): "Evidence on the role of cash flow for investment," Journal of Monetary Economics, 36, 541-572.

Gourteroux, C., AND A. MONForT (1995): Statistics and Econometric Models. Cambridge University Press, Cambridge, UK.

__ (1996): Simulation-based Econometric Methods. Oxford University Press, Oxford, UK.

HALL, R. (2004): "Measuring factor adjustment costs," Quarterly Joumal of Economics, pp. 899-927. 
HAMERMESH, D. (1989): "Labor demand and the structure of adjustment costs," The American Economic Review, 79(4), 674-689.

- (1993): Labor Demand. Princeton University Press.

HAMERMESH, D., AND G. PFANM (1996): "Adjustment costs in factor demand," Journal of Economic Literature, 34, $1264-1292$.

HANSEN, B. (1996): "Tnference when a musance parameter is not identified under the null hypothesis," Econometrica, 64, 413-430.

(1999): "Threshold effects in non-dynamic panels: estimation, testing, and inference," Journal of Econometrics, 93, 345-368.

- (2000): "Sample spliting and threshold effects," Econometrica; $68(3), 575-603$

HANsEN, L. (1982): "Large Sample Properties of Generalized Method of Moments Estimators," Econometrica, 50(4), 1029-1054.

HANSEN, L., AND K. SINGLETON (1982): "Generalized instrumental variable estimation of nonlinear rational expectations models," Econometrica, $50(5), 1269-1288$.

HAYASH, F. (1982): "Tobin's average $q$ and marginal $q$ : a neodassical interpretation," Econometrica, 50, 213-224.

HECKMAN, J. (1979): "Sample selection as specification error," Econometrica, 47(1), 153-161.

Holt, C., F. Modiglani, J. MUTH, AND H. Simon (1960): Planning Production, Inventories and Work Force. Prentice-Hall, Englewood Cliffs, New Jersey.

Honore, B. (1993): "Orthogonality conditions for Tobit models with fixed effects and lagged dependent variables," Journal of Econometrics, 59, 3561. 
Hoogdun, L., AND H. Huisman (1998): "The financial structure in the Netherlands and Germany: different, harmonious, and on the move?," in The German and Dutch Economies: Who Follows Whom?, ed. by L. Delsen, and E. de Jong. Physica-Verlag, Heidelberg, Germany.

Hoogstrate, A., T. Osang, and D. Slottje (2002): "Saving, openness, and growth: a panel data VAR approach," working paper.

HU, L. (2002): "Estimation of a censored dynamic panel data model," Econometrica, 70, 2499-2517.

Janz, N., G. Ebling, S. Gotrschalk, and H. Niggemann (2001): "The Mannheim Innovation Panels (MIP and MIP-S) of the Centre for European Economic Research (ZEW)," Schmollers Jahrbuch, 121, 123-129.

Koop, G., M. Pesaran, And S. Potter (1996): "Impulse response analysis in nonlinear multivariate models," Journal of Econometrics, 74, 119147 .

Kydland, F., AND E. PrescotT (1982): "Time to build and aggregate fluctuations," Econometrica, 50, 1345-1370.

LAW, A., AND W. KELTON (1991): Simulation modeling \& analysis. McGraw-Hill, Singapore.

LetTerie, W., and G. PFann (2003): "On the identification of nonlinearity in equipment investment expenditures," working paper.

Letterie, W., G. Pfann, and J. Polder (2004): "Factor adjustment spikes and interrelation: an empirical investigation," Economics Letters, $85(2), 145-150$.

LrTtLE, R., AnD D. Rubin (1987): Statistical analysis with missing data. John Wiley \& Sons, New York.

Merz, M., AND E. YASHIV (2003): "Labor and the market value of the firm," IZA Discussion Paper, 965. 
NADIR, M., AND S. ROSEN (1969): "Interrelated factor demand functions," The American Economic Review, $59,457-471$.

NEWEY, W., J. POWELL, AND J. WALKER (1990): "Simiparametric estimation of selection models: some empirical results," American Economic Review Papers and Proceedinge, 80(2), 324-328.

NICKELL, S. (1978a): "Fixed costs, employment and labour demand over the cycle," Economica, 45, 329-345.

Lin_- (1978b): The Investment Decisions of Firms. Cambridge University Press, Cambridge, UK.

(1985): "Error correction, partial adjustment and all that" an expository note," Oxford Bulletin of Economics and Statistics, 47, 119-129. - (1986): "Dynamic models of labor demand," in Handbook of Labor Economics, vol. 1, ed. by O. Ashenfelter; and R. Layard. North-Holland, Amsterdam.

NILSEN, O., K. SALVANES, AND F. SCHANTARELli (2003): "Employment. changes, the structure of adjustment costs, and plant size," working paper.

TNLSEN, O., AND F'. SCHANTARELLI (2013): "Zeroes and lumps in investment: empirical evidence on irreversibilities and non-convexities," Review of Economics and Statistics, 85, 1021-1037.

OECD (1999): "Employment protection and labour market perfonmance" in OECD Employment Outlook, pp. 45-132. OECD, Paris.

P貯K, S. (1974): "Altemative investment models for furms in the electric utilities industry," The Bell Joural of Economics and Management Science, $5(2), 420 \cdots 458$

PFANN, G., AND F. PALM (1993): "Asymmetric adjustment costs in nonlinear labour demand models for the Netherlands and U.K. manufacturing sectors" The Review of Economic Studies, 60, 397-412. 
Pfann, G., and B. Verspagen (1989): "The structure of adjustment costs for labour in the Dutch manufacturing sector," Economic Letters, 29, 365371 .

POWELL, J. (1986): "Symmetrically trimmed least squares estimation for Tobit models," Econometrica, 54, 1435-1460.

Power, L. (1998): "The missing link: technology, investment, and productivity," Review of Economics and Statistics, 80, 300-313.

PUHANi, P. (2000): "The Heckman correction for sample selection and its critique," Journal of Economic Surveys, 14(1), 53-68.

Rota, P. (2001): "Dynamic labour demand with lumpy and kinked adjustment costs," FEEM Working Paper.

RotemberG, J. (1987): "The new Keynesian foundations," in NBER Macroeconomics Anmual, ed. by O. Blanchard, and S. Fischer, pp. 69-104. MIT Press, Cambridge, MA.

RothschiLD, M. (1971): "On the cost of adjustment," Quarterly Journal of Economics, 85(4), 605-622.

SAkellaris, P. (2004): "Patterns of plant adjustment;" Journal of Monetary Eeonomics, 51, 425-450.

Scheuer, E., AND D. SToller (1962): "On the generation of normal random vectors," Technometrics, 4, 278-281.

Shaprro, M. (1986): "The dynamic demand for capital and labor," The Quarterly Journal of Economics, 51, 513-542.

STATA (2001): Stata statistical software: release 7.0. Stata Press: College Station, TX.

SUMmers, L. (1981): "Taxation and corporate investment: a Q-theory approach," Brookings Papers on Economic Activity, 1, 67-140. 
WHTED, T. (1998): "Why do investment Euler equations fail?" Joumal of Business and Economic Statistics, 16,479488

WTMDMEIJER, $F$. (2000): "A finite sample correction for the variance of linear two-gtep GMM estimators, IFS working paper $00 / 19$.

ZELLNER; A. (1962): "An efficient method for" estimating seemingly unrelated regressions and tests for aggregation bias," Journal of the American Statistical Association, 57, 500-509. 




\section{Nederlandstalige samenvatting}

Het doen van investeringen in kapitaalgoederen en het aanpassen van het aantal werknemers brengt kosten met zich mee voor bedrijven. Naast de directe kosten als gevolg van de investeringsuitgave en de loonkosten vam een additionele werknemer, zijn er ook indirecte kosten die verband houden met de aanpas-sing zelf. De installatie van nieuwe kapitaalgoederen kan tot gevolg hebben dat de productie-activiteiten van een bedrijf gedeeltelijk of in hun geheel moeten worden opgeschort. Daarnaast moeten werknemers opgeleid worden om met de nieuwe technologie te werken en moet er tijd en inspanning worden gestoken in het herstructureren van het productieproces. Met betrekking tot aenpassingen van arbeid, maken bedrijwen kosten die samenhangen met het zoeken en aannemen van werknemers, reorganisatile en het opleiden van nieuw personeel. Bovendien zijn er kosten verbonden aan negatieve aanpassingen. Zo kumnen kapitaalgoederen vaak niet tegen hun eigenlijke waarde worden doorverkocht vanwege het probleem van asymmetrische informatie. Voor wat betreft arbeid zijn or in de meeste landen expliciete kosten verbonden aan het ontslaan van werknemers, bovenop de impliciete kosten die het gevolg kunnen zijn van een verminderde productiviteit bij het personeel van een inkrimpend bedrijf.

Deze zogeheten aanpassingskosten zijn een belangrijke reclen waarom bedrijwen niet onmiddellijk reageren op economische schokken. In tegenstelling tot investeringsuitgaven en loonkosten is dit type losten vaak niet waarneembaar. Bij het modelleren van de wraag naar kapitaal of arbeid is het daarom nodig om functionele vormen te veronderstellen die de kosten 
van een aanpassing relateren aan de grootte van de aanpassing. In de traditionele literatuur is de meest populaire aanname dat de kosten van een aanpassing kwadratisch zijn in (een maatstaf van) de grootte. Dit leidt tot lineaire vraagvergelijkingen voor de productiefactoren.

De kwadratische specificatie van aanpassingskosten impliceert dat een reeks wan kleine aanpassingen mincler kostbaar is dan een enkele grote aanpassing. Bovendien is de optimale aanpassing altijd ongelijk aan mul (of, om preciezer zijn, de kans dat een aanpassing gelijk is aan nul is oneindig klein). Dit staat in scherp contrast met de empirische bevindingen in de recente literatuur, die wijzen op een aanpassingspatroon waarin perioden van grote aanpassingen van kapitaal en arbeid worden afgewisseld met perioden van kleine aanpassingen of inactiviteit. Een dergelijk dynamisch patroon is consistent met het bestaan van schaalwoordelen, dat wil zeggen dat de gemiddelde kosten afnemen met de grootte van de anpassing. In veel gevallen worden deze schaalvoordelen gemodelleerd door middel van een vaste kostencomponent, oftewel een component die niet afhankelijk is van de aanpassingsgrootte. In het geval van dit soort zogeheten niet-convexiteiten, is het niet altijd optimaal voor een bedrijf om te investeren of arbeid aan te passen: als de opbrengsten niet hoog genoeg zijn om de kosten te dekken, kiest een bedrijf ervoor om niet aan te passen. Aan de andere kant, àls een bedrijf aanpast, zal het vanwege de schaalvoordelen een grote verandering doorvoeren. Een dergelijk dynamisch patroon wordt ook wel niet-linear genoemd, ondat een bedrijf niet proportioneel reageert op economische schokken.

Een onderwerp waar in deze context nog weinig aandacht aan is besteed, is het verband tussen investeringen en arbeidsaanpassingen. Gegeven dat kapitaal en arbeid de voornaamste ingrediënten zijn in de productietechnologie van een bedrijf, is het aannemelijk dat de beslissingen omtrent de aanpassingen van beide factoren samenhangen. Dit onderwerp is voornamelijk onderzocht op basis van macro-data, en met behulp van systemen van lineaire vraagvergelijkingen, waaraan de $k$ wadratische aampassingskostenstructuur ten grondslag ligt. Er bestaat nagenoeg geen onderzoek dat ingaat op 
de interrelatie tussen productiefactoren in de context van niet-lineariteit.

In dit proefschrift staan twee thema's centraal. Ten exste wordt met behulp van data op bedrijtseenheidniveau voon de Nederlandse nijverheidssector de dynamiek van aanpassingen van kapitaal en arbeid onderzocht. De data zijn afkomstig van het Centrum voor Research van Economische Microdata (CEREM) bij het Centraal Bureau woor de Statistiek (CBS). In het bijzonder wordt gekeken naar de niet-lineaire dynamiek van de productiefactoren, dat wil zeggen een aanpassingspatroon waarbij en sprake is wan afwisselend perioden van grote aampassingen en perioden van kleine aanpassingen of inactiviteit. Ten tweede wordt de samenhang tussen de dymamiek van investeringen en arbeidsaanpassingen bestudeerd. In het onderzoek wordt gebruik gemaakt van statistische beschrijvingen van de data en structurele modellen voor de vraag naar productiefactoren worden afgeleid en geschat.

In Hoofdstuk 3 wordt een uitgebreide statistische beschrijuing gegeven van de data. Deze beschrijving laat onder andere zien dat de investeringen in een klein aantal jaren verantwoordelijk zijn voor een groot deel van de totale investeringensuitgaven van een bedrijf over de bekeken periode. Hetzelfde resultaat wordt gevonden woor arbeidsaanpassingen. Dit geeft aan dat bedrijven inderdaad de niet-lineaire aanpassingsdynamiek vertonen zoals die hierboven is beschreven. En is ooli statistisch bewijs voor de interrelatie var kapitaal-en arbeidsampassingen. Dit volgt onder meer uit het resultat dat er een relatie is tussen de kans dat een aanpassing in een bepald rogime valt (positief, negatief of mul) en het regime van de aanpassing in de andere productiefactor. Tot slot lat de statistische analyse zien dat de niet-lineaire dynamiek wan de productiefactoren op microniveau invloed heeft op de dynamiek van aanpassingen op hogere aggregatisniveaus.

In Hooldstuk 4 wordt een relatie gelegd tussen de ampassingen van een productiefactor en de timing van grote aanpassingen in de andere factor. Er wordt bewijs gevonden dat er sprake is van grotere ampassingen van arbeid als er sprake is van een grote investering in hetzelfde of het volgende jaar. Er is tevens bewijs dat investeringen hoger zijn als er in hetzelfde jaar sprake is van 
een grote arbeidsaanpassing en er is een indicatie dat investeringen ook hoget zifin als deze in het voorgaande jaar heeft plaatsgevonden. Deze resultaten suggereren dat er en dynamisch element zit in de interrelatie tussen arbeid en kapitaal. Het resultaat dat er meer personeel wordt aangenomen in het jaat woorafgaande an en grote investering, bijworbeeld, zou een indicatie kinnen zijn dat bedrijven anticiperen op het feit dat nieuw personeel getraind moet worden.

In de overige hoofdstukken wordt gebruik gemaakt van structurele modellen om de dynamiek van de vaag naar productiefactoren en de interrelatie te beschrijven. Dat wil zeggen dat de schattingsvergelijkingen zijn afgeleid uit een economisch model, waarin wordt verondersteld dat een bedrijf winstmaximalisatie nastreeft. In Hoofdstuk 5 wordt onderzocht of de niet-lineaire dynamiek van anbeid het gevolg kan zijn van interrelatie, zelfs als er geen sprake is van vaste aampassingskosten woor deze productiefactor. Dit ligt in lijn met de bevindingen van Abel en Eberly (1998), die aartonen dat arbeidsaampassingen niet-lineairiteit kummen vertonen als arbeid kosteloos kan worden aangepast, maar er sprake is van vaste aanpassingskosten voor kapitaal. Omdat de aanname dat er geen aanpassingskosten voor arbeid zijn voor de Nederlandse arbeidsmarkt te sterk is, wordt in dit hoofdstuk een specificatie gekozen met kwadratische kosten. Investeringen hebben kwadratische en vaste anpassingskosten. De resultaten wijzen uit dat er sterk bewijs is woor de niet-- lineariteit van investeringen. Er is echter geen indicatie dat deze niet-lineariteit effect heef op arbeidsaanpassingen in dit model. De voornamste reden hiervoor is dat de geschatte aanpassingskosten voor arbeid erg hoog zijn, hetgeen impliceert dat de anpassingstijd erg lang is. Dit wijst. erop dat een uitgebreiclere ampassingshostenstructur nodig is om de arbeidsdyngmiek tie modelleren, bijwoorbeeld door middel van thet toevoegen van een vaste kostencomponent woor arbeid.

De mogelijkheid voor bedrijven om zich aan te passen aan veranderende omstandigheden, stat onder invloed van institutionele factoren en overheidsbeleid. Voorbeelden hiervan zijn de mate van regulering van de arbeidsmarkt, 
de invloed van vakbonden en belasting- en subsidiemaatregelen. Dergelijke factoren hebben invloed op de ampassingskosten en daardoor ook op de dynamiek van productiefactoren. Het is daarom te verwachten dat er tussen landen met, een verschillende institutionele achtergrond, verschillen optreden in de dynamiek van arbeid en kapitaal. Dit onderwerp wordt aangesneden in Hoofdstuk 6 , waarin een vergelijking wordt gemaakt tussen de dynamiek van de productiefactoren in Duitse en Nederlandse bedrijven. Hoewel de kapitaalmarkten in beide landen nagenoeg dezelfde kenmerken vertonen, is er in Duitsland sprake van een striktere regulering wan de arbeidsmarkt. Het theoretische model in dit hoofdstuk houdt rekening met vaste aanpassingskosten voor beide productiefactoren en met interrelatie tussen de aanpassingsbeslissingen. Het resultaat dat veranderingen in loonkosten en investeringen invloed hebben op arbeidsaanpassingen in Nederland maar niet in Duitsland, is consistent met het uitgangspunt dat de arbeidsmarkt in Nederland ten opzichte van Duitsland in mindere mate gereguleerd is. Een verdere bevestiging hiervan is dat er alleen voor Duitse bedrijven aanwijzingen zijn dat de investeringsvoet afhangt van de verandering in arbeid, maar niet vice versa. Dit suggereert dat de aanpassingskosten van arbeid in Duitsland relatief hoog zijn in vergelijking tot Nederland.

Tot slot wordt in Hoofdstuk 7 gekeken naar het schatten van de aanpassingssnelheid van arbeid. Hoewel er sterk empirisch bewijs bestaat voor de niet-lineaire dynamiek van arbeid op micro-niveau, gaat men er in de macro-economische literatuur vaak vanuit dat deze niet-lineariteit geen rol speelt op hogere aggregatieniveaus. Om de ampassingssnelheid van een variabeje te schatten, wordt derhalve doorgaans gebruik gemaakt van lineaire zogeheten partiële aampassingsmodellen. Recent onderzoek van Caballero en Engel (2004) wijst echter uit dat als er sprake is van vaste aampassingskosten, het schatten van de aanpassingssnelheid op basis van een linear model en geaggregeerde data, kan leiden tot ernstige vertekening van de resultaten. In Hoofdstuk 7 wordt beschreven dat het lineaire model echter nog steeds gebruikt kan worden voor het schatten van de aknpassingssnelheid, op basis 
van micro-data. Echter, het model is alleen geldig voor arbeidsanpassingen ongelik an mul. Jis moet dan ook gecorrigeerd worden voor het feit dat nijet wlle warmeningen kunnen worden meegenomen in de schatting, het zogenaamde sample-selectie probleem. De schatting van de anpassingssnelheid dhe op deze manier in dit hoofdstuk wordt verkregen, impliceert dat arbeidsadnpassingen binmen een kwartaal voltooid zijn. Schattingen op basis wan geaggregeerde dak of die verkregen zijn zonder te controleren voor sampleselectie, gewen dearentegen schattingen die theoretisch niet toelaatbaar zijn. Hoewel het gebruikte model duidelijk geen complete beschrijving biedt wan de aampassingsdynamiek op micro-niveau, laten de resultaten zien dat aggregatie de schattingsmethode niet immun maakt voor het bestaan van vaste aanpassingskosten en dat voor het schatten van de aanpassingssnelheid van arbeid een micromeconomische analyse van belang is.

Samenvattend kan het volgende gezegd worden over de twee hoofd hema's. Bedrijven in de Nederlandse nijverheidssector vertonen niet-lineair aanpassingsgedrag van arbeid en kapitaal, in de zin dat perioden wan grote aanpassingen worden afgewisseld met perioden van kleine aanpassingen of inactiviteit. Dit volgt uit statistisch bewijs gegeven in Hoofdstuk 3 en uit de schattingsresultaten voor het structurele model in Hoofdstuk 5. Deze resultaten zijn consistent met het bestaan van vaste aanpassingskosten. De kosten van anpassing worden bovendien beinvloed door institutionele factoren, zoals blijkt uit de resultaten van Hoofdstuk 6 . Statistisch bewijs in Hoofdstuk 3 en 4 laat ook ziten dat de vraag nazr kapitaal en arbeid onderling afhankeljk is, dat wil zeggen dat er en relatie is tussen de ampassingen wan de factoren. In Hoofdstuk 5 is er echter geen bewijs dat vaste aarpassingskosten voor kapitanl leiden tot miet-lineaire aanpassingen van arbeid. Dit is een indicatie dat vaste anpassingskosten voor de productiefactor arbeid zelf een rol spelen. Interrelatie in de anpassingskostenstructuur is moeilijk te identificeren. Echter, hoewel de specificatie waraan deze conclusie wordt ontleend niet structureel is, suggereren de resultaten in Hoofdstuk 6 dat het bestaan van deze worm van interrelatie plausibel is. Tot slot laat Hoofdstuk 7 zien dat 
het bestaan van vaste aanpassingskosten impliceert dat micro-data dient te worden gebruikt bij het schatten van de aampassingssnelheid van arbeid. 



\section{Curriculum vitae}

Michrel Polder was borm in Rotterdam, the Netherlands, on June 25, 1977. He followed his high school education at the Libanon Lyceum in Rotterdam, which he completed in 1995. In that year he started his study Econometrics at the Erasmus University Rotterdam. He graduated in 2000 with a master thesis titled 'Modeling and forecasting international trade flows', written during a trainee-ship at NEA Transport Research and Training. The present thesis is the product of a Ph.D. at the University of Meastricht from 2000 to 2004, as a member of the Business Investment Research Center (BIRC) and the department of Quantitative Economics. He completed the Ph.D. program of the Network of Economics and Quantitative Economics (NAKE) in 2002. From January to March, 2003, he visited the Institute for the Future of Lam bor (IZA) in Bonn, Germany. Since April 2005 he is employed at Statistics Netherlands (CBS) as a statistical researcher. 